\title{
SIMULATION STUDY OF SOLAR CHIMNEY ASSISTED SOLARIUM
}

\author{
By \\ Afrooz Ravanfar \\ M. Sc., Iran University of Science and Technology, 2003
}

\begin{abstract}
A thesis presented to Ryerson University in partial fulfillment of the requirements for the degree of

Masters of Applied Science

In the Program of

Building Science
\end{abstract}

Toronto, Ontario, Canada, 2011

(C) (Afrooz Ravanfar) 2013 


\section{AUTHOR'S DECLARATION FOR ELECTRONIC SUBMISSION OF A THESIS}

I hereby declare that I am the sole author of this thesis. This is a true copy of the thesis, including any required final revisions, as accepted by my examiners.

I authorize Ryerson University to lend this thesis to other institutions or individuals for the purpose of scholarly research.

I further authorize Ryerson University to reproduce this thesis by photocopying or by other means, in total or in part, at the request of other institutions or individuals for the purpose of scholarly research.

I understand that my thesis may be made electronically available to the public.

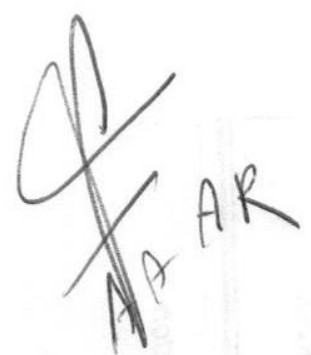




\author{
Abstract \\ Simulation Study of Solar Chimney Assisted Solarium \\ Afrooz Ravanfar, MSc, Iran University of Science and Technology, 2003 \\ Masters of Applied Science, Building Science \\ Ryerson University
}

The objective of this study is to develop a modelling method for optimizing the design of a solar chimney integrated solarium to maximize the ventilation rate in the solarium.

A thermal model is developed and implemented in SIMULINK to simulate the thermal response of the solarium combined with a solar chimney based on the first principle of thermal engineering. Thermal simulations are performed for critical summer days. The greenhouse air temperature and its ventilation rate with various geometrical configurations are calculated on the basis of solar irradiance intensity and ambient temperature. The preliminary numerical simulation results show that a solar chimney, combined with an appropriately inclined roof of a solarium, would be a better option for ventilation improvement in the solarium. The solarium height and solarium/solar chimney cross section areas are the critical parameters. The combination of a shorter solar chimney with a high solarium would be suitable for Toronto. 


\section{Acknowledgments}

"At times our own light goes out and is rekindled by a spark from another person. Each of us has cause to think with deep gratitude of those who have lighted the flame within us."1

I would like to express my sincere gratitude to Dr. Zaiyi Liao and Dr. Hua Ge, my supervisors. I would like to thank Dr. Liao for providing the research and thank both of my supervisors for their financial support to finish this work. I am extremely grateful and indebted to them for their support, expert, sincere and valuable guidance and encouragement extended to me.

I would like to gratefully and sincerely thank Dr. Mark Gorgolewski, Dr. Miljana Horvat and Elizabeth Hollowell for their guidance, understanding, patience, and most importantly, their friendship during the hardship in my life during my graduate studies.

I would like to thank my dear friends Dr. Ali Asadian, Dr. Ali Talasaz and Dr. Saeed Chehreh Chelgani with whom I have consulted at various stages of this thesis.

I would like to express my sincere gratitude to Arman for being a constant source of support and encouragement throughout this work.

I also place on record, my sense of gratitude to one and all who, directly or indirectly, have lent their helping hand in this venture.

To all those people who may have had some small influence on my life as I stumbled across this small blue ball, I tip my glass, may others be as fortunate as I.

Last but not the least, I would like to express my deepest thanks to my family: my beloved parents and lovely sisters for their unceasing encouragements and support throughout my life. It was under their watchful eye that I gained so much drive and an ability to tackle challenges head on.

\footnotetext{
1. Albert Schweitzer
} 


\section{Table of Contents}

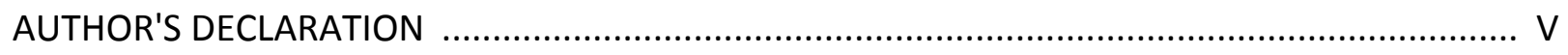

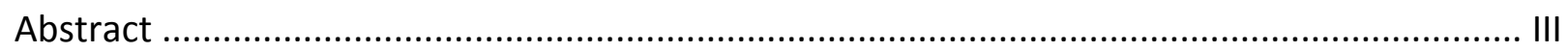

Acknowledgements ................................................................................................. IV

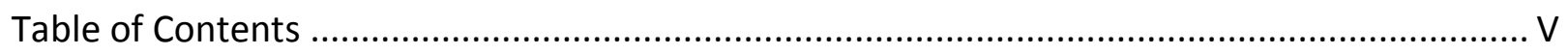

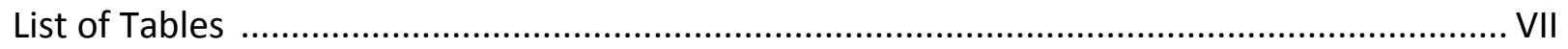

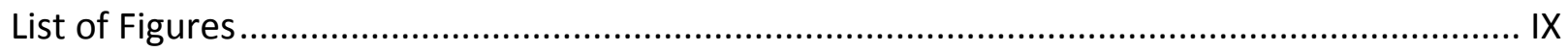

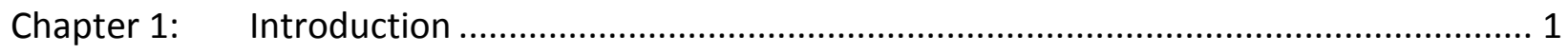

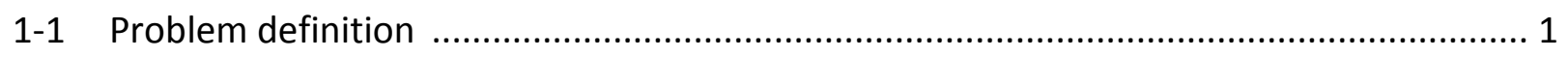

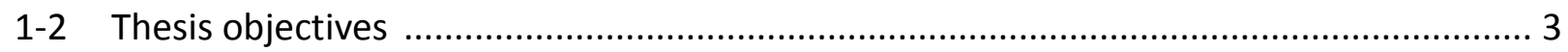

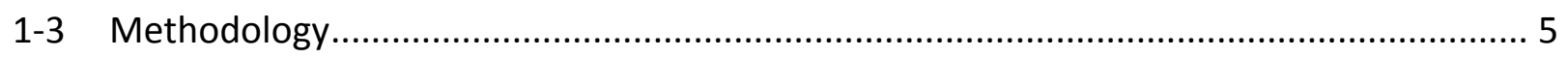

Chapter 2: Literature review .................................................................................... 6

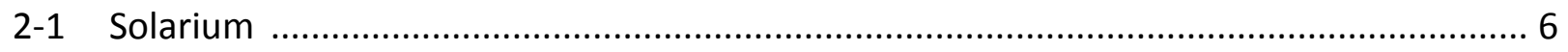

2-1-1 Effect of solarium shape …………........................................................................... 6

2-1-2Effect of back wall properties ....................................................................................... 7

2-1-3Effect of inclination angle ........................................................................................... 8

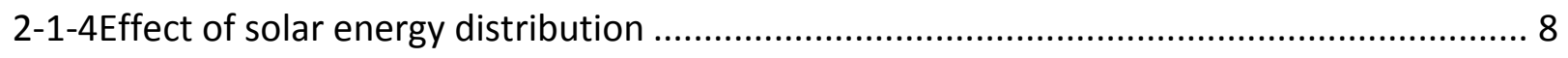

2-2 Solar chimney ………………................................................................................ 9

2-2-1 Effect of solar chimney height and width ............................................................... 9

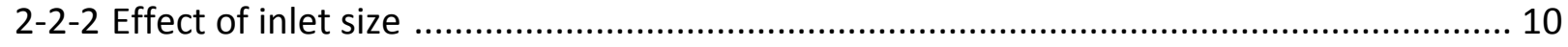

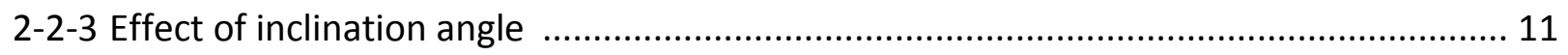

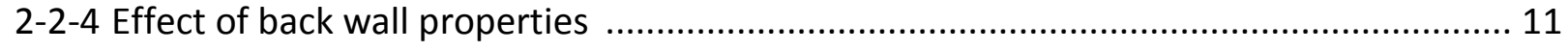

2-2-5 Effect of glazing type ....................................................................................... 12

2-3 Natural ventilation in a highly glazed space ……..................................................... 12

2-3-1 Integration of solar chimney in atrium ...................................................................... 13

2-3-2 Integration of solar chimney in solar crop dryer ............................................................ 14

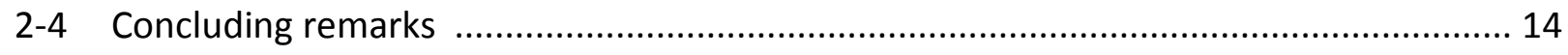

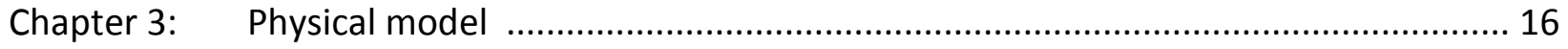




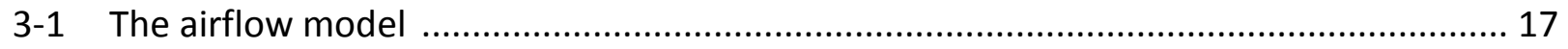

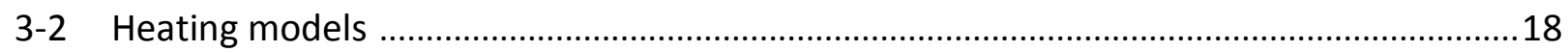

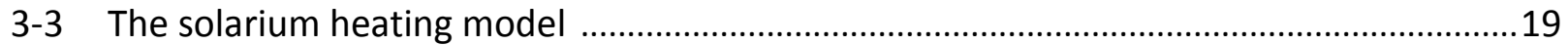

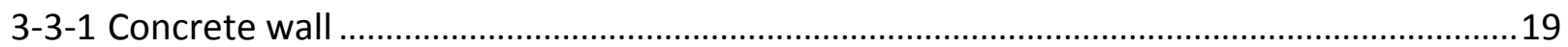

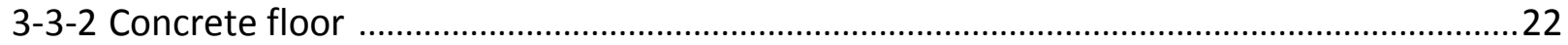

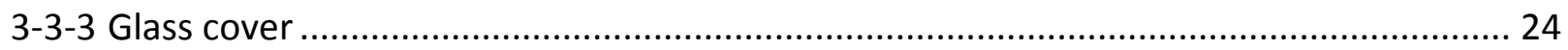

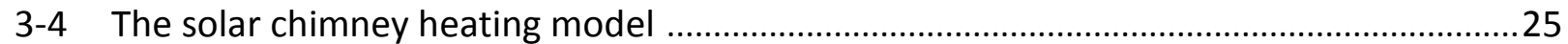

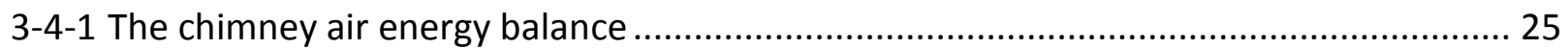

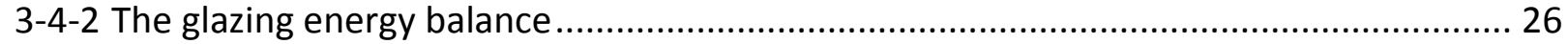

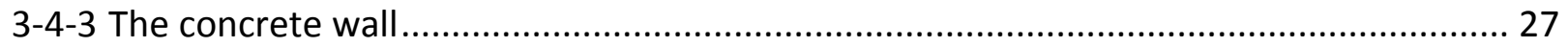

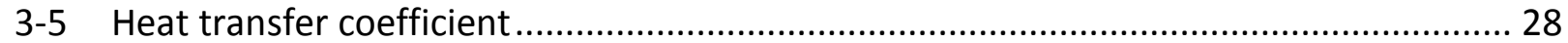

3-5-1 Convective heat transfer coefficients .............................................................. 28

3-5-1-1Convective heat transfer coefficient due to the wind $\left(h_{\text {wind }}\right)$................................ 28

3-5-1-2 Convective heat transfer between air and concrete wall, glass cover and the solarium

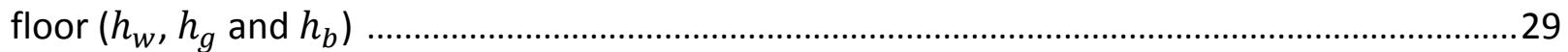

3-5-2 Coefficient of heat transfer to the air stream which flows out $(\gamma)$..................................32

3-5-3 Radiative heat transfer coefficients................................................................... 33

3-5-4 Conductive heat transfer coefficients ................................................................ 34

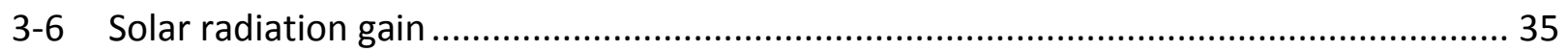

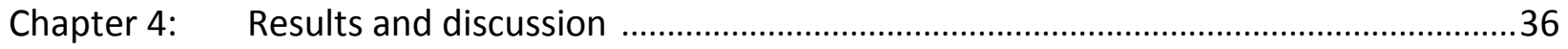

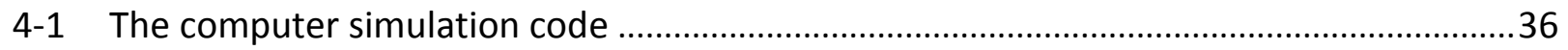

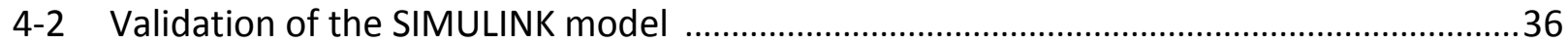

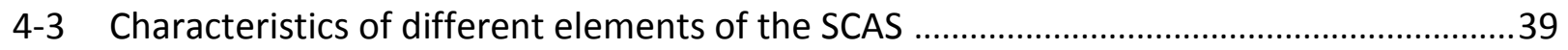

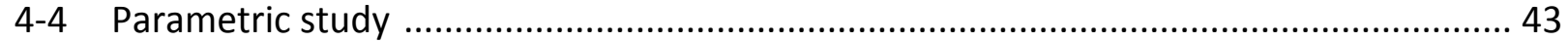

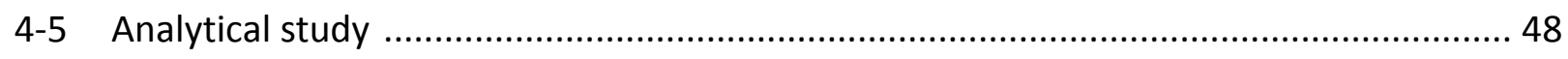

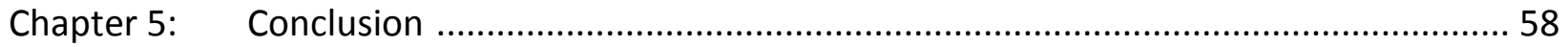

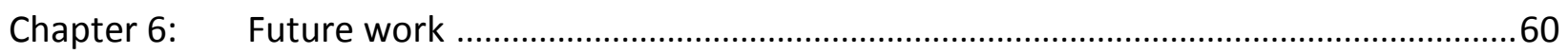

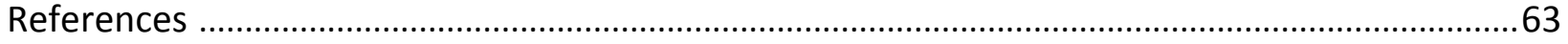

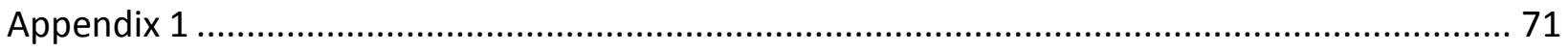




\section{List of Tables}

Table 1. Assigned parameters in the validation process all of which have been chosen from experimental study has performed by Afriyie et al. (2011) 37

Table 2. Comparison results of simulation outcome of present study (Sim), Simulation results (Afriyie) and results of the experimental trial (Exp) of published study and their relative difference (RD) 38

Table 3. The input parameters for the analytical study, determined through parametric study or assumed from previous published researches 40

Table 4. Selected parameters for parametric study and their values 44 


\section{List of figures}

Fig. 1. Ambient temperature, adaptive and predictive mean comfort temperatures in the month of July 4

Fig. 2. Schematic side section of the SCAS: Ws and Ls are the width and height of the solarium 16

Fig. 3. Heat transfer process in the dynamic model of SCAS 18

Fig. 4. Schematic side section of the chimney-dependent solar crop dryer designed by the Afriyi et al. (2011) 36

Fig. 5. Toronto weather data (ambient temperature) corresponding to the trials of the month of July, employed in the physical model evaluation as input data 41

Fig. 6. Toronto weather data (ambient temperature) corresponding to the trials of month of July July $15-18$, employed in the physical model evaluation as input data 41 Fig. 7. Toronto weather data (solar radiation on south faced vertical surface) corresponding to the trial of the month of July 42

Fig. 8. Toronto weather data (solar radiation on south faced vertical surface) corresponding to the trial of July $15-18$ 42

Fig. 9. Mass flow rate $(\dot{m})$ for different inlet/outlet area ratios Ai/Ao of the SCAS 45

Fig. 10. Mass flow rate $(\dot{m})$ for the trial with fixed total height of SCAS and different solarium height values 46

Fig. 11. Mass flow rate $(\dot{m})$ for the second trial with fixed solarium height of $5 \mathrm{~m}$ and varying Chimney/solarium height ratio values 46

Fig. 12. Mass flow rate $(\dot{m})$ for fixed solarium/solar chimney length, fixed solarium width of $4 \mathrm{~m}$ and different chimney width values

Fig. 13. Mass flow rate $(\dot{m})$ for fixed solarium/solar chimney length, fixed chimney width of $0.3 m$ and various $A b / A s c$ ratio values.

Fig. 14. The SCAS glass temperatures applying parameters of parametric study corresponding the time frame of the month of July (trial 1) 49 Fig. 15. The SCAS glass temperatures applying parameters of parametric study corresponding the time frame of July 15 - 18 (trial 2) 49 
Fig. 16. The SCAS inside air temperature applying parameters of parametric study corresponding the time frame of the month of July (trial 1)....

Fig. 17. The SCAS inside air temperature applying parameters of parametric study corresponding the time frame of July 15 - 18 (trial 2)

Fig. 18. The Solarium concrete floor nodes temperature applying parameters of parametric study corresponding the time frame of the month of July (trial 1)

Fig. 19. The Solarium concrete floor nodes temperature applying parameters of parametric study corresponding the time frame of July 15 - 18 (trial 2)

Fig. 20. The Solarium concrete wall nodes temperature applying parameters of parametric study corresponding the time frame of the month of July (trial 1)....

Fig. 21. The Solarium concrete wall nodes temperature applying parameters of parametric study corresponding the time frame of July 15 - 18 (trial 2)

Fig. 22. The Solar chimney concrete wall nodes temperature applying parameters of parametric study corresponding the time frame of the month of July (trial 1).... 54 Fig. 23. The Solar chimney concrete wall nodes temperature applying parameters of parametric study corresponding the time frame of July 15 - 18 (trial 2) 54 Fig. 24. The mass flow rate that crosses the SCAS applying parameters of parametric study corresponding the time frame of the month of July (trial 1) . 55 Fig. 25. The mass flow rate that crosses the SCAS applying parameters of parametric study corresponding the time frame of July 15 - 18 (trial 2 )........................................................ 55 Fig. 26. Effects of solar radiation intensity on the mass flow rate inside the SCAS 56 


\section{Chapter 1: Introduction}

\section{1-1 Problem definition}

Passive solar heating and natural ventilation is a very ancient concept that has been used since man started building inhabitations (Tiwari et al 1988). In recent years, energy efficiency demands and environmental concerns have influenced building designers to reconsider natural ventilation in summer, solar heating in winter and the use of day lighting in order to reduce energy consumption in residential buildings. The advanced technology of highly glazed solariums is currently being incorporated in buildings in order to benefit from day lighting and solar energy. The addition of a solarium attached to a house is a promising design alternative that can be implemented in both retrofit and new buildings to provide additional high quality space with abundant solar radiation levels (Bastien and Athienitis, 2010). According to Mihalakakou (2000), such a space may improve the appearance of the building and reduce the temperature swing and heating requirements of a house. However, Bryn and Schiefloe (1996) found that an improper design may raise the energy consumption of the building or lead to frequent overheating and high temperatures that are not desirable either for people or plant growth. Hence, to maintain the desirable condition, excess heat must be evacuated from the sunspace. They introduced natural ventilation as a common cooling technique in a highly glazed space such as a solarium and emphasized on the role of natural ventilation, not only for cooling the sunspace but also any adjacent building.

Solar chimneys can contribute to the production of this natural ventilation when they are applied to buildings (Marti-Herrero and Heras-Celemin, 2006). A solar chimney consists of one or more walls of a vertical chimney that are made transparent by providing glazed walls, while solar energy heats up the air inside the chimney. Consequently, a natural convection air flow is thermally induced due to the difference in air density between the inside and outside of the chimney. The solar chimney is similar to the Trombe wall physical concept. The distinct difference between them is that while the Trombe wall has a massive thermal bulk that absorbs solar energy and recirculates warm air for passive heating of the building, the solar chimney is dedicated to 
natural ventilation production. The structural difference relies on the existence of insulation between solar chimney and interior of the building, in contrast to the Trombe wall that has the radiator function toward the indoors.

The solar chimney contributes to building conditioning by using solar radiation to produce convective air flow. A study by Ekechukwu and Norton (1997) showed that the buoyancy force is proportional to the air density variation between the inside chimney air and outside air. The process pulls warm air out of the building, in this case the solarium, replacing it with cool air from outside or an adjacent space providing natural ventilation inside the solarium and in the second case, it also provides ventilation in the adjacent space.

As air flow inside the chimney is incorporated with a solarium, the temperature drops inside the solarium causing a similar condition in those outside. This phenomenon pauses the air movement or it may lead to reverse flow, unless the Bernoulli Effect occurs due to a strong wind (Murphy and Brusca, 1986). Utilizing a solar chimney in combination with a solarium can ensure lower air density by heating the air further above the solarium to enhance the air flow (Afriyie et al., 2009 and Reuss et al. 1997).

Since the design of a solarium can impact the total energy cost of a building, the best approach is to design the solarium with the aim of reducing the total energy cost of the building and providing a net energy benefit. A solarium is a complex environment in terms of thermal and lighting behaviour. Such space has dynamic interactions with the outdoor environment and its adjacent spaces, which vary by time and season, when building mechanical systems (Bryn and Schiefloe, 1996). Hence to design an effective solarium, a comprehensive understanding of these different thermal and luminous interactions is required, as well as the impact of design configurations on them.

The performance variables of a solarium can be determined and evaluated only by calculation and simulation apart from measuring an experimental model. However, only simplified design tools can be used in an early design stage when identifying basic parameters; and the places where problems may occur is important as the design expands and various details are identified for solving the remaining problems (Bryn and Schiefloe, 1996). 


\section{1-2 Thesis objectives}

The main objective of this thesis is to develop a numerical thermal model in solar-assisted buoyancy-driven natural ventilation; used in simple attached solarium in a residential two-story building in the city of Toronto during summer weather conditions (month of July).

As air enters the solarium through a bottom inlet, it absorbs heat from the floor and walls of the solarium. Afterward, the air enters the solar chimney and absorbs further heat to ensure a steady flow in the solar chimney to the outside, through an exit that will be referred to as an outlet in this study. This process can be accomplished in two different ways: (1) the bottom is placed in a way that connects the solarium to the outside or (2) the inlet connects the solarium to its adjacent space. In the first method, the solar chimney produced ventilation only inside the solarium. However the second method generated air flow and ventilation not only inside the solarium but also inside the adjacent living space and acted as one big chimney with different sectional areas and heights. The second method had the advantage of producing natural ventilation in the adjacent house during the summer time contributing in further energy saving. According to Raja et al. (2001) one of the best ways to enhance the thermal comfort in a building is through air movement. The study identified natural ventilation as an important means of controlling air temperature and quality in summer. The research also showed that adequate natural ventilation can prevent overheating, even in a hot climate. The authors demonstrated that cross ventilation is an effective factor in temperature reduction inside the building.

In a study, Brager and de Dear (2002) compared naturally ventilated buildings with HVAC buildings. The study showed that while occupants of naturally ventilated buildings become adapted to a vast range of air conditions close to outdoor air conditions, occupants of HVAC buildings adapt to only a limited number of consistent conditions provided by mechanical conditioners. The researchers proposed the adaptive comfort standard (ACS) as an alternative to the predicted mean vote (PMV) method in ASHRAE standard 55. The study introduced optimum comfort temperature, $\mathrm{T}_{\text {comf, }}$ which has following mathematical expression:

$\mathrm{Tcomf}=0.31 \times \mathrm{Ta}+17.8\left({ }^{\circ} \mathrm{C}\right)$ 
where $\mathrm{T}_{\mathrm{a}}$ is ambient or outdoor temperature. Fig. 1 . shows the adaptive and predictive mean vote comfort temperature as well as the outdoor temperature in the city of Toronto during the month of July.

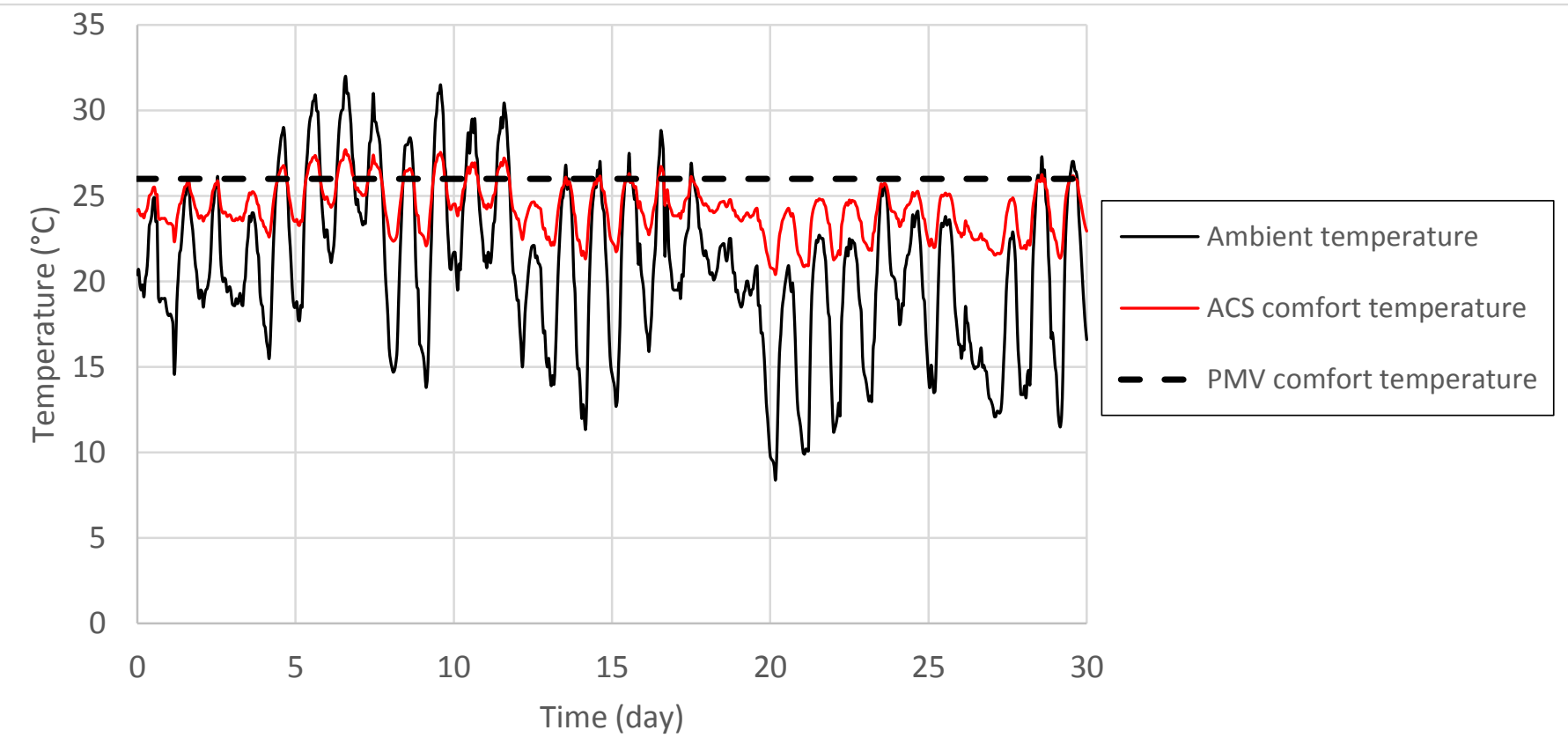

Fig. 1. Ambient temperature, adaptive and predictive mean comfort temperatures in the month of July

The study introduced the ACS as an effective way of analyzing the ambient temperature to evaluate the feasibility of utilizing natural ventilation in a building. The energy saving potential of such an application can be investigated in the research method.

The ASHRAE-55 Standard (2010) has also introduced the prevailing mean outdoor temperature as an input variable for this adaptive model. It is based on the average of the mean daily outdoor temperatures of the month in question. In order to apply the adaptive model, the prevailing mean temperature calculated must be greater than $10^{\circ} \mathrm{C}\left(50^{\circ} \mathrm{F}\right)$ and less than $33.5^{\circ} \mathrm{C}$ $\left(92.3^{\circ} \mathrm{F}\right)$ according to this standard. This number is $20.8^{\circ} \mathrm{C}$ for the month of July in Toronto, which confirms the applicability of this method for this region and month.

As can be seen in Fig. 1., the outdoor temperature for the month of July in Toronto is within the range of both comfort temperatures $85.7 \%$ of the time, for the whole month. The cross sectional air movement produced by a solar chimney assisted solarium potentially produces higher air 
movement compared to using only the operable window, which was the base of above mentioned study. Hence the proposed residential building interior condition is able to be maintained within ASC limits around $85 \%$ of the time during the month of July by natural means. However, the air conditioner might be used to keep inside extreme temperatures from rising past the ASC acceptability limits.

\section{1-3 Methodology}

Since the second proposed method of performing this study, the bottom inlet connecting the solarium to the house was chosen for this study due to the fact that this method not only enhances the ventilation process inside the solarium but also provides an energy saving potential to its adjacent space.

This study aims to analyze the geometrical configuration in the Solar Chimney Assisted Solarium (SCAS) so as to obtain the highest ventilation rate in the solarium and adjacent residential building for the hottest period of the year in the city of Toronto. To achieve this aim, a research methodology has been envisaged that involves the following stages:

- A detailed thermal analysis using the heat balance method is performed to calculate the passive thermal response of the solarium/greenhouse combined with a solar chimney.

- Thermal simulation will be performed during critical summer days using a computer-aided technique implemented in MATLAB R2010b version 7.11 with SIMULINK toolbox. The program calculates the greenhouse air temperature and its ventilation rate in different geometrical configurations, using the actual weather data from the city of Toronto.

- Performing a parametric study for the solarium and a solar chimney as the means of natural ventilation for the following parameters: solar chimney to solarium height ratio, Solarium height, solarium width, chimney width and the inlet-outlet area ratio for the selected range of variance of the aforementioned parameters. The performance indicators for the SCAS is the ventilation rate.

- Ultimately, the modeling scheme will be validated through comparison with previous published results and experimental data to test the robustness of this design configuration. 


\section{Chapter 2: Literature review}

Numerous research studies have been performed on the solarium and solar chimney concepts. These studies have increased our understanding of the applicability, performance and various parameters that affect the performance of these systems for passive heating and cooling, and natural ventilation of buildings. This section provides general information about these studies and their approaches. Afterwards, findings of those studies regarding integration of highly glazed spaces and a solar chimney as the means of natural ventilation will be presented, since they are greatly related to this study.

\section{2-1 Solarium}

The solarium is an enclosure attached to a house with glass walls and roof. This south facing space can be installed in both new and retrofit buildings to provide a comfortable space with positive architectural qualities that can reduce the temperature swings and heating demands of the house, and therefore can lead to big savings in the operating costs of the building (Mihalakakou, 2000). Even though this energy saving approach is rather simple and inexpensive, an improper design may cause overheating and result in an increase in the energy consumption of the building (Bryn and Schiefloe, 1996).

Despite the fact that the thermal performance of a solarium has been studied often, monitored results are scarce and related to heating the load of the sunspace (Hussaini and Suen, 1998; Ismail and Goncalves, 1999; Santamouris et al., 1994a, b; Tiwari and Dhiman, 1986; Abak et al., 1994; Bargach et al., 2000; Connellan, 1986; Santamouris et al., 1996; Kurpaska and Slipek, 2000; Jain and Tiwari, 2003; S. Kumar et al., 1994). All of these studies admitted the positive role of the solarium as a means of passive heating especially in a cold climate. Results of these studies will be presented in this section, regarding the effect of different parameters on the performance of solar chimney.

\section{2-1-1 Effect of solarium shape}

The design of a solarium or a greenhouse is important in regard to thermal efficiency. According to Bastien and Athienitis (2010), the functionality of a solarium or a greenhouse directly depends 
on the shape and tilt angle. They found notable differences in terms of solar radiation absorption between different configurations of a sunspace. The shapes of four different greenhouses have been studied by Gupta and Tiwari (2003). They found that depending on the date, time, shape and size of a greenhouse, those variables have a pivotal role in heating a solarium, especially in the winter. They observed that an even shape is the best option at a lower latitude due to the fact that the weighted solar fraction is higher for this shape.

\section{2-1-2 Effect of back wall properties}

With an increase of glazing area in the solarium, temperature fluctuations in the adjacent living space rises (Kumar et al., 1994). Furthermore, in a sunspace where surfaces are mostly glazed, only $30 \%$ to $85 \%$ of the radiation remains in the space depending on the absorptivity of the opaque surfaces. (Wall, 1995, 1997). Hence, it is not necessary to have glazing on all sides of the solarium and the best design is to have an opaque and insulated north wall, which keeps more transmitted radiation inside and decreases heat loss.

A model of an attached sunspace has been developed by Mottard and Fissore (2006). They also studied the solarium with respect to its dimension, shape and orientation. They included time step and numerous spatial nodes in every material layer and the results of their calculations have been confirmed with their measurements. The study showed a difference of $3.4 \%$ and $11.2 \%$ in terms of the supplied energy into the living space by the solarium during the time frame of June and July. They demonstrated the importance of the solar absorptance and the convective heat coefficient of the back wall in their experiment.

The thermal mass also affects temperature fluctuations: temperature swings decrease with the greater thermal storage potential of the collecting wall (Kumar et al., 1994). Fuchs and McClelland, (1979), Sodha et al. (1986) and Maloney and Habib (1979) studied the role of different types of thermal mass on the temperature fluctuations in the living area. They found

direct dependence between thermal comfort and the thermal mass. As a result, the opaque north wall is the best option for thermal mass.

Wall (1995) demonstrated in a study that in a rectangular shape solarium with double glazed south, east and west walls, roof and $20 \%$ of north wall, the percentage of the solar radiation that 
stays in the solarium depends on the amount of opaque surface absorption. This method is based on the monthly average of solar radiation and does not include the effect of incidence angle.

\section{2-1-3 Effect of inclination angle}

According to Kumar et al. (1994), a solarium, the glass roof of which is inclined to the south with an optimum tilt angle, maintains better thermal comfort in the living space compared to other sunspaces with the same glass area.

Duffie and Beckman (1980) found that in an inclined sunroom when the tilt angle is higher than the latitude, the transmittance is higher in the winter, which has a lower sun and is lower in the summer with the higher sun. Bastien and Athienitis (2010) studied the solarium roof tilt angle range of $25^{\circ}$ up to $65^{\circ}$ and absorptance of 0.5 to 0.9 for interior wall surfaces of the sunspace, and analyzed the solar radiation distribution and the thermal response. The results demonstrated that the optimum inclination angle for a solarium in Montreal and for the winter time period is $65^{\circ}$. According to their study, the worst case scenario is a solarium sloped by $25^{\circ}$.

\section{2-1-4 Effect of solar energy distribution}

Tiwari et al. (2002) in their research on the evaluation of solar fraction (Fn) for the north wall of a controlled environment greenhouse confirmed that the distribution of solar energy on different walls and doors of a solarium is an important factor in predicting the performance of the sunroom. Gupta and Tiwari (2003) showed that the floor is as important as the north wall in the weighted solar fraction. Weighted solar fraction has a direct relationship with available radiation for heating the living space. Wall (1997) compared four different simulation programs used for calculating the solar radiation distribution in a solarium. The author explained that detailed programs, based on the geometrical configuration of a highly glazed space such as a sunroom, are more accurate. The research also emphasized the transmission through the glazing reflection and absorption into account. 


\section{2-2 Solar chimney}

Unlike the solarium, numerous prior studies have been carried out on the subject of the solar chimney. They can fall under different categories of numerical, analytical and experimental studies. All of these studies confirmed the positive role of the solar chimney as a means of passive ventilation.

Parametric analysis has been employed in the majority of these studies and has played an important role in understanding the performance of the solar chimney. The results of these studies will be presented in this section, regarding the effect of different parameters on the performance of the solar chimney.

\section{2-2-1 Effect of solar chimney height and width}

Rodrigues et al. (2000) performed a study of solar chimney air flow and its transition from laminar to turbulent flow. They used a finite-volume method for their study and they concluded that an appropriate balance between thermal comfort and ventilation should be considered in designing the chimney. They argued that as cavity width increases, ventilation rate improves but the growth ratios decreases. In this regard, Spencer et al. (2000) and Chen and Li (2001) explored an optimum cavity width (or optimum width/height ratio) that maximises the ventilation rate. However, a wider gap causes the reverse flow that resulted in a decrease in mean flow rate in the solar chimney. Gan (2006) used a CFD program to examine the role of different parameters such as channel width and floor area on the flow rate. Replacing outer skin with a photovoltaic panel was investigated in this study. Expectedly, from the bottom to the top as stack height reduces, room ventilation reduces. A difference of $17 \%$ to $34 \%$ was observed for a $40 \mathrm{~cm}$-width cavity. This issue can be improved by utilising the photovoltaic panel as the outer skin. The optimum channel width was explored in this application to be 0.55 to $0.6 \mathrm{~m}$ for a $6 \mathrm{~m}$-high chimney. Another parametric study on a solar chimney attached to a residential building was performed by Lee and Strand (2009). They have developed their numerical model in the Energy Plus computer program and did a one-day simulation considering different locations for the dwelling. They explored whether the air change rate in a solar chimney depends directly on back wall height. Their results depicted an increase of $73 \%$ in ventilation rate by wall height rise by as much as $6 \mathrm{~m}$. The climate of the 
location of the chimney was also examined in this study and the results showed a significant impact in ventilation rate depending on the location and therefore radiation availability. Hence, the amount of yearly energy savings were rather similar indicating that the application of the chimney is beneficial, even in the climate conditions in which they are assumed not to be the best of all. Ong and Chow (2003) used a mathematical model of steady-state heat transfer for a solar chimney to predict its thermal efficiency. The weather conditions were taken into account in their study. They compared their results with a full-size solar chimney and their experiment showed a $56 \%$ higher air change rate when solar chimney width is $30 \mathrm{~cm}$ compared to $10 \mathrm{~cm}$. Bassiouny and Koura (2008) also studied the buoyancy-driven natural room ventilation by a solar chimney using a steady-state mathematical model. They proved that the chimney width had significant effects on the flow rate and air change per hour in comparison with the inlet area. Their results indicated that even when inlet size increases by three times the flow rate rises only $11 \%$, an increase of 3 times in width of the chimney boosts the flow rate by $25 \%$. The research results also showed that inlet sharp edges improved the flow rate. Bouchair (1988) showed that there is an optimal cross-section ratio of length to width that maximizes the air flow rate in the solar chimney. Gan (1998) showed an improvement in the performance of the chimney by a rise in the chimney length, gap width, solar radiation and wall temperature.

\section{2-2-2 Effect of inlet size}

Inlet size has been investigated by Gan (1998) and Chen et al. (2003). They were unable to find an optimum inlet width due to the fact that with an increase in inlet size and cavity width, the inlet pressure drop is less, resulting in reverse flow and therefore lower flow rate. In 2009, Nouanégué and Bilgen performed a comprehensive numerical study on heat transfer in the solar chimney system. The study clearly confirmed the positive role of surface radiation on the flow rate. The ventilation rate is found to be an increasing function of the Rayleigh number and the surface emissivity, and the decreasing function of inlet size. They explained how the volume flow rate and convective heat transfer are increased with the Reyleigh number when the radiative heat transfer is fairly constant. 


\section{2-2-3 Effect of inclination angle}

Chen et al. (2003) also examined the effect of various tilt angles at $15^{\circ}, 30^{\circ}, 45^{\circ}$ and $60^{\circ}$ on air change rates in the solar chimney. They kept cavity height and width constant during their experiment. They found that for different values of uniform back wall temperature, as heat flux on that wall increases by three times, the ventilation rate would increase by $38 \%$. According to their experiment, the flow rate increased by $45 \%$ resulting from lower pressure drops in inlet and outlet when the chimney was sloped. A numerical study of the role of tilt angle, double glazing and low emissivity coating on the back wall of a solar chimney were carried out by Harris and Helwig (2007) using the CFD modeling technique. They explored that both heat gain and heat transfer to the air through an inclined solar chimney are higher than that of the vertical chimney depending on the latitude of the building. Hence, the performance of the solar chimney at $45^{\circ}$ was approximately the same as that of a vertical solar chimney. However, they found the optimum angle of $67.5^{\circ}$ from the horizontal line which increases the flow rate by $11 \%$ for the location studied, being Edinburgh, Scotland.

\section{2-2-4 Effect of back wall properties}

As mentioned earlier, the back wall thickness is an important parameter in a solar chimney. Charvat et al. (2004) and Marti-Herrero and Heras-Celemin (2006) not only demonstrated this fact but also proved that the thicker the thermal mass, the better night-time ventilation. Their study proved that despite the fact that with a thicker thermal mass, the sum total of the daily ventilation rate stays almost constant but the night-time air flow rate improves. In another study in 2000, Afonso and Oliveira used the finite difference method including climate, back wall thermal inertia and dependence of heat transfer coefficient on temperature and air flow rate in their model. They used a simplified thermal model, one dimensional and non-steady heat transfer model, and a computer program to investigate the flow rate in their model. Their results showed an improvement of $10-20 \%$ in the efficiency of the solar chimney for the average climate condition of Portugal. They proved that insulating the back wall avoided overheating in the space connected to the chimney and increased the flow rate by $60 \%$. Ventilation efficiency of a Trombe wall was investigated by Gan in 1998. The study showed that when the back wall is insulated, the 
wall surface temperature increases by $9^{\circ} \mathrm{C}$ and there would be $40 \%$ of heat lost through the wall when it is non-insulated. Lee and Strand (2009) found that increasing back wall absorptivity by 0.75 improves the flow rate by $15 \%$. Harris and Helwig (2007) observed $10 \%$ improvement in ventilation by utilizing a low emissivity coating on the back wall and consequently reducing the radiative heat loss.

\section{2-2-5 Effect of glazing type}

In 1998 Gan and Riffat used the CFD technique to numerically study effects of solar heat gain and glazing type on the ventilation rate in the buildings using a solar chimney for heat recovery. Their research indicated that double or even triple glazing can optimize the air change rate and using a heat pipe recovery system reduces the thermal buoyancy and increases the resistance against the air flow. Gan (1998) revealed that utilizing double glazing in construction of the Trombe wall enhances the air flow rate by $17 \%$ for cavity width beyond $0.3 \mathrm{~m}$. In addition, Chantawong et al. (2006) analyzed experimentally and numerically the performance of a glazed solar chimney wall (GSCW) with different types of glazing panes. They highly recommended application of GSCW in hot countries as their study proved that it decreases the chimney heat gain through the glass by circulating the air inside the cavity. However, Harris and Helwig (2007) found an insignificant improvement of air change rate in summer conditions resulting from double glazing, which can be ignored due to the cost effect.

\section{2-3 Integration of solar chimney in a highly glazed space}

Investigating the performance of a solar chimney in combination of highly glazed spaces such as atriums and crop dryers holds great interest due to the high potential of contribution in providing the environmental comfort and energy economy. This subject has only been studied numerically in the past few years, mainly with CFD simulations assuming steady-state temperature and air velocity fields. The CFD models were validated against small-scale experimental data. 


\section{2-3-1 Integration of solar chimney in atrium}

A small-scale model experiment along with a CFD simulation was carried out by Ding et al. (2005) on an eight-story office building. This building included an atrium on the north side and a southern double-skin façade with a solar chimney. They have studied the building with changing some of the important parameters such as the height of the solar chimney and inlet opening of each floor to the double façade. To achieve the best ventilation rate, they proposed the lower floor in the building and a two-story height solar chimney

In 2001, Holford and Hunt performed a numerical and small-scale experimental study on the natural ventilation of an atrium. Their model had an opening on the top and an exterior bottom air inlet. Their study illustrated that an atrium with a medium-size top outlet of $5.2 \mathrm{~cm}$ and a small exterior inlet size of $2 \mathrm{~cm}$ has the most effective configuration with regards to the ventilation rate in the building.

$\mathrm{Ji}$ and Cook (2007) have studied the natural ventilation of a multi-story building attached in an atrium using CFD program. Their results indicated that the CFD program is a valuable computational program to simulate natural ventilation in multi-story buildings.

Horan and Finn (2008) investigated the effects of different wind speeds and directions on air flow rate in a two-story building connected to an atrium naturally ventilated by a series of entry wall and roof vents. They also used the CFD program to simulate their model. They detected a linear increase in flow rate by 25 to $250 \%$ of the mean wind speed of $5.7 \mathrm{~m} / \mathrm{s}$. Their study showed different notable patterns of air flow rate change with various wind directions. The research showed how variation in wind conditions causes a notable change in the flow rate inside the atrium, emphasizing in the role of non-design wind conditions in the design of buildings with buoyancy-driven ventilation.

Khalaji Assadi et al. (2011) examined the natural ventilation in an atrium attached to a threestory office building in Tehran. They found a reduction in energy consumption of $19.5 \%$ in the first two weeks of January. Their study considered the time of day in the simulation and recommended the use of insulation cover at night to reduce heat loss through the glazing area during the night. Their results showed that the complete (100\%) natural ventilation or passive heating of the building is impossible. 


\section{2-3-2 Integration of solar chimney in solar crop dryer}

The applications of a solar chimney in highly glazed spaces such as a crop dryer have been studied by Koua et al. (2011) and Afriyie et al. (2011). These two studies are conceptually the closest research studies to the contents of this thesis. The former numerically and experimentally studied a natural convection solar dryer. This dryer was a combination of a chamber and a solar chimney, used for drying cassava. They studied the thermal behaviour of the dryer but the research was mainly focused on various influential factors of drying the crops such as drying duration, initial mass of the crops, and their diameter. The air temperature was also studied as a factor affecting the drying process.

On the other hand, the latter study is more focused on the physical properties of the drying chamber and its solar chimney without considering the drying products. In addition to their numerical and computational simulation model, they also built a small scale experimental model consisting of an inclined drying chamber paired with a solar chimney called chimney-dependent solar crop dryer (CDSCD). The study confirmed the critical impact of the chamber roof tilt angle and chimney height in the performance of CDSCD. They found an optimal ratio of 4:1 of inlet/outlet area producing the highest flow rate in the CDSCD. They concluded that for a region far from the equator, a combination of the high solar chimney and short drying chamber has the best performance.

\section{2-4 Concluding remarks}

The potential of a solarium system to reduce the temperature swing and heating demand of the house and achieve big savings in the operating costs of the building has been explored in several studies and was found to be satisfactory. Most of these researches however, ignored the ventilation requirements of the solarium, despite the fact that it is proven in those studies that an improper design may cause overheating, resulting in an increase in the energy consumption of the building.

Moreover, the preceding information collected on the physical aspects of the solar chimney and different variables affecting its performance, affirming that solar chimney can provide airflow 
and acquire adequate passive ventilation in a building. As mentioned earlier in this chapter, several studies on the ventilation of crop dryers and atriums demonstrate that using a solar chimney in conjunction with a highly glazed space can ensure stable natural ventilation performance even without the encouragement of wind force. Recent studies have shown the additional complexity and challenges posed by integrating a solar chimney with a highly-glazed space.

Most of these studies however, have been performed based on steady state condition. Those studies subjected to dynamic climate condition were mostly performed not only for hot and arid climates but also for typical buildings of those locations.

Since it is imperative in practice to design based on performance estimations for dynamic conditions, climate and surroundings. Dynamic thermal and airflow simulations for solarium systems ventilated with solar chimney should be performed to explore the feasibility, benefits and possible improvement of this application.

Nevertheless, research to date does not appear to consider the application of a solar chimney as the means of solar-driven natural ventilation in a solarium attached in a residential building, especially in a cold climate such as Toronto area. It indicates the need for further study on various aspects of the application of solar chimney for passive ventilation of a solarium attached in a residential building.

The current study develops a numerical model and a computational simulation of the inclined solarium combined with a solar chimney using non steady heat transfer equations. The results will be used for parametric and analytical studies. In the next chapter, the physical model of this study will be represented. 


\section{Chapter 3: Physical model}

In this study, a simple two-story residential building has been simulated with various solariums and the solar chimney configurations. Parametric studies were carried out to examine the effect of each design parameter on the thermal conditions in the building. The simulated solarium is assumed to be located on the south side of a building in the region of Toronto, Canada with the glass wall facing south. A vertical solar chimney has been used in conjunction with inclined roof of the solarium to enhance the ventilation through the solarium. Schematic side section of the SCAS is presented in Fig. 2. As it is shown, adjacent room air enters the solarium through a bottom inlet. This air then absorbs energy in the solarium. The air then enters the solar chimney to be further warmed up into the chimney with the same mechanism as the solarium. The air finally exits into the ambient air, producing flow from living space to the outdoor. Uniform cross sections are assumed throughout the solar chimney in this application.

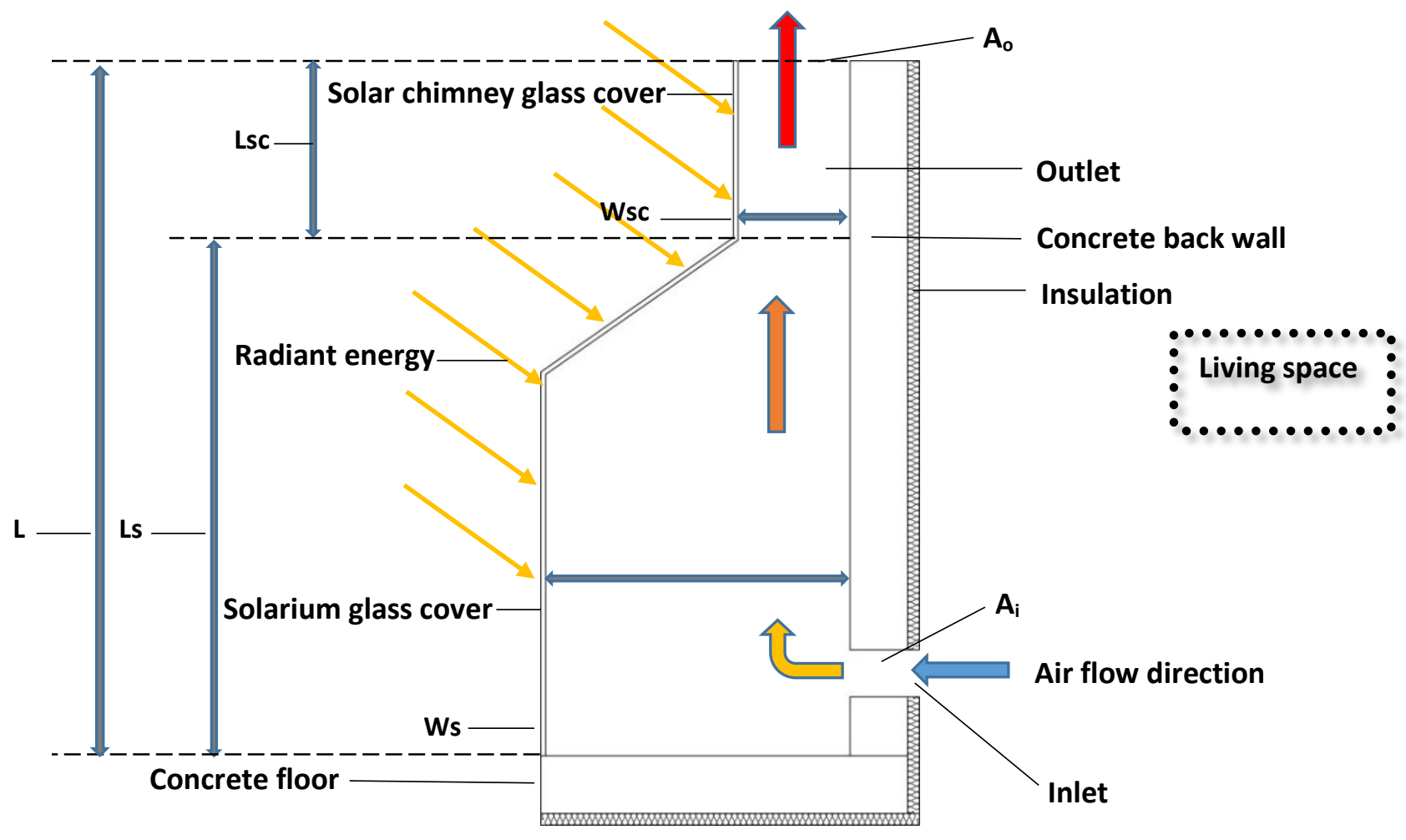

Fig. 2. Schematic side section of the SCAS: Ws and Ls are the width and height of the solarium; WsC and LSC are width and height of the chimney 
As it can be seen in Fig. 2, the solarium in this SCAS has a south faced glass wall to effectively absorb solar radiation. The glass roof is inclined to the south to improve the heat gain in the solarium. The back wall in both chimney and solarium, thermal mass, is made of concrete. Thermal inertia of the back wall converts the wall to a heat source for the air inside the SCAS when solar radiation is not properly provided. The solarium concrete floor has the same specification as the back wall and acts as a capturing surface. The back walls in both the solarium and the solar chimney and the solarium concrete floor have an insulation layer as their last layer to be less affected with the adjacent room, ambient and the ground temperature respectively.

\section{3-1 The airflow model}

The air inside a SCAS is heated in two stages, first in the solarium and then in the chimney, to reach a higher temperature than it has in the solarium. It is assumed in this study that the air inside the solarium is replaced entirely by the adjacent room air and the friction is ignored inside the SCAS between air and interior surfaces. Afosono and Oliveira (2000) found out that compared to losses from expansion, contraction and bending friction losses between fluid, air inside in this case, and wall surfaces is insignificant when wall surfaces are smooth.

With the above assumption, $\dot{m}$ is the air mass flow rate $(\mathrm{kg} / \mathrm{s})$ that crosses the SCAS and as Bansal et al. (1993) and Andersen (1995) explored, has the following expression:

$$
\begin{aligned}
& \dot{m}=\rho A_{o} v_{o} \\
& \dot{m}=C_{d} \frac{\rho_{f, o} A_{o}}{\sqrt{1+\left(\frac{A_{o}}{A_{i}}\right)^{2}}} \sqrt{\frac{2 g L\left(T_{f s c}-T_{r}\right)}{T_{r}}}
\end{aligned}
$$

where $C_{d}$ is coefficient of discharge of air channel which according to Flourentzou et al. (1997) has the value of $0.57, \rho_{f, o}$ is the density of the air when leaving the chimney, $A_{o}$ and $A_{i}$ are the outlet and inlet areas of the SCAS openings, $T_{f s c}$ is the air temperature in the chimney, $T_{r}$ is the living space temperature that enters the solarium, $g$ is gravitational constant and $L$ is the SCAS height which is the sum of solarium and the solar chimney heights. 


\section{3-2 Heating models}

Fig. 3. illustrates the physical heat exchange process in this model. Since the heat transfer in highly glazed spaces such as a solarium is a very complicated process, the following assumptions have been made to simplify the formulation phase.

- The air inside the solarium and the solar chimney are assumed to be well mixed and have only values of $T_{f s}$ and $T_{f s c}$ at every time $n$ respectively.

- The glass surfaces in the solarium and the chimney, concrete walls and floor in the chimney are also assumed to stay at the one temperatures of $T_{g s}, T_{g s c}, T_{w s}, T_{w s c}$ and $T_{b}$ respectively.

- Thermal inertia of the glass and the air inside the SCAS are negligible.

- Heat flow in the model is steady and one dimensional.

- The glass walls and roof are opaque to the diffused radiation from thermal masses throughout the model.

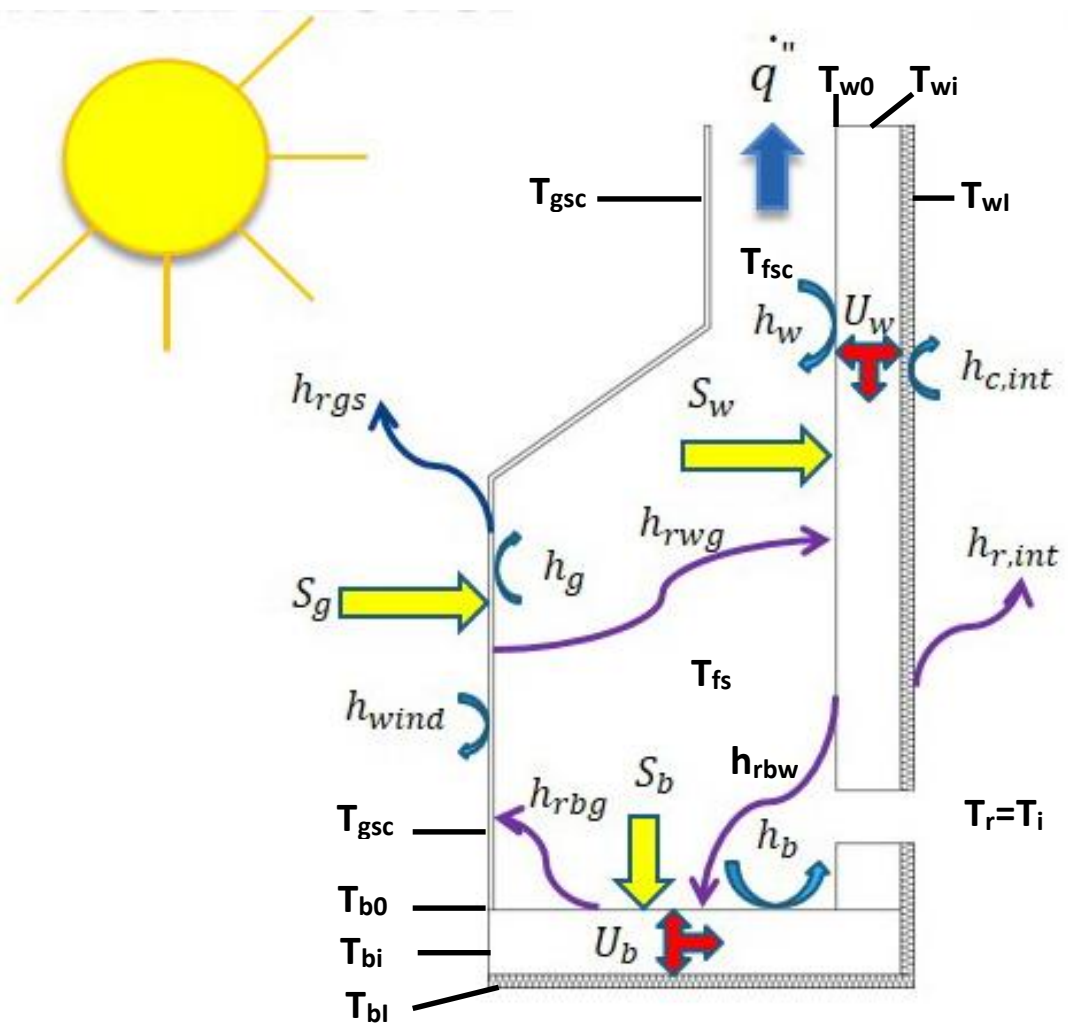

Fig. 3. Heat transfer process in the dynamic model of SCAS 
In Fig. 3, $S_{g}, S_{w}$ and $S_{b}$ are solar radiation incident on the glass wall, concrete back wall and floor of the solarium respectively, $h_{r w b}, h_{r w g}, h_{r b g}$ and $h_{r g s}$ are radiative heat transfer coefficient between wall and floor, wall and glass cover, concrete floor and glass cover and glazing and the sky, $h_{w}, h_{b}$ and $h_{g}$, is the convective heat transfer coefficients of wall, concrete floor and glass cover and air inside the solarium, $h_{c, i n t}$ and $h_{r, i n t}$ are convective and radiative heat transfer coefficients between wall and adjacent room, $h_{\text {wind }}$ and $h_{r g s}$ are convective and radiative heat transfer coefficients between glass cover and ambient due to the wind and sky respectively and $U_{w}$ and $U_{b}$ are the $U$ values of the back wall and concrete floor.

\section{3-3 The solarium heating model}

Energy balance method has been employed to determine different temperatures inside the solarium. These temperatures are: $T_{g}$ glass cover temperature, $T_{w}$ concrete back wall temperature, $T_{b}$ floor temperature and $T_{f}$ temperature of the air inside the solarium.

\section{3-3-1 Concrete wall}

Thermal mass of the concrete back wall plays a critical role in the performance of the SCAS. Hence, heat conduction in solid equation has been used in development of the energy balance in this part of the solarium.

Absorbed solar radiation energy + absorbed radiant energy from the concrete floor $=$ radiant energy lost to the glass wall + convective energy lost to the air inside the solarium + conductive energy lost through the wall to the living space + heat stored in the concrete wall.

$S_{w}+h_{r w b}\left(T_{w}-T_{b}\right)=h_{r w g}\left(T_{w}-T_{g}\right)+h_{w}\left(T_{w}-T_{f}\right)+U_{w}\left(T_{w}-T_{r}\right)+\rho C_{p} \frac{d T}{d t}$

where $S_{w}$ is solar radiation incident on the concrete wall of the solarium, $h_{r w b}$, radiative heat transfer coefficient between wall and floor, $h_{r w g}$, radiative heat transfer coefficient between wall and glass cover, $T_{w}$ is wall temperature, $T_{g}$ is solarium glazing temperature, $h_{w}$ is the convective heat transfer coefficient of wall and air inside the solarium, $T_{f}$ is the air temperature inside the solarium, $U_{w}, U$ value of the back wall, $T_{r}$ is the living space temperature that enters the solarium, $\rho$ is density and $c_{p}$ is the specific heat of the concrete. 
The temperature of the concrete wall is characterized by 14 interior and 2 surface temperatures of $T_{w i}$. These are calculated employing conductive heat transfer equation in a solid which can be described as follows:

$\frac{\partial^{2} T}{\partial x^{2}}=\frac{1}{\alpha} \frac{\partial T}{\partial t}$

where $\alpha$, thermal diffusivity, has the following form:

$\alpha=\frac{k}{\rho c_{p}}$

where $k$ is the thermal conductivity, $\rho$ is density and $c_{p}$ is the specific heat.

The surface temperatures can be calculated using this equation. Some approximations have been introduced to solve the above equation, which are:

$\frac{\partial T}{\partial x}=\frac{T(x+\Delta x)-T(x)}{\Delta x}=\frac{T_{i+1}-T_{i}}{\Delta x}$

$\frac{\partial T}{\partial t}=\frac{T(t+\Delta t)-T(t)}{\Delta t}=\frac{T^{n+1}-T^{n}}{\Delta t}$

Therefore:

$\frac{\partial^{2} T}{\partial x^{2}}=\frac{T_{i+1}+T_{i-1}-2 T_{i}}{\Delta x^{2}}$

Subscript $i$ denotes the temperature in distance $x$ and the superscript $n$ defines the temperature in time $t$. Combining the last two equations with the equation 4 introduces the following equation:

$\frac{T_{i+1}^{n}+T_{i-1}^{n}-2 T_{i}^{n}}{\Delta x^{2}}=\frac{1}{\alpha} \frac{T_{i}^{n+1}-T_{i}^{n}}{\Delta t}$

The temperature in node $i$ and in time $n+1$ has the following expression:

$T_{i}^{n+1}=\frac{\alpha \Delta t}{\Delta x^{2}}\left(T_{i+1}^{n}+T_{i-1}^{n}-2 T_{i}^{n}\right)+T_{i}^{n}$

Boundary conditions should be defined to solve the conductive heat transfer equation in a solid.

Two space and one time dependant boundary conditions are described as follows:

- $T_{i}^{0}$, initial temperature in each node.

- $T_{0}^{n}$, temperature in node 0 , wall surface, in time step $n$.

- $T_{I}^{n}$, temperature in node $I$, second wall surface, in time step $n$.

The last two temperatures can be described as follows:

$T_{0 w}^{n}:$ 
$S_{w}=h_{w}\left(T_{0 w}^{n}-T_{f}^{n}\right)+h_{r w g}\left(T_{0 w}^{n}-T_{g}^{n}\right)+k \frac{\left(T_{-1, w}^{n}-T_{1, w}^{n}\right)}{2 \Delta x}$

and $T_{I w}^{n}$ :

$$
k \frac{\left(T_{I-1 w}^{n}-T_{I+1 w}^{n}\right)}{2 \Delta x}=h_{\text {cint }}\left(T_{I w}-T_{r}\right)+h_{\text {rint }}\left(T_{I w}-T_{r}\right)
$$

where $S_{w}$ is solar radiation incident on the concrete wall of the solarium, $T_{0 w}^{n}, T_{g}^{n}$ and $T_{f}^{n}$ are wall temperature in node 0 , glass cover temperature and air inside the solarium respectively in any time $n, h_{r w g}$ radiative heat transfer coefficient between wall and glass cover, $h_{w}$ is the convective heat transfer coefficient of wall and air inside the solarium, $k$ is the air thermal conductivity, $\Delta x$ is distance between nodes in the wall, $h_{\text {cint }}$ and $h_{\text {rint }}$ are convective and radiative heat transfer coefficients between back wall and the living space, $T_{I W}$ is the wall temperature in the last node and $T_{r}$ is the living space temperature that enters the solarium.

Solving these equations needs more information. For instance, in the case of wall surface temperature $T_{I w}^{n}$, knowing the temperature of node $I+1$ is necessary. This can be achieved through solving the following equation:

$$
T_{I+1 w}^{n}=T_{I-1 w}^{n}-\frac{2 \Delta x}{k}\left(h_{\text {cint }}\left(T_{I w}^{n}-T_{r}^{n}\right)+h_{\text {rint }}\left(T_{I w}^{n}-T_{r}^{n}\right)\right)
$$

In order to find $T_{0 w}^{n}$, the temperature of interest is $T_{-1 w}^{n}$ that must be found through solving the following equation:

$T_{-1 w}^{n}=\frac{2 \Delta x}{k}\left(S_{w}-h_{w}\left(T_{0 w}^{n}-T_{f}^{n}\right)+h_{r w g}\left(T_{0 w}^{n}-T_{g}^{n}\right)\right)-T_{1 w}^{n}$

where $S_{w}$ is solar radiation incident on the concrete wall of the solarium, $T_{I w}^{n}, T_{0 w}^{n}, T_{g}^{n}, T_{f}^{n}$ and $T_{r}^{n}$ are the wall temperature in the last node, wall temperature in node 0 , glass cover temperature, air inside the solarium and the living space temperature that enters the solarium respectively in any time $n, h_{r w g}$ radiative heat transfer coefficient between wall and glass cover, $h_{w}$ is the convective heat transfer coefficient of wall and air inside the solarium, $k$ is the air thermal conductivity, $\Delta x$ is distance between nodes in the wall and $h_{c, \text { int }}$ and $h_{r, \text { int }}$ are convective and radiative heat transfer coefficients between back wall and the living space. 
It can be concluded that to calculate the node temperature in the concrete wall, Equation 11 is used. It must be noted that in the case of two surface nodes, Equations 14 and 15 are used to calculate the first and the last node temperatures.

\section{3-3-2 Concrete floor}

The base floor in the solarium is made of concrete that has the same thickness as concrete wall. Therefore its thermal inertia is as important as the concrete wall. Energy balance in this part of the solarium has the following form:

Absorbed solar radiation energy $=$ radiant energy lost to the glazing + radiant energy lost to the concrete wall + convective energy lost to the air inside the solarium + conductive energy lost through the base to the ground+ heat stored in the concrete floor.

$S_{b}=h_{r b g}\left(T_{b}-T_{g}\right)+h_{r b w}\left(T_{b}-T_{w}\right)+h_{b}\left(T_{b}-T_{f}\right)+U_{b}\left(T_{b}-T_{E}\right)+\rho C_{p} \frac{d T}{d t}$

where $S_{b}$ is solar radiation incident on the concrete floor of the solarium, $T_{b}, T_{g}, T_{f}$ and $T_{E}$ are the floor temperature, glass cover temperature, air temperature and the temperature of the ground beneath the concrete floor respectively, $h_{r b g}$ radiative heat transfer coefficient between floor and glass cover, $h_{r b w}$ radiative heat transfer coefficient between floor and wall, $h_{b}$ is the convective heat transfer coefficient of floor and air inside the solarium, $U_{b}$ is the $U$ value of the solarium floor, $\rho$ is density and $c_{p}$ is the specific heat of the concrete.

The same as the absorber wall, the temperature of floor is characterized by 14 interior and 2 surface temperatures of $T_{b i}$ as well. The same method is used to calculate the node's temperature in the floor. Though, due to some differences between the floor and concrete wall, some modifications have been made to the above equations as follows:

$T_{I b}^{n}$ :

$k \frac{\left(T_{I-1 b}^{n}-T_{I+1 b}^{n}\right)}{2 \Delta x}=U_{b}\left(T_{I b}^{n}-T_{E}\right)$

$T_{0 b}^{n}$

$$
S_{b}=h_{b}\left(T_{0 b}^{n}-T_{f}^{n}\right)+h_{r b g}\left(T_{0 b}^{n}-T_{g}^{n}\right)+h_{r b w}\left(T_{0 b}^{n}-T_{w}^{n}\right)+k \frac{\left(T_{-1 b}^{n}-T_{1 b}^{n}\right)}{2 \Delta x}
$$


$T_{-1 b}^{n}=\frac{2 \Delta x}{k}\left(S_{b}-h_{b}\left(T_{0 b}^{n}-T_{f}^{n}\right)+h_{r b g}\left(T_{0 b}^{n}-T_{g}^{n}\right)\right)-T_{1 b}^{n}$

and finally:

$$
T_{I+1 b}^{n}=T_{I-1 b}^{n}-\frac{2 \Delta x}{k} U_{b}\left(T_{g}^{n}-T_{E}\right)
$$

where $S_{b}$ is solar radiation incident on the concrete floor of the solarium, $T_{0 b}^{n}, T_{I b}^{n}, T_{f}^{n}, T_{g}^{n}$ and $T_{E}$ are the floor temperature in node 0 , the floor temperature in node I (last node), air temperature, glass cover temperature and the ground beneath the concrete floor respectively in any time $n$, $h_{r b g}$ radiative heat transfer coefficient between floor and glass cover, $h_{r b w}$ radiative heat transfer coefficient between floor and wall, $h_{b}$ is the convective heat transfer coefficient of floor and air inside the solarium, $\Delta x$ is the distance between two nodes and $U_{b} U$ value of the solarium floor.

\section{3-3-3 Fluid (air inside the solarium)}

Energy balance of the fluid, air inside the solarium, considering the air is well mixed and has one unique temperature $\left(T_{f}\right)$ has the following time dependant expression:

Convective energy lost to the glass cover + heat transferred and stored into the air inside the solarium which leaves the solarium through ventilation = energy received from absorber wall by convection + convective energy received from absorber concrete floor

$h_{g}\left(T_{f}^{n}-T_{g}^{n}\right)+\dot{q}^{\prime \prime}=h_{w}\left(T_{0 w}^{n}-T_{f}^{n}\right)+h_{b}\left(T_{0 b}^{n}-T_{f}^{n}\right)$

where $q^{\prime \prime}$, heat transferred to the air stream, is:

$$
q^{\prime \prime}=\frac{\frac{d m}{d t} C_{f}\left(T_{f s}-T_{r}\right)}{\gamma W L}
$$

with $h_{g}$ being the convective heat transfer coefficient of glass cover, and air inside the solarium, $T_{0 b}^{n}$, $T_{0 w}^{n}, T_{f}^{n}$ and $T_{g}^{n}$ are the floor temperature in node 0 , the wall temperature in node 0 , air temperature and glass cover temperature respectively in any time $\mathrm{n}, T_{f s}$ and $T_{r}$ are solarium air temperature and air room temperature which enters the solarium, $h_{g}, h_{w}$ and $h_{b}$ are the convective heat transfer coefficients of glass cover, the solarium wall and floor and air inside the solarium respectively, $W$ is the width of the solarium, $L$ is the height of the solarium and the $C_{f}$ is the heat capacity of the air in this equation. 
According to the bulk fluid temperature relation (Hirunlabh et al., 1999; Ong, 2003; Ong and Chow, 2003) the fluid average temperature related to the inlet and outlet has the following mathematical form:

$$
T_{f}=\gamma T_{f o}+(1-\gamma) T_{f i}
$$

where $\gamma$ is the coefficient of heat transfer to the air stream which flows out, $T_{f}, T_{f o}$ and $T_{f i}$ are mean fluid temperature, air temperature in the outlet when is leaving the chimney and air temperature that enters the SCAS which in this case is equal to $T_{r}$, adjacent room temperature. The heat transferred to the air stream inside the solarium can be rewritten as follows:

$$
\dot{q}^{\prime \prime}=\frac{\dot{m} C_{f}\left(T_{f}-T_{f i}\right)}{\gamma_{s} W L}=M\left(T_{f}-T_{r}\right)
$$

$M$, heat that leaves the solarium, can be explained as:

$$
M=\frac{\dot{m} C_{f}}{\gamma_{s} W s L S}
$$

Temperature of the air inside the chimney can be then figured by freezing the $T_{f}^{n}$ in above equation and it has the following form:

$$
T_{f}^{n}=\frac{h_{g} T_{g}^{n}+M T_{r}^{n}+h_{w} T_{0 w}^{n}+h_{b} T_{0 b}^{n}}{h_{g}+h_{w}+h_{b}+M}
$$

where $\dot{m}$ is the air volume that cross the solarium, was introduces earlier, $T_{f}$ and $T_{r}$ are air temperature and room temperature which enters the SCAS, $C_{f}$ is the heat capacity of the air in this equation, $\gamma$ is the coefficient of heat transfer to the air stream which flows out, $W$ and $L$ are the width and the height of the solarium, $\dot{q}^{\prime \prime}$ is heat transferred to the air stream and $M$ is heat that leaves the solarium.

\section{3-3-4 Glass cover}

In this section energy balance of the glass wall of the solarium is expressed to determine its temperature $\left(T_{g}\right)$. As it was explained earlier, a unique temperature is assigned for the glass cover and the thermal inertia of the glass is ignored. With all these assumptions, the energy balance on the glass wall has the following expression: 
Radiant energy lost to the sky + energy lost to the ambient by convection = absorb solar radiation energy + energy received from air inside the solarium by convection + radiant energy received from back wall + radiant energy received from concrete floor.

$h_{r g s}\left(T_{g}-T_{s k y}\right)+h_{\text {wind }}\left(T_{g}-T_{a}\right)=S_{g}+h_{g}\left(T_{f}-T_{g}\right)+h_{r w g}\left(T_{w}-T_{g}\right)+h_{r b g}\left(T_{b}-T_{g}\right)$

The temperature of the glass wall is a time-dependant variable. Hence, the energy balance of this part can be rewritten as:

$S_{g}+h_{g}\left(T_{f}^{n}-T_{g}^{n}\right)+h_{r w g}\left(T_{0 w}^{n}-T_{g}^{n}\right)+h_{r b g}\left(T_{0 b}^{n}-T_{g}^{n}\right)=h_{w i n d}\left(T_{g}^{n}-T_{a}^{n}\right)+h_{r g s}\left(T_{g}^{n}-T_{s k y}^{n}\right)$

The glass temperature can be calculated for the time $n, T_{g}^{n}$, by replacing the $T_{f}^{n}$ in above equation with Equation 26, thereupon, the final $T_{g}^{n}$ equation is:

$T_{g}^{n}:$

$$
T_{g}^{n}=\frac{S_{g}+\frac{h_{g} M T_{r}^{n}}{B}+\frac{h_{g} h_{w} T_{0 w}^{n}}{B}+\frac{h_{g} h_{b} T_{0 b}^{n}}{B}+h_{r w g} T_{0, w}^{n}+h_{r b g} T_{0, b}^{n}+h_{w i n d} T_{a}^{n}+h_{r g s} T_{s k y}^{n}}{h_{w i n d}+h_{r g s}+h_{r b g}+h_{r w g}+h_{g}-\frac{h_{g}{ }^{2}}{B}}
$$

where $B=h_{g}+h_{w}+h_{b}+M, S_{g}$ is solar radiation absorbed on the glass cover of the solarium, $T_{0 b}^{n}, T_{0 w}^{n}, T_{r}^{n}, T_{a}^{n}$ and $T_{s k y}^{n}$ are the floor and wall temperatures in node 0 , adjacent room temperature, ambient temperature and the sky temperature respectively in any time $n$, $h_{r b g}, h_{r w g}$ and $h_{r g s}$ are radiative heat transfer coefficients between floor, wall and the sky and the glass cover and $h_{b}, h_{g}$ and $h_{\text {wind }}$ are convective heat transfer coefficients of floor and glazing and air inside the solarium and convective heat transfer coefficient due to the wind.

\section{3-4 The solar chimney heating model}

The heating models of the solar chimney in the SCAS application to determine the temperatures of $T_{g}$ glass cover temperature, $T_{w}$ concrete back wall temperature and $T_{f}$ fluid temperature have been developed as follows in the coming sections.

\section{3-4-1 The chimney air energy balance}

Energy gained from concrete wall through convection = heat lost to the glass cover by convection + heat lost to the air stream inside the chimney. 
$h_{w}\left(T_{0 w}^{n}-T_{f}^{n}\right)=h_{g}\left(T_{f}^{n}-T_{g}^{n}\right)+M\left(T_{f}^{n}-T_{f s}^{n}\right)$

$M$ in this equation has the following form:

$$
M=\frac{\dot{m} C_{f}}{\gamma_{s c} W s c L s c}
$$

where $W S C$ and $L S C$ are width and height of the chimney respectively. $\gamma_{s c}$ is an experimental coefficient which will be explained later. The air temperature of the chimney therefore has the following mathematical form:

$$
T_{f}^{n}=\frac{h_{g} T_{g}^{n}+M T_{f s}^{n}+h_{w} T_{0, w}^{n}}{h_{g}+h_{w}+M}
$$

where $\dot{m}$ is the air volume that cross the chimney, $T_{0 w}^{n}, T_{f}^{n}, T_{g}^{n}$ and $T_{f s}^{n}$ are temperatures of chimney wall in node 0 , air inside the chimney, glass wall of the chimney and air inside the solarium in any time $n, C_{f}$ is the heat capacity of the air in this equation, $\gamma$ coefficient of heat transfer to the air stream which flows out, $h_{g}$ and $h_{w}$ are convective heat transfer coefficients of chimney glass cover and chimney back wall and air inside the solar chimney and $M$ is heat that leaves the chimney.

\section{3-4-2 The glazing energy balance}

Radiant heat lost to the sky + convective heat lost to the environment due to air motion = solar energy received by radiation + convective heat gain from air inside the chimney + radiant heat gain from back wall.

$h_{r g s}\left(T_{g}-T_{s k y}\right)+h_{\text {wind }}\left(T_{g}-T_{a}\right)=S_{g}+h_{g}\left(T_{f}-T_{g}\right)+h_{r w g}\left(T_{w}-T_{g}\right)$

As it is explained in the glass cover energy balance in the solarium section, the glazing temperature in the chimney is also a time dependant variable which is also related to the air temperature inside the chimney.

$h_{r w g}$ and $h_{r g s}$ are radiative heat transfer coefficients between wall and the sky and the chimney glass cover and $h_{g}$ and $h_{\text {wind }}$ are convective heat transfer coefficients of chimney glazing and air inside the solar chimney and convective heat transfer coefficient due to the wind.

$S_{g}+h_{g}\left(T_{f}^{n}-T_{g}^{n}\right)+h_{r w g}\left(T_{0 w}^{n}-T_{g}^{n}\right)=h_{w i n d}\left(T_{g}^{n}-T_{a}^{n}\right)+h_{r g s}\left(T_{g}^{n}-T_{s k y}^{n}\right)$ 


$$
T_{g}^{n}=\frac{S_{g}+\frac{h_{g} M T_{f s}^{n}}{C}+\frac{h_{g} h_{w} T_{0, w}^{n}}{C}+h_{r w g} T_{0, w}^{n}+h_{w i n d} T_{a}^{n}+h_{r g s} T_{s k y}^{n}}{h_{w i n d}+h_{r g s}+h_{r w g}+h_{g}-\frac{h_{g}{ }^{2}}{C}}
$$

where $C=h_{g}+h_{w}+M, S_{g}$ is solar radiation incident on the glass cover of the chimney, $T_{0 w}^{n}, T_{g}^{n}$, $T_{f}^{n}, T_{a}^{n}$ and $T_{s k y}^{n}$ are the chimney wall temperature in node 0 , chimney glazing temperature, the temperature of air inside the chimney, ambient temperature and the sky temperature respectively in any time $n, h_{r w g}$ and $h_{r g s}$ are radiative heat transfer coefficients between wall and the sky and the chimney glass cover and $h_{w}, h_{g}$ and $h_{\text {wind }}$ are convective heat transfer coefficients of chimney wall and glazing and air inside the solar chimney and convective heat transfer coefficient due to the wind.

\section{3-4-3 The concrete wall}

Radiative solar energy gain $=$ radiative energy lost to the glazing + convective heat lost to the air inside the chimney + conductive energy lost to the room through the wall thickness+ heat stored in the concrete wall.

$$
S_{w}=h_{r w g}\left(T_{w}-T_{g}\right)+h_{w}\left(T_{w}-T_{f}\right)+U_{w}\left(T_{w}-T_{r}\right)+\rho C_{p} \frac{d T}{d t}
$$

where $S_{w}$ is solar radiation incident on the concrete wall of the chimney, $h_{r w g}$ is radiative heat transfer coefficient between chimney wall and glass wall, $h_{r w g}$, radiative heat transfer coefficient between wall and glass cover, $T_{w}$ is wall temperature, $T_{g}$ is solarium glazing temperature, $h_{w}$ is the convective heat transfer coefficient of wall and air inside the solarium, $T_{f}$ is the air temperature inside the solarium, $U_{w}, U$ value of the back wall and $T_{r}$ is the living space temperature that enters the solarium.

As mentioned earlier the thermal inertia of the concrete wall has a pivotal role in thermal performance of the chimney. Similar to the back wall in the solarium, heat conduction in the solid equation is used to determine the wall temperature in the solarium. The wall has the same thickness of the wall in the solarium and therefore, the same numbers of the nodes (14 internal and 2 external) are assigned for the heat transfer model of the concrete wall in the chimney. The temperature are both time and place dependant and as described earlier the subscript $i$ and 
superscript $n$ demonstrate the place and the time of each node respectively. Temperature of each external node is calculated employing the following equation:

$T_{i}^{n+1}=\frac{\alpha \Delta t}{\Delta x^{2}}\left(T_{i+1}^{n}+T_{i-1}^{n}-2 T_{i}^{n}\right)+T_{i}^{n}$

The surface temperatures are calculated using the following expressions:

$T_{-1 w}^{n}=\frac{2 \Delta x}{k}\left(S_{w}-h_{w}\left(T_{0 w}^{n}-T_{f}^{n}\right)+h_{r w g}\left(T_{0 w}^{n}-T_{g}^{n}\right)\right)-T_{1 w}^{n}$

$T_{I+1, w}^{n}=T_{I-1, w}^{n}-\frac{2 \Delta x}{k}\left(h_{r g s}\left(T_{g}-T_{s}\right)+h_{\text {wind }}\left(T_{g}-T_{a}\right)\right)$

The boundary conditions for the collecting wall in the chimney, temperatures in node $I$ and $O$ in the time $n$, are described as:

$T_{I}^{n}$ :

$k \frac{\left(T_{I-1}^{n}-T_{I+1}^{n}\right)}{2 \Delta x}=h_{r g s}\left(T_{g}-T_{s k y}\right)+h_{w i n d}\left(T_{g}-T_{a}\right)$

$T_{0}^{n}:$

$S_{w}=h_{w}\left(T_{0 w}^{n}-T_{f}^{n}\right)+h_{r w g}\left(T_{0 w}^{n}-T_{g}^{n}\right)+k \frac{\left(T_{-1}^{n}-T_{1}^{n}\right)}{2 \Delta x}$

\section{3-5 Heat transfer coefficients}

As it is shown before, various convective, conductive and radiative heat transfer coefficient play critical roles in the heating models of the SCAS. These coefficients will be introduced in detail in the following section.

\section{3-5-1 Convective heat transfer coefficients}

\section{3-5-1-1 Convective heat transfer coefficient due to the wind $\left(h_{\text {wind }}\right)$}

External convective heat transfer coefficient is the major parameter affects the building envelope heat lost to the ambient. According to Palyvos (2008), improper assigned value for this coefficient can lead to an error of $20-40 \%$ in the energy demand calculation process in a building. It has also been mentioned in this study that convective heat loss through the envelope is 3 to 4 times bigger than radiative heat loss. McAdams (1994) introduced an experimental convective heat transfer coefficient which has been used vastly in the modeling process of several studies (Ong 2003, Ong 
and chow 2003, Marti-Herrero and Heras-Celemin 2006, Afriyie et al. 2011) despite its deficiency. This coefficient has the following form:

$$
h_{\text {wind }}=5.7+3.8 \mathrm{~V}
$$

where $V$ is the wind velocity. Some important factors such as the wind direction and averageacross the surface-wind speed are ignored in this calculation (Oliphant, 1980). Furthermore, the above equation has been produced based on the unrealistic database.

In a study by Palyvos (2008) the existing correlations for the external wind induced convective heat transfer have been summarized and a simple average correlation has been introduced which has the following forms for a windward and leeward surface respectively:

$$
\begin{aligned}
& h_{\text {wind }}=7.4+0.4 \mathrm{~V} \\
& h_{\text {wind }}=4.2+3.5 \mathrm{~V}
\end{aligned}
$$

where $V$ is the wind velocity. Since the south wind is the prevailing wind direction in Toronto area in the summer time, July,

in the modeling of corresponding SCAS the external surface is considered a windward surface and therefore the Equation 43 is used in external convective heat loss calculation process.

\section{3-5-1-2 Convective heat transfer between air and concrete wall, glass cover and the solarium floor $\left(\boldsymbol{h}_{w}, \boldsymbol{h}_{g}\right.$ and $\left.\boldsymbol{h}_{b}\right)$}

According to Duffie and Beckman (1980) and Incropera et al. (2007), convective heat transfer coefficients between air and wall, glass and solarium floor has the following mathematical forms of:

$h_{i}=\frac{N u \cdot k_{f}}{L}$

where $i=$ glass, wall and floor, $L$ is the length of corresponding component (glass, wall or floor), $\mathrm{Nu}$ is the Nusselt number and $k_{f}$ is the thermal conductivity of air. As it can be seen in the above equation, these coefficients are calculated based on the Nusselt number which itself is calculated through experimental correlation and depends on the Rayleigh number (Ra) and the Prandtl number (Pr) (Incropera and DeWitt, 1996). The Rayleigh and PrandtI numbers are dependent on the type of fluid and difference between the surface and the air temperature respectively. The 
Nusselt number in case of the chimney glazing and wall and the solarium glazing and wall has the following mathematical form:

When $R a<10^{9}$ the flow is laminar and the Nusselt number has the form:

$N U=0.68+\frac{0.67 R a^{1 / 4}}{\left[1+(0.492 / P r)^{9 / 16}\right]^{4 / 9}}$

In case of turbulent flow and when $R a>10^{9}$

$N U=\left[0.825+\frac{0.387 R a^{1 / 6}}{\left[1+(0.492 / P r)^{9 / 16}\right]^{8 / 27}}\right]^{2}$

Where:

$R a=\frac{g \beta\left(T_{r}-T_{f}\right) L^{3}}{\alpha v}$

and:

$\operatorname{Pr}=\frac{c_{f} \cdot \mu_{f}}{k_{f}}$

where $g$ denotes gravitational constant, $\alpha$ presents thermal diffusivity, $\beta$ is coefficient of expansion of air, $v$ is air velocity, $c_{f}, \mu_{f}$ and $k_{f}$ are specific heat, dynamic viscosity and thermal conductivity of the air inside the solarium or the solar chimney, $L$ is the height and $T_{r}$ and $T_{f}$ are adjacent room and mean fluid (air inside the SCAS) temperature.

It should be noted here that in case of the solarium glazing due to the fact that the glazing comprised of a vertical plate and an inclined one, called roof in this study, the convective heat coefficient of the glass $h_{g s}$ is calculated using the following equation:

$h_{g s}=\frac{h_{g w} A_{g w}+h_{\text {groof }} A_{\text {groof }}}{A_{g w}+A_{\text {groof }}}$

where $h_{g w}$ and $A_{g w}$ are convective heat transfer coefficient and the area of the vertical wall of the solarium, $h_{\text {groof }}$ and $A_{\text {groof }}$ are convective heat transfer coefficient and the area of the inclined roof of the solarium. In calculation of $h_{g w}$ and $h_{\text {groof }}$, height of the vertical wall and the roof are used respectively. The convective heat transfer coefficient for the horizontal floor of the solarium $h_{b}$ is calculated differently employing the following expression:

$h_{b}=\frac{N u_{b} \cdot k_{f}}{L_{b}}$ 
where:

$N u_{b}=0.54 R a^{1 / 4}$

if $10^{4}<R a<10^{7}$ and:

$N u_{b}=0.15 R a^{1 / 3}$

if $10^{7}<R a<10^{11}$.

where $N u_{b}$ is the Nusselt number, $k_{f}$ is the thermal conductivity of air inside the solarium, $L_{b}$ is solarium length and $R a$ is the Rayleigh number.

Incropera et al. (2007) found out that for an inclined roof facing downward which has the tilt angle of $0<\theta<60$ the convective heat transfer coefficient for the roof, $h_{\text {groof }}$ will be calculated by replacing g with $g \cos \theta$ in Equation 48 .

In all above equations, the corresponding fluid is air and the mean surface fluid film temperature is considered as the air temperature. Physical properties of the air are introduced by Ong (2003) and Ong and Chow (2003). These properties are dependent to the temperature and based on the interval temperature of 300-350 $\mathrm{K}$. These properties are:

$$
\begin{aligned}
C_{f} & =\left(1.007+0.00004\left(T_{f}-300\right)\right) \times 10^{3} \\
\mu_{f} & =\left(1.846+0.00472\left(T_{f}-300\right)\right) \times 10^{5} \\
\rho_{f} & =1.1814-0.00353\left(T_{f}-300\right) \\
k_{f} & =0.0263-0.000074\left(T_{f}-300\right)
\end{aligned}
$$

where:

$$
\begin{aligned}
& v=\frac{\mu_{f}}{\rho_{f}} \\
& \alpha=\frac{k_{f}}{\rho_{f} C_{f}} \\
& \beta_{f}=\frac{1}{T_{f}}
\end{aligned}
$$

being $\alpha$ thermal diffusivity, $\beta$ is coefficient of expansion of air, $v$ is air velocity, $c_{f}, \mu_{f}$ and $k_{f}$ are specific heat, dynamic viscosity and thermal conductivity of the air inside the solarium or the solar chimney and $T_{f}$ is the mean fluid (air inside the SCAS) temperature. 
The other convective heat transfer coefficient is $h_{c, i n t}$. This coefficient is the convective heat transfer coefficient between collecting wall and the living space. The mathematical expression of $h_{c, i n t}$ is:

$h_{C, i n t}=1.31\left|T_{w}-T_{r}\right|^{1 / 3}$

where $T_{w}$ is the solarium wall surface temperature in the last node $(I)$ and $T_{r}$ is the adjacent space temperature.

\section{3-5-2 Coefficient of heat transfer to the air stream which flows out $(\gamma)$}

As explained before, $\gamma$ is an experimental coefficient which is used in the bulk fluid temperature relation. The bulk fluid temperature is an equilibrium temperature of an adiabatically mixed fluid in a given cross section of a duct which is more accurate than for instance film temperature. This average has been used in either chimney or solarium equations to reflect the air temperature inside of them. $\gamma$ has the following mathematical form in the solarium and the solar chimney respectively:

$$
\begin{aligned}
& \gamma_{s}=\frac{T_{f s}-T_{r}}{T_{f s c}-T_{r}} \\
& \gamma_{s c}=\frac{T_{f s c}-T_{f s}}{T_{o}-T_{f s}}
\end{aligned}
$$

where $T_{f s}$ and $T_{f s c}$ are air temperature inside the solarium and the chimney respectively. $T_{r}$ is the room temperature that enters the SCAS and finally $T_{o}$ is outdoor air temperature.

According to Hirunlabhbet al. (1999) this coefficient has the value of 0.75. However, Ong and Chow (2003) found the value of 0.74 for this coefficient. Afriyie et al. (2011) found the value of 0.756 for the $\gamma_{S C}$ and explored that for various configurations of the solarium $\gamma_{s}$ is dependent to the tilt angle $\left(\theta^{\text {Rad }}\right)$ and has the following form:

$\gamma_{s}=-0.3856 \theta^{2}+1.084 \theta-0.0844$ 


\section{3-5-3 Radiative heat transfer coefficients}

Based on the aforementioned research assumptions and the study performed by Marti- Herrero and Heras-Celemin (2006), the radiative heat transfer coefficient between absorber wall and the glazing in both the solar chimney and the solarium is given by:

$$
h_{r w g}=\frac{\sigma\left(T_{w}+T_{g}\right)\left(T_{w}{ }^{2}+T_{g}{ }^{2}\right)}{\frac{1}{\epsilon_{g}}+\frac{1}{\epsilon_{w}}-1}
$$

where $\sigma$ is the Stefan-Boltzmann constant, having the value of :

$\sigma=5.67 \times 10^{-8}$

The solarium concrete floor has the radiative heat transfer with the glass cover and concrete wall as well. This heat transfer coefficients, based on Afriyie et al. (2011) are expressed respectively as follows:

$$
\begin{aligned}
& h_{r b g}=\frac{\sigma}{A_{b}} \frac{\left(T_{b}+T_{g}\right)\left(T_{b}{ }^{2}+T_{g}{ }^{2}\right)}{\frac{1-\epsilon_{g}}{\epsilon_{g} A_{g}}+\frac{1-\epsilon_{b}}{\epsilon_{b} A_{b}}+\frac{1}{A_{b}}} \\
& h_{r b w}=\frac{\sigma}{A_{b}} \frac{\left(T_{b}+T_{w}\right)\left(T_{b}{ }^{2}+T_{w}{ }^{2}\right)}{\frac{1-\epsilon_{w}}{\epsilon_{w} A_{w}}+\frac{1-\epsilon_{b}}{\epsilon_{b} A_{b}}+\frac{1}{A_{b}}}
\end{aligned}
$$

The absorbing concrete wall has the radiative heat alternation with the living space. This radiant heat transfer coefficient, $h_{r, i n t}$, can be explained as:

$$
h_{r, \text { int }}=\frac{\sigma\left(T_{w}+T_{r}\right)\left(T_{w}^{2}+T_{r}^{2}\right)}{\frac{1}{\epsilon_{r}}+\frac{1}{\epsilon_{w}}-1}
$$

There is also radiative heat transfer between glass cover in the solarium and the solar chimney and the sky. The following equation represents the coefficient of this radiative heat exchange between the sky and the glazing (Marti- Herrero and Heras-Celemin, 2006):

$$
h_{r g s}=\sigma\left(T_{g}+T_{s k y}\right)\left(T_{g}{ }^{2}+T_{s k y}{ }^{2}\right)
$$

The concrete absorber wall in the chimney is in direct contact with the ambient. This wall has radiative heat transmission with the sky having a coefficient of the following form (Marti- Herrero and Heras-Celemin, 2006):

$$
h_{r w s}=\sigma\left(T_{w}+T_{s k y}\right)\left(T_{w}{ }^{2}+T_{s k y}{ }^{2}\right)
$$


In the above equations $T_{\text {sky }}$ denotes the sky temperature which is given by (Swinbank, 1963):

$T_{\text {sky }}=0.0552 T_{a}^{1.5}$

where $T_{w}, T_{g}, T_{r}, T_{b}, T_{a}$ and $T_{s k y}$ are temperatures of concrete wall, glass cover, adjacent room, concrete floor, ambient and sky respectively, $\epsilon_{g}$ and $A_{g}$ are emissivity and area of the glass cover, $\epsilon_{b}$ and $A_{b}$ are emissivity and area of the concrete floor and $\epsilon_{w}$ and $A_{w}$ are emissivity and area of the concrete back wall.

\section{3-5-4 Conductive heat transfer coefficients}

There is conductive heat transfer through concrete wall and floor of the solarium as well as the concrete wall of the solar chimney. These elements have the same material and thickness. They all are isolated from their adjacent space with the same insulation. Hence the conductive heat transfer coefficient in all of these elements have the same value which can be calculated using the following equations:

$$
R_{i}=\frac{\Delta w_{i}}{k_{i}}
$$

where $i$ represents insulation, wall and floor and $\Delta w$ is the thickness and $k$ is thermal conductivity of corresponding component. The total $U$ value of the concrete wall/ floor then can be calculated using the following expressions:

$$
\begin{aligned}
& R_{\text {total } w}=R_{\text {ins }}+R_{w} \\
& R_{\text {total } b}=R_{\text {ins }}+R_{b} \\
& U_{\text {total } j}=\frac{1}{R_{\text {total } j}}
\end{aligned}
$$

where $j$ denotes wall or floor, $R_{\text {total } w}$ is the thermal resistance value of the back wall, $R_{\text {ins }}$ is the thermal resistance value of the insulation, $R_{w}$ is the thermal resistance value of concrete part of the back wall and $R_{b}$ is the thermal resistance value of concrete part of the floor. 


\section{3-6 Solar radiation gain}

Solar radiation absorbed by the solarium glass cover, back wall and absorbing floor and the solar chimney glazing and concrete wall $\left(S_{g s}, S_{w s}, S_{b}, S_{g s c}\right.$ and $\left.S_{w s c}\right)$ have the following mathematical forms respectively:

$S_{g s c}=\alpha_{g s c} I_{\text {vertical }}$

$S_{g s}=\frac{\alpha_{g s} I_{\text {vertical }}}{A_{g w}+A_{\text {groof }}}\left(A_{g w}+A_{\text {groof }} \frac{\operatorname{Sin}(\delta+\theta)}{\operatorname{Cos} \delta}\right)$

$I_{\text {vertical }}=I_{\text {horizontal }} \operatorname{Cotan} \delta$

$S_{w k}=\tau_{g k} \alpha_{w k} I_{v e r t i c a l}$

$S_{b}=\tau_{g s} \alpha_{b} I_{\text {horizontal }}$

where $k$ represents solarium $(s)$ and solar chimney $(s c), I_{\text {vertical }}$ is solar radiation on vertical surface, $I_{\text {horizontal }}$ is solar radiation on horizontal surface, $\theta$ is solarium roof tilt angle, $\delta$ is elevation angle, $\alpha_{g s c}$ and $\alpha_{g s}$ are absorptivity of the solar chimney and the solarium glass covers respectively and $\tau_{g}$ is emissivity of the glass cover.

$\delta$, elevation angle is calculated through following equations:

$\delta=90-\phi+\lambda$

where $\phi$ is the latitude; and $\lambda$ is the declination angle with following mathematical form:

$\lambda=23.45^{\circ} \sin \left[\frac{360}{365}(284+d)\right]$

where $d$ is the day of the year.

As it can be seen in the above expressions, the radiative solar gain in the glazing depends on the glass absorptance and incident solar radiation on the glazing $I$. However in concrete wall and floor in addition to these parameters the solar gain is also dependent on the transmitted radiation by the glazed cover. 


\section{Chapter 4: Results and discussion}

\section{4-1 The computer simulation code}

As the next step, a thermal simulation was performed during the critical summer days using a computer-aided technique implemented in SIMULINK toolbar of the MATLAB software. The program calculates the greenhouse air temperature and its ventilation rate for different geometrical configurations. This simulation study will also be employed to predict the thermal performance of the greenhouse and the solar chimney according to the actual weather data for Toronto and corresponding solar intensity and ambient temperature.

\section{4-2 Validation of the SIMULINK model}

The simulation model that was created in this study to predict the performance of the SCAS has been validated by comparison between the numerical predictions obtained from the simulation code of this study and the theoretical and experimental results of Afriyie et al. (2011).

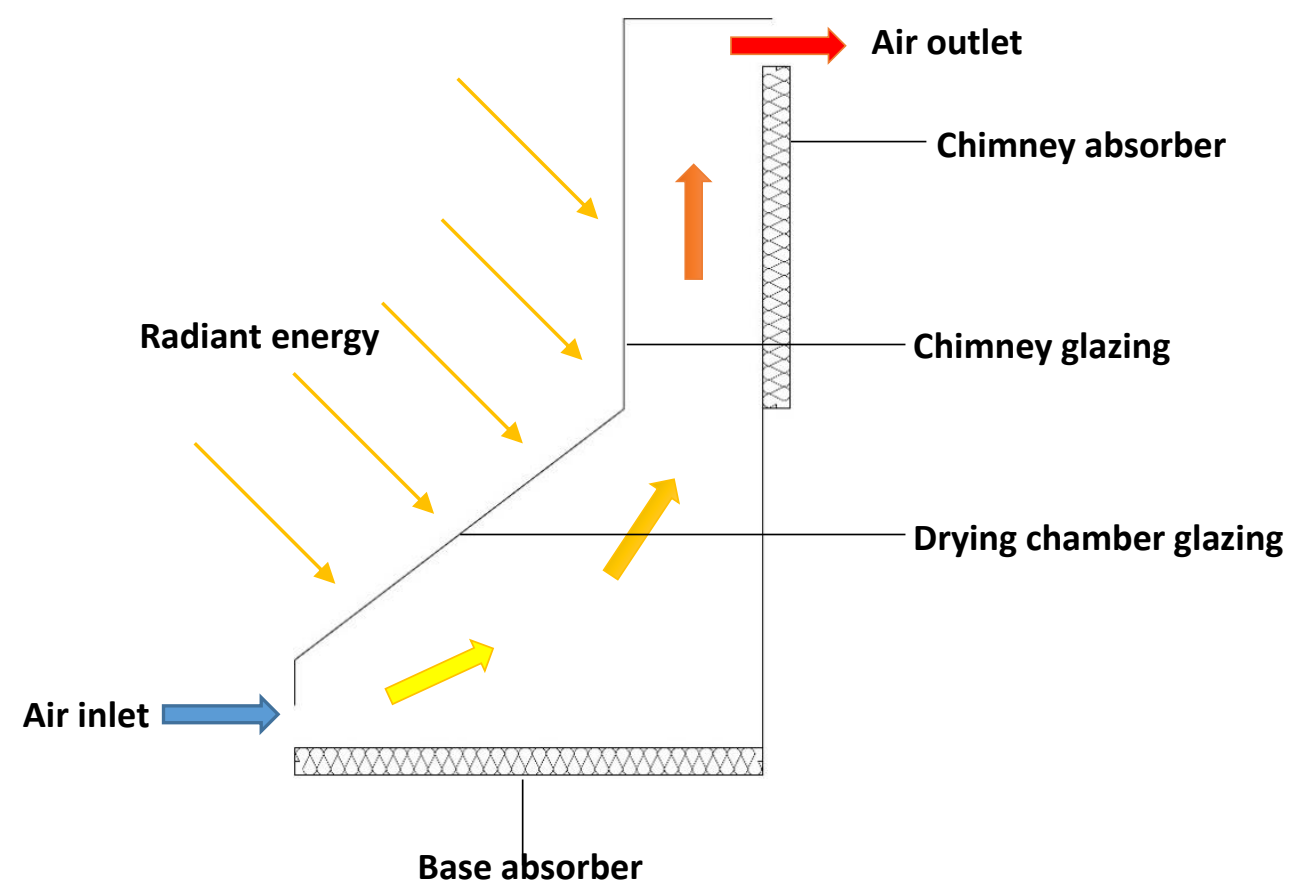

Fig. 4. Schematic side section of the chimney-dependent solar crop dryer designed by the Afriyi et al. 
As Fig. 4. shows the physical model of the chimney-dependent solar crop dryer designed by the Afriyi et al. (2011) is similar to the physical model of this study. The crop dryer consists of a drying chamber that has glass walls and inclined glass roof facing south. A solar chimney is incorporated with a drying chamber inclined roof to enhance the ventilation in the dryer.

\begin{tabular}{|c|c|}
\hline Parameter & Input value \\
\hline Solarium base width & $0.44 \mathrm{~m}$ \\
\hline Solarium base Length & $0.42 \mathrm{~m}$ \\
\hline Solar chimney width & $0.08 \mathrm{~m}$ \\
\hline Solarium height & $0.6 \mathrm{~m}$ \\
\hline Chimney height & $0.49 \mathrm{~m}$ \\
\hline Solarium concrete floor thickness & $0.04 \mathrm{~m}$ \\
\hline Chimney concrete wall thickness & $0.0121 \mathrm{~m}$ \\
\hline outlet area & $0.01076 \mathrm{~m}^{2}$ \\
\hline Glass absorbtivity & 0.66136 \\
\hline Glass transmissivity & 0.33864 \\
\hline Glass emissivity & 0.66136 \\
\hline Back wall emissivity & 0.98 \\
\hline Base absorbtivity & 0.98 \\
\hline Solarium roof tilt angle & $64^{\circ}$ \\
\hline Back wall conductivity & $0.1716 \mathrm{~W} / \mathrm{mK}$ \\
\hline Base conductivity & $0.18 \mathrm{~W} / \mathrm{mK}$ \\
\hline Irradiation to chimney glass cover & $390.78 \mathrm{~W} / \mathrm{m}^{2}$ \\
\hline Irradiation to solarium glass cover & $186.6 \mathrm{~W} / \mathrm{m}^{2}$ \\
\hline
\end{tabular}

The experimental model of a corresponding study was a laboratory model that consisted of three replaceable roof with different angles $81^{\circ}, 64^{\circ}$ and $51^{\circ}$. The drying chamber width and length 
were $440 \mathrm{~mm}$ and $420 \mathrm{~mm}$ respectively. The researchers used black painted wood with $40 \mathrm{~mm}$ thickness as absorber chamber floor. The experiment was performed for different inlet widths of $0.03 \mathrm{~m}, 0.05 \mathrm{~m}$ and $0.07 \mathrm{~m}$. The solar chimney in this model had a rectangular cross section of $440 \mathrm{~mm}$ length, an $80 \mathrm{~mm}$ width and a $625 \mathrm{~mm}$ height. The outlet had a gap of $30 \mathrm{~mm}$ and a width of $335 \mathrm{~mm}$. This chimney had a black painted back wall made of wood.

The same dimensions and related environmental conditions in the Afriyie et al. (2011) experimental study were used as input data for the simulation code. Corresponding input simulation data are listed in the Table 1.

A comparison between the present study simulation results (Sim) and the theoretical (Afriyie) and experimental results (Exp) of Afriyie et al. (2011) is shown in Table 2.

\begin{tabular}{|c|c|c|c|c|c|c|c|c|c|}
\hline \multicolumn{4}{|c|}{ Inlet gap $0.03 m$} & \multicolumn{2}{|c|}{ Inlet gap $0.05 m$} & \multicolumn{4}{|c|}{ Inlet gap $0.07 m$} \\
\hline & Sim & Afriyie & $\operatorname{Exp}$ & Sim & Afriyie & $\operatorname{Exp}$ & Sim & Afriyie & $\operatorname{Exp}$ \\
\hline$T_{f s}(K)$ & 296.2 & 296.40 & 299.7 & 300.00 & 298.4 & 299.57 & 300.00 & 296.64 & 296.86 \\
\hline$R D(\%)$ & 1.17 & 1.11 & & 0.33 & 0.39 & & 1.06 & 0.08 & \\
\hline$T_{f s c}(K)$ & 307.6 & 300.32 & 304.3 & 307.2 & 301.91 & 303.63 & 307.00 & 300.00 & 301.37 \\
\hline$R D(\%)$ & 1.08 & 1.23 & & 1.18 & 0.57 & & 1.87 & 0.46 & \\
\hline$T_{b}(K)$ & 302.56 & 303.28 & 307.00 & 303.00 & 305.40 & 306.83 & 302.65 & 303.66 & 305.33 \\
\hline$R D(\%)$ & 1.45 & 1.23 & & 1.25 & 0.47 & & 0.88 & 0.55 & \\
\hline$T_{w}(K)$ & 316.50 & 314.30 & 315.54 & 316.15 & 316.24 & 314.58 & 316.10 & 314.47 & 313.17 \\
\hline$R D(\%)$ & 0.30 & 0.39 & & 0.49 & 0.52 & & 0.94 & 0.42 & \\
\hline$T_{g}(K)$ & 314.88 & 312.47 & 313.48 & 314.9 & 314.5 & 313.10 & 314.9 & 312.74 & 311.08 \\
\hline$R D(\%)$ & 0.45 & 0.32 & & 0.57 & 0.44 & & 1.23 & 0.53 & \\
\hline
\end{tabular}
(Afriyie) and results of the experimental trial (Exp) of published study and their relative difference (RD)

As it can be clearly seen in Table 2., the relative difference, $\mathrm{RD}$, of the simulation results of the present study with those of the experimentation trial of the study by Afriyie et al. (2011) is up to 
$1.87 \%$, where $\mathrm{RD}=\frac{|\operatorname{Sim}-\operatorname{Exp}|}{\operatorname{Exp}} \times 100, \mathrm{~T}_{\mathrm{fs}}$ is the temperature of air inside the solarium, $\mathrm{T}_{\mathrm{fsc}}$ is the air temperature of the solar chimney, $\mathrm{T}_{\mathrm{b}}$ is the solarium floor temperature, $\mathrm{T}_{\mathrm{w}}$ is wall temperature and $T_{g}$ is the glass temperature. This comparison shows that the simulation results of the present study are in a good agreement with the theoretical and experimental results of previous published results within their operating conditions.

\section{4-3 Characteristics of different elements of the SCAS}

The physical characteristics of the SCAS should be defined for the evaluation process. Toronto's weather data for the month of July, being the warmest with the least wind force on the SCAS, have been used in this process (Fig. 5-8). Physical properties of different components of the SCAS all of which were selected based on ASHRAE (2008) and are presented in Table 3. are as follows:

- Glass:

The glazing in this application is assumed to be a double glaze without any low $E$ coating both of which have $6 \mathrm{~mm}$ thickness. According to ASHRAE (2009) this glass cover has the absorptance, $\alpha$, of 0.11 ; transmittance, $\tau$, of 0.70 and emissivity, $\epsilon$, of 0.87 .

- Air (fluid inside the SCAS):

As mentioned earlier, Ong (2003) introduced an empirical correlation by which the physical properties of the air inside the SCAS are determined. These correlations depend directly on the air temperature and are fitted for 300-350 $\mathrm{K}$.

- Heat absorbing back walls and concrete floor:

The back wall in both the solarium and the solar chimney and also the floor in the solarium are made of reinforced concrete. These elements are all assumed to be $24 \mathrm{~cm}$ thick. The internal surface of each of these elements is painted black to increase solar radiation absorption. To simplify the problem, they all have the same physical properties and are insulated from external condition with the same insulation material with the same thickness. Walls and the floor have the absorptance, $\alpha$, of 0.82 ; conductivity, $k$, of 1.63 $\mathrm{W} / \mathrm{m} \mathrm{K}$; emissivity, $\epsilon$, of 0.95 ; density, $\rho$, of $2400 \mathrm{~kg} / \mathrm{m}^{3}$ and heat capacity, $C_{w, b}$, of 1090 $\mathrm{J} / \mathrm{kg} \mathrm{K}$. 


\begin{tabular}{|c|c|}
\hline Parameter & Input value \\
\hline Solarium base width & $4 \mathrm{~m}$ \\
\hline Solarium base Length & $8 \mathrm{~m}$ \\
\hline Solar chimney width & $0.4 \mathrm{~m}$ \\
\hline Solarium height & $5 \mathrm{~m}$ \\
\hline Chimney height & $1 \mathrm{~m}$ \\
\hline Solarium concrete wall thickness & $0.24 \mathrm{~m}$ \\
\hline Solarium concrete floor thickness & $0.24 \mathrm{~m}$ \\
\hline Chimney concrete wall thickness & $0.24 \mathrm{~m}$ \\
\hline Inlet/outlet area ratio & $4: 1$ \\
\hline Glazing thickness & $6 \mathrm{~mm}$ \\
\hline Glass absorbtivity & 0.006 \\
\hline Glass transmissivity & 0.84 \\
\hline Glass emissivity & 0.8 \\
\hline Concrete emissivity & 0.95 \\
\hline Concrete density & $2400 \mathrm{~kg} / \mathrm{m}^{3}$ \\
\hline Concrete emissivity & 0.95 \\
\hline Concrete absorbtivity & 0.82 \\
\hline Concrete heat capacity & $1090 \mathrm{~J} / \mathrm{kg} \mathrm{K}$ \\
\hline Solarium roof tilt angle & $65^{\circ}$ \\
\hline Back wall conductivity & 1.63 \\
\hline
\end{tabular}

Table 3. The input parameters for the analytical study, determined through parametric study or assumed from previous published researches 


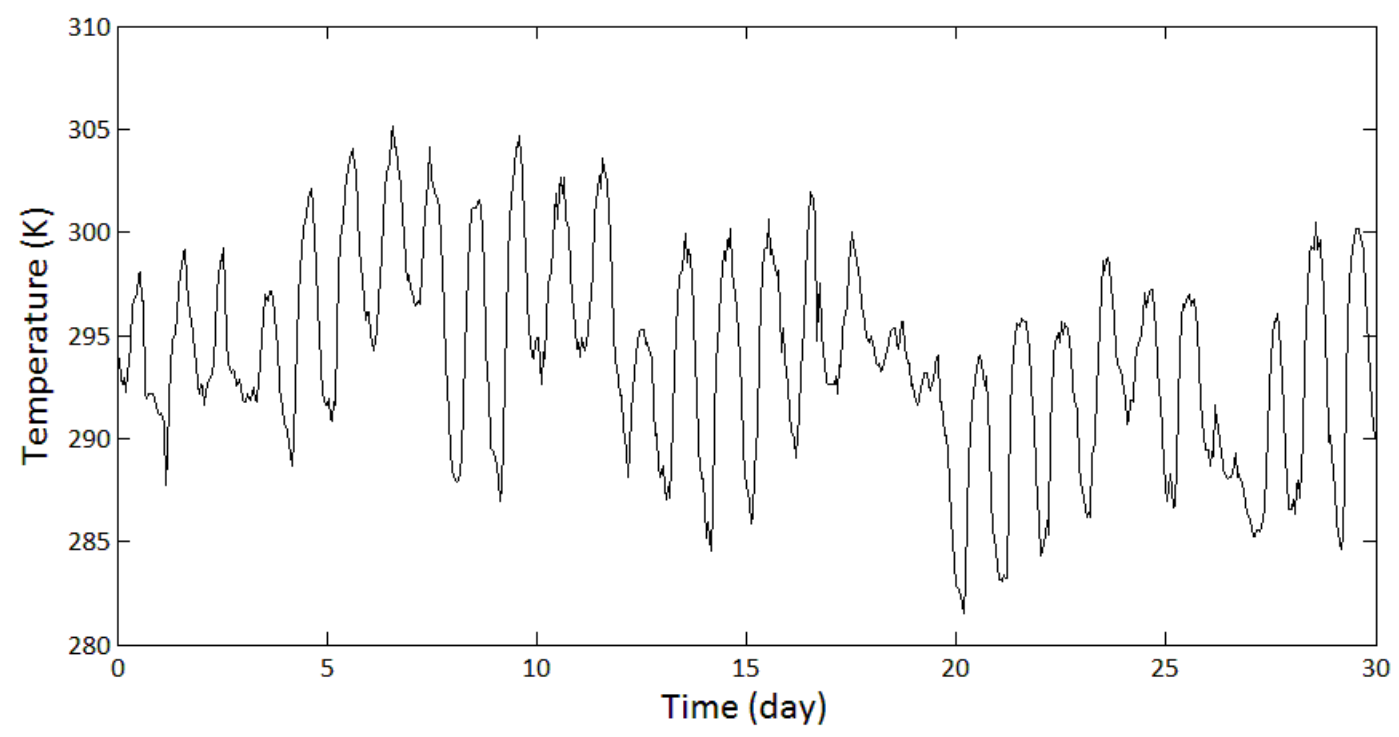

Fig. 5. Toronto weather data (ambient temperature) corresponding to the trials of the month of July, employed in the physical model evaluation as input data

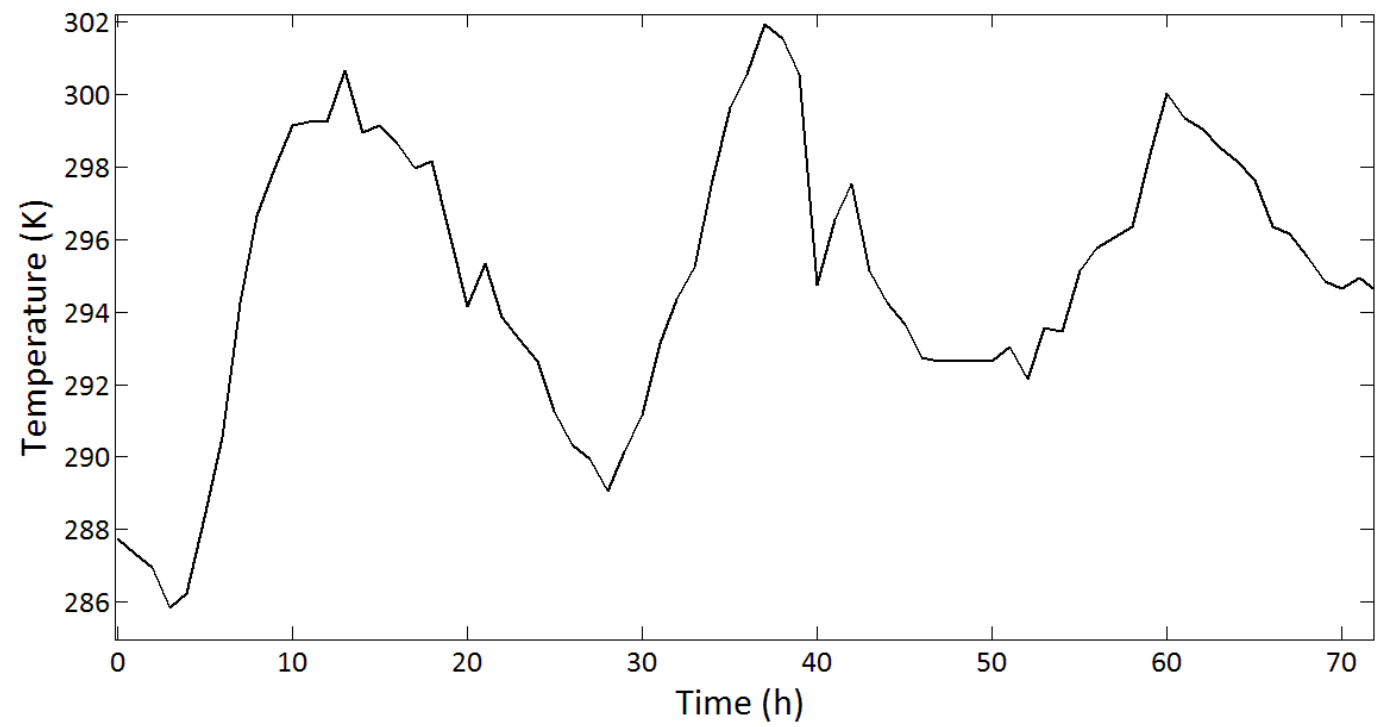

Fig. 6. Toronto weather data (ambient temperature) corresponding to the trials of month of July July 15 18 , employed in the physical model evaluation as input data

As Heras-Celemin (2007) proposed, to assign the number of nodes inside the walls and the floor, the following convergence criterion has been used in this application:

$\frac{\Delta t}{\Delta x^{2}}<0.25$ 


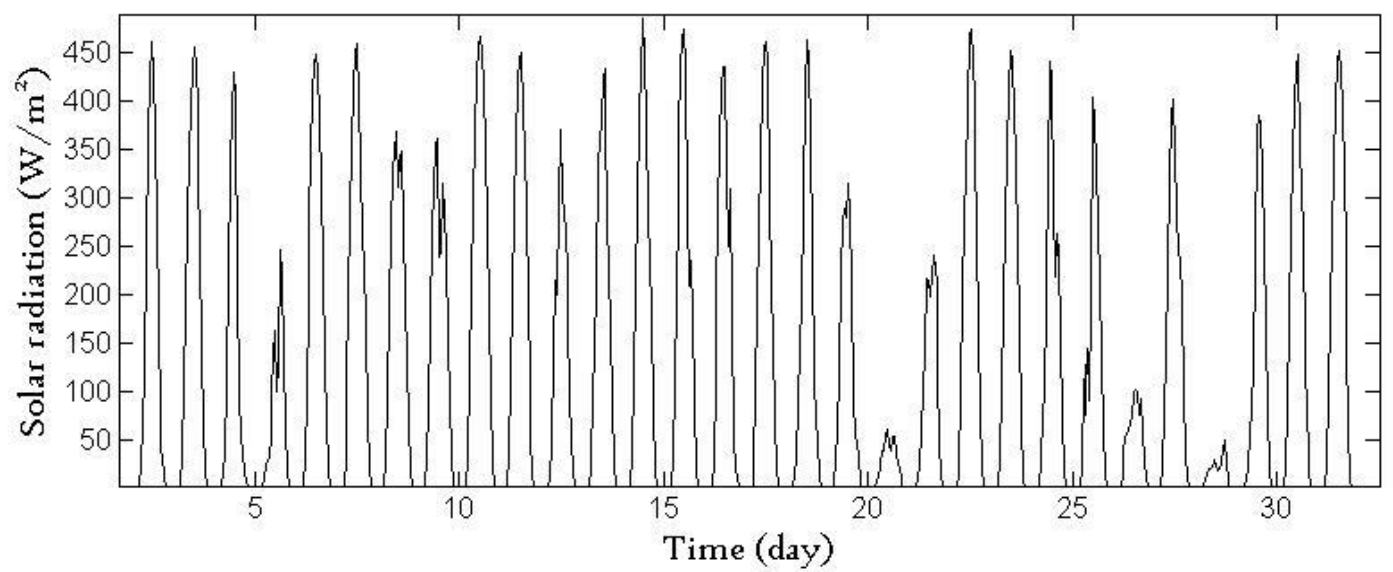

Fig. 7. Toronto weather data (solar radiation on south faced vertical surface) corresponding to the trial of the month of July

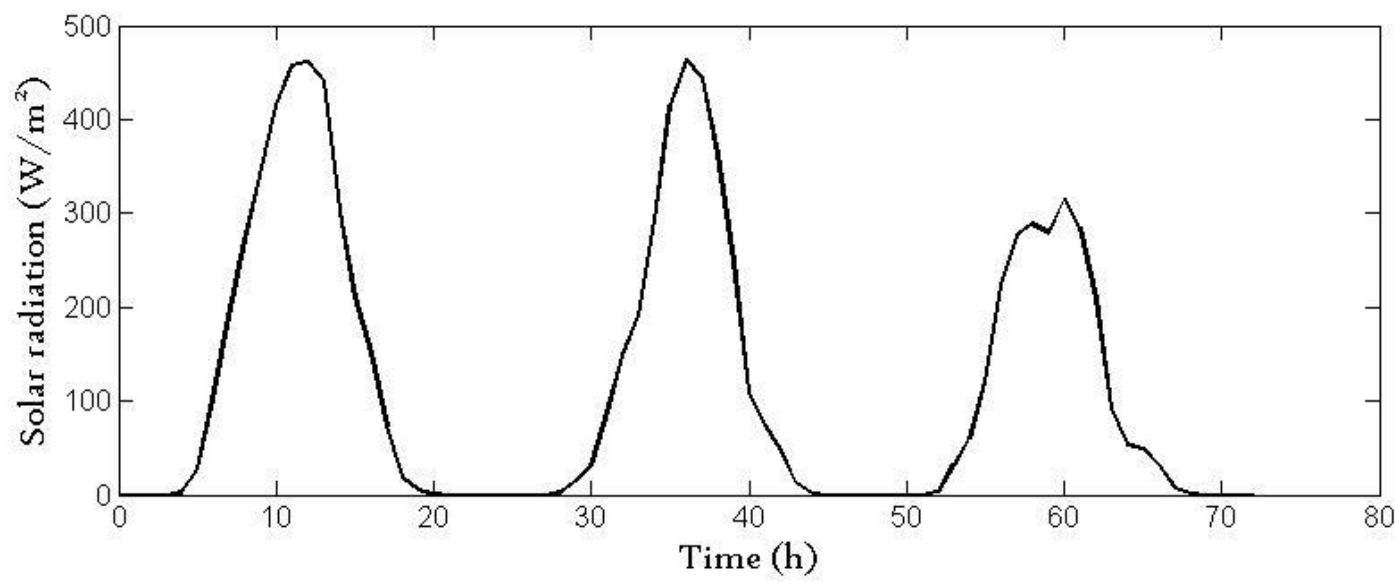

Fig. 8. Toronto weather data (solar radiation on south faced vertical surface) corresponding to the trial of July $15-18$

$\Delta t$ is considered to be one minute in this study. Hence, $\Delta x$, the distance between nodes, can be calculated for this time which in this case is $0.015 \mathrm{~m}$ which is acceptable according to Equation 82 as:

$\frac{\Delta t}{\Delta x^{2}}=0.17<0.25$

Since the walls and the floor thickness are $24 \mathrm{~cm}$, the number of nodes in each element is 16 . This number is used in the Equations $11,14,15,19,20,37,38$ and 39 to determine the thermal performance of the concrete walls and the floor. 
It should be mentioned here that the wall and floor nodes' new temperatures are dependent on the temperatures and heat transfer coefficients at the previous time. To solve the equations of glass and fluid temperatures, however, the temperatures and heat transfer coefficients of the same time are needed due to the deduction of their equations from an instantaneous energy balance. Therefore the equations are solved iteratively until the system converges.

\section{4-4 Parametric study}

In order to quantify the impact of each variable on the numerical model and simulation process and to determine their optimum dimensions to reach the best ventilation performance in the SCAS, a parametric study has been performed in this research. In this process, the air mass flow rate through the SCAS has been investigated in relation to different variables under the actual weather condition of Toronto. $\dot{m}$, mass flow rate $(\mathrm{kg} / \mathrm{s})$, has been used as the performance index of the SCAS. This study covers all the climate parameters except for the wind in the simulation process. This study investigates the effect of the most influential parameters on the performance of the solarium, solar chimney and their interaction.

For different value, in a certain range of each of parameter that has been investigated, the simulation code has been run several times while the other variables stayed constant. In this study the following variables were included: inlet/outlet area ratio $R_{i o}$, solarium height $L_{s}$, Solar chimney/solarium height ratio $L_{s} / L_{s c}$, solarium width $W_{s}$ and solar chimney width $W_{s c}$. These parameters have been investigated as follows:

- Inlet -outlet area ratio: in this trial for 4 fixed outlet area values of $0.1,0.2,0.3$ and $0.4 \mathrm{~m}$, 8 different inlet areas have been examined from $A i / A o=1$ up to 8 in the interval of 1 . In this trial $L_{s}=5 \mathrm{~m} \mathrm{Lsc}_{s c}=1 \mathrm{~m}, \mathrm{~W}_{\mathrm{s}}=4 \mathrm{~m}$ and $\mathrm{W}_{\mathrm{sc}}=0.4 \mathrm{~m}$.

- Solarium/solar chimney height: these parameters have been examined using two different methods:

- The total height of the SCAS is kept constant at $6 \mathrm{~m}$ and therefore when the solarium height rises, the solar chimney height decreases and vice versa. In this trial 8 values of $3.5 \mathrm{~m}$ up to $4.5 \mathrm{~m}$ in each $0.125 \mathrm{~m}$ were assigned for solarium height and $L_{s c}=6-L_{s} m, W_{s}=4 m, W_{s c}=0.4$ and $R_{i_{0}}=4$. 
- For the constant solarium height, 6 different chimney/solarium height ratio values of 1:3 up to 1:0.5 in the intervals of 1:0.5 were examine in this trial. The values of other variables are: $L_{s}=5 \mathrm{~m}, \mathrm{~W}_{\mathrm{s}}=4 \mathrm{~m}, \mathrm{~W}_{\mathrm{sc}}=0.4$ and $\mathrm{R}_{\mathrm{io}}=4$.

- Solarium width/solar chimney widths (cross sections): these parameters have been investigated using two methods:

- In this part, for the constant length of both the solarium and the solar chimney and also solar chimney width, 10 different values of $1.5 \mathrm{~m}$ up to $4 \mathrm{~m}$ at each $0.25 \mathrm{~m}$ have been assigned to the solarium width. In this trial: $L_{s}=5 m L_{s c}=1 \mathrm{~m}, W_{s c}=0.4 \mathrm{~m}$ and $\mathrm{R}_{\mathrm{io}}=4$.

- In this trial for constant, the solarium and the solar chimney lengths and solarium width of $4 \mathrm{~m}, 8$ values of $0.1 \mathrm{~m}$ up to $0.4 \mathrm{~m}$ were considered as the solar chimney width and $L_{s}=5 \mathrm{~m} \mathrm{~L}_{\mathrm{sc}}=1 \mathrm{~m}, \mathrm{~W}_{\mathrm{s}}=4 \mathrm{~m}$ and $R_{i_{0}}=4$. A limit of $0.4 \mathrm{~m}$ on the chimney width is applied in this application due to the fact that Ong and Chow (2003) and Chen et al. (2003) both specified in their research that a reverse flow has been observed for the gap larger than $0.3 \mathrm{~m}$ for radiation values of $200-650 \mathrm{~W} / \mathrm{m}^{2}$ and $0.4 \mathrm{~m}$ respectively.

Every parametric study has been conducted for the time frames of the month of July. The results are presented as Figs 9-13. These parameters and their different values can be seen in Table 4.

\begin{tabular}{llll} 
Parameter & Dimensional limits & Interval \\
\hline Outlet-inlet area ratio & $1-8$ & 1 \\
\hline Solarium height & $3-5 \mathrm{~m}$ & $0.2 \mathrm{~m}$ \\
\hline Solar chimney/solarium height ratio & $0.2-2$ & 0.2 \\
\hline Solarium width & $1.5-4 \mathrm{~m}$ & $0.5 \mathrm{~m}$ \\
\hline Solar chimney width & $0.1-0.4 \mathrm{~m}$ & $0.05 \mathrm{~m}$ \\
\hline Solarium/solar chimney width ratio & $5-10$ & 0.5
\end{tabular}

Table 4. Selected parameters for parametric study and their values 


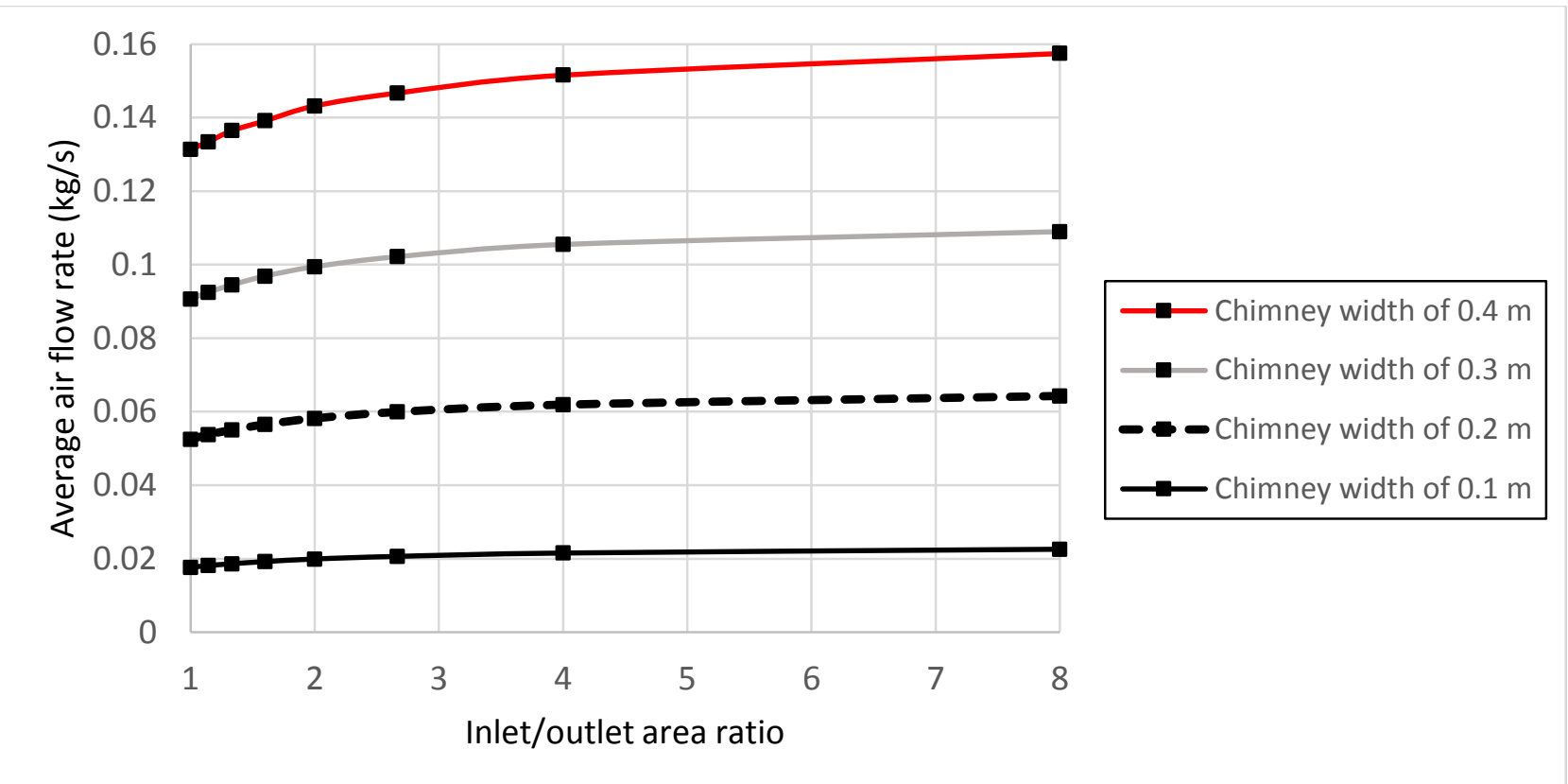

Fig. 9. Mass flow rate $(\dot{m})$ for different inlet/outlet area ratios Ai/Ao of the SCAS

Fig. 9 demonstrates the relation between the mass flow rate and inlet/outlet area ratios. The mass flow rate increases up to the area ratio of $4: 1$, above which the mass flow rate stays almost constant. The graph also shows that with the increase of the outlet gap, mass flow rate increases and inlet/outlet area ratio is more influential in the mass flow rate variation rate. This means that for the smaller outlet width, the mass flow rate is not as sensitive to the inlet/outlet area ratio. This graph also shows clearly that the mass flow rate increases with the increase of the solar chimney width. 


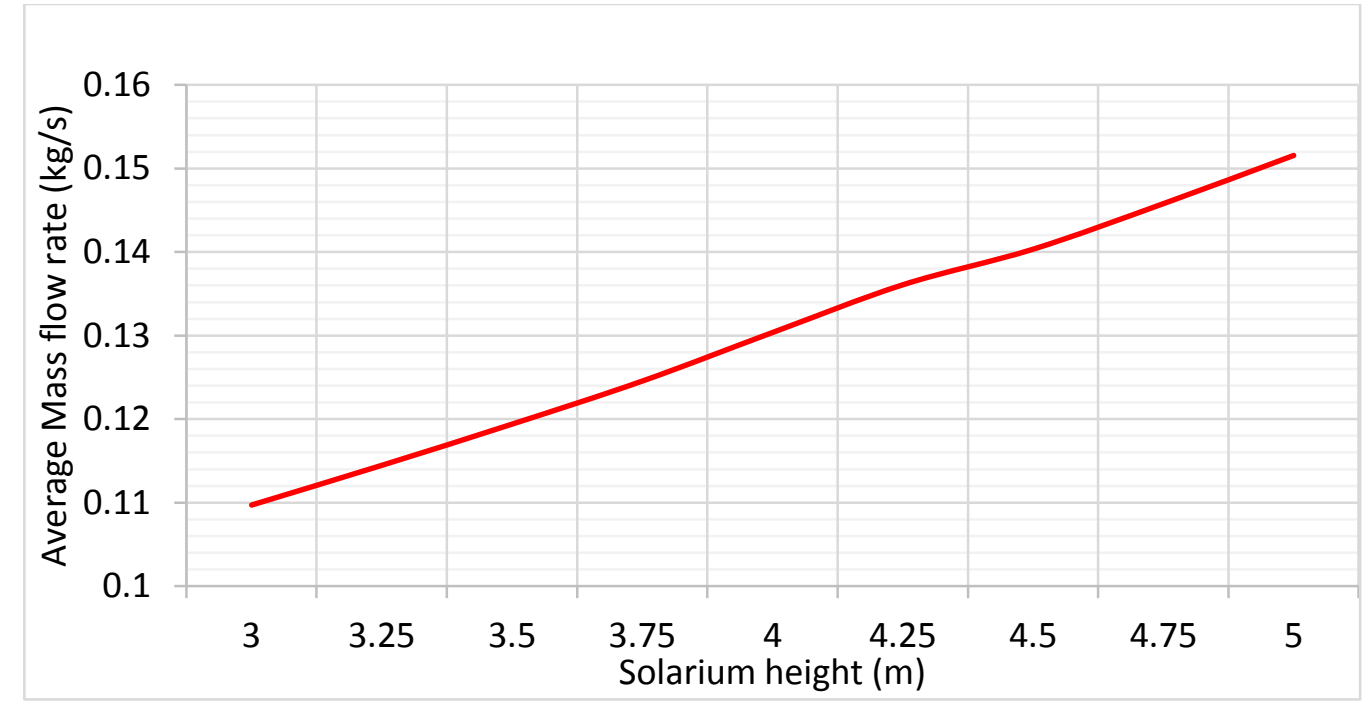

Fig. 10. Mass flow rate $(\dot{m})$ for the trial with fixed total height of SCAS and different solarium height values

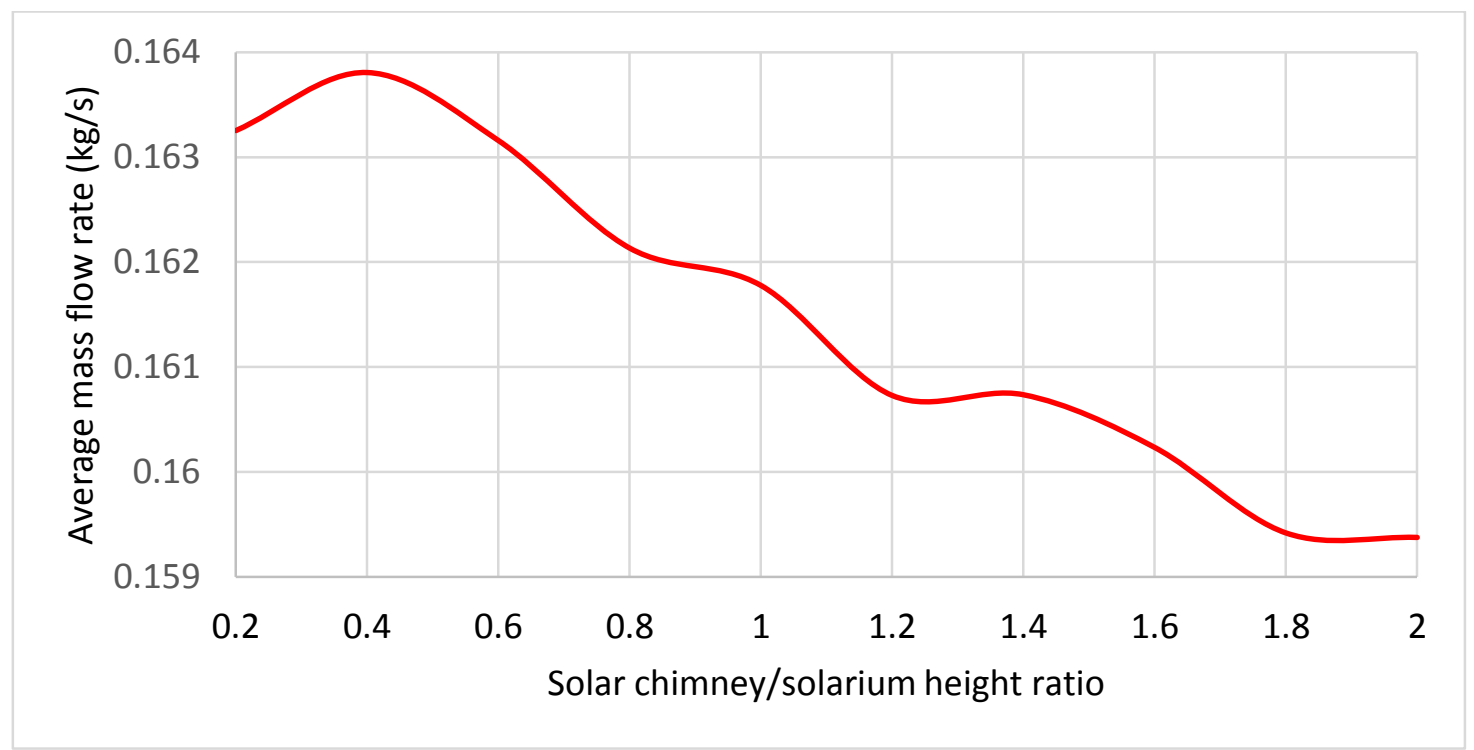

Fig. 11. Mass flow rate $(\dot{m})$ for the second trial with fixed solarium height of $5 \mathrm{~m}$ and varying Chimney/solarium height ratio values

Fig. 10-11 illustrates how chimney/solarium heights affect the mass flow rate inside the SCAS. Fig. 10 shows the results of a fixed total height of SCAS of $6 \mathrm{~m}$ with 10 various solarium height values of $3 \mathrm{~m}$ to $5 \mathrm{~m}$. The solarium height has been examined for every $20 \mathrm{~cm}$. Fig. 11 represents the mass flow rate for a fixed solarium height of $5 \mathrm{~m}$ and varying Chimney/solarium height ratio values of 0.2 to 2 in the interval of 0.2 . As it can be clearly seen in these two figures, for a fixed SCAS height of $6 \mathrm{~m}$ as the solarium height increases, the mass flow rate rises so a high solarium 
with a short solar chimney is favoured. The trial in Fig. 11 not only confirms this fact but also shows that the mass flow rate is maximized for the fixed solarium height when the solar chimney height is $40 \%$ of that of the solarium. This implies that in the second trial, a $2 \mathrm{~m}$ high chimney is optimised. Comparing the above figures also shows that even though in the second trial optimum configuration has the total height of $7 \mathrm{~m}$, the maximum flow rate in both trials are $118 \mathrm{~kg} / \mathrm{s}$ while the total height of SCAS in first trial is $6 \mathrm{~m}$. The flow rate variation in the second trial is smaller than the first one $(30 \mathrm{~kg} / \mathrm{s}$ compared to around $3 \mathrm{~kg} / \mathrm{s})$. This means that the flow rate is not sensitive to the second parameters, chimney/solarium height ratio.

Fig 12-13 demonstrates the influence of a solarium/solar chimney cross section areas on the amount of mass flow rate inside the SCAS. Fig. 12 shows the study of 6 various values of the solarium from $1.5 \mathrm{~m}$ up to $4 \mathrm{~m}$ every $0.5 \mathrm{~m}$. The results depict that the mass flow rate increases as the solarium floor area increases for a given chimney width. This is caused by the increase in the solar radiation absorbing floor area and therefore increasing the thermal mass in a place that absorbs the most solar radiation due to its position in the solarium. Fig. 13 shows that the mass flow rate enhances by increasing the solarium floor area for a given chimney cross-section area of $0.16 \mathrm{~m}^{2}$. Increasing the floor area enlarges the floor surface for both convection and radiation, boosting the buoyancy in the solarium.

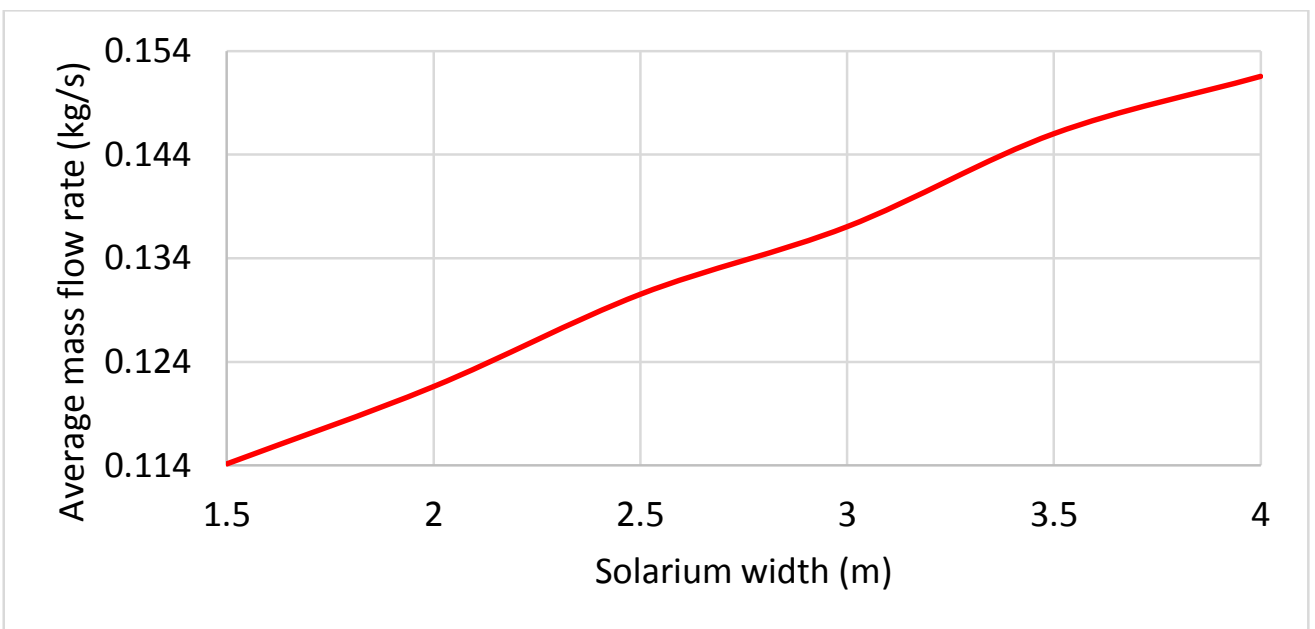

Fig. 12. Mass flow rate $(\dot{m})$ for fixed solarium/solar chimney length, fixed solarium width of $4 \mathrm{~m}$ and different chimney width values 


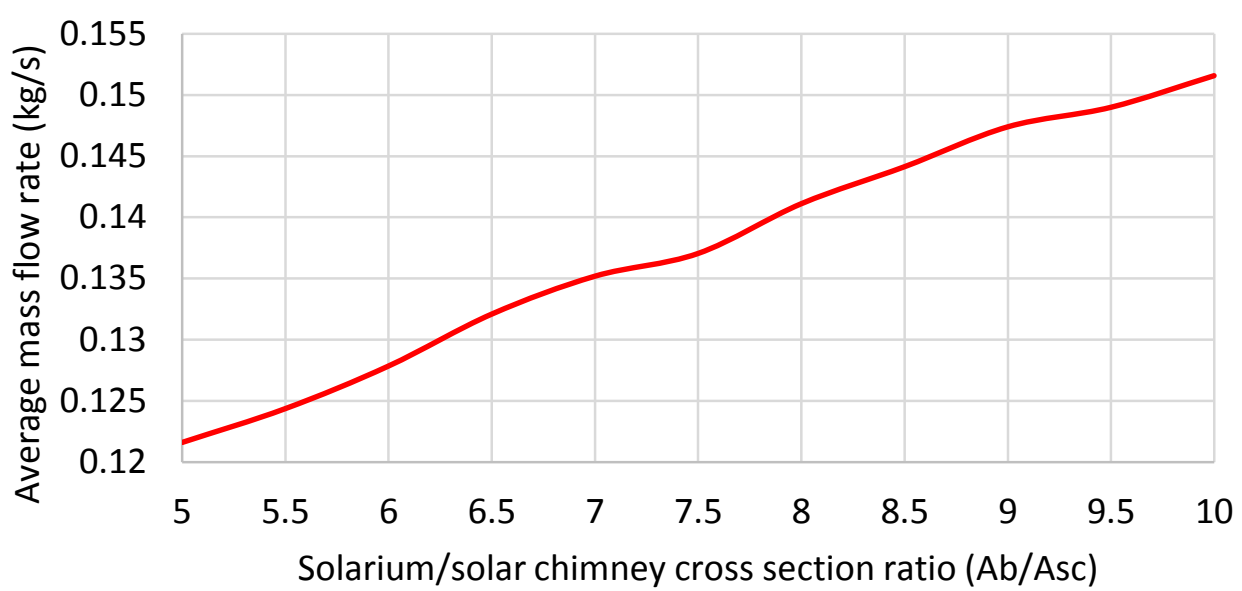

Fig. 13. Mass flow rate $(\dot{m})$ for fixed solarium/solar chimney length, fixed chimney width of $0.4 \mathrm{~m}$ and various $A b / A s c$ ratio values.

\section{4-5 Analytical study}

The objective of this study is to analyze the thermal and dynamic performance of the SCAS with the optimum configuration. Applying the values of parametric study, further simulations have been performed for two different time frames of the whole month of July (trial 1) and July 15-18 (trial 2). The actual weather data from the city of Toronto were applied as entry data of these simulations. The purpose of running the simulation for two time frames is that the first trial provides the whole picture for the warmest month of the year in Toronto and the second one presents more focused results which can be discussed more accurately. The results of this study are shown in Fig. 14-26. 


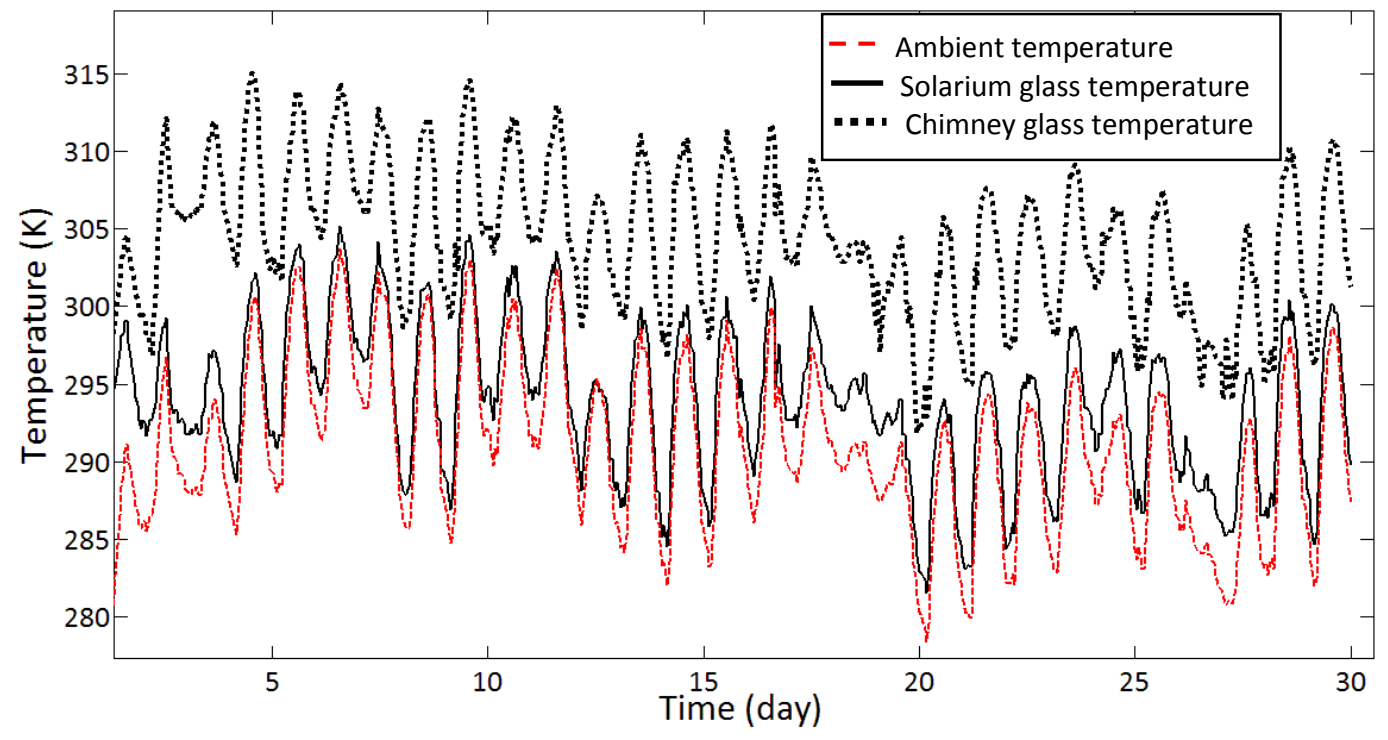

Fig. 14. The SCAS glass temperatures applying parameters of parametric study corresponding the time frame of the month of July (trial 1 )

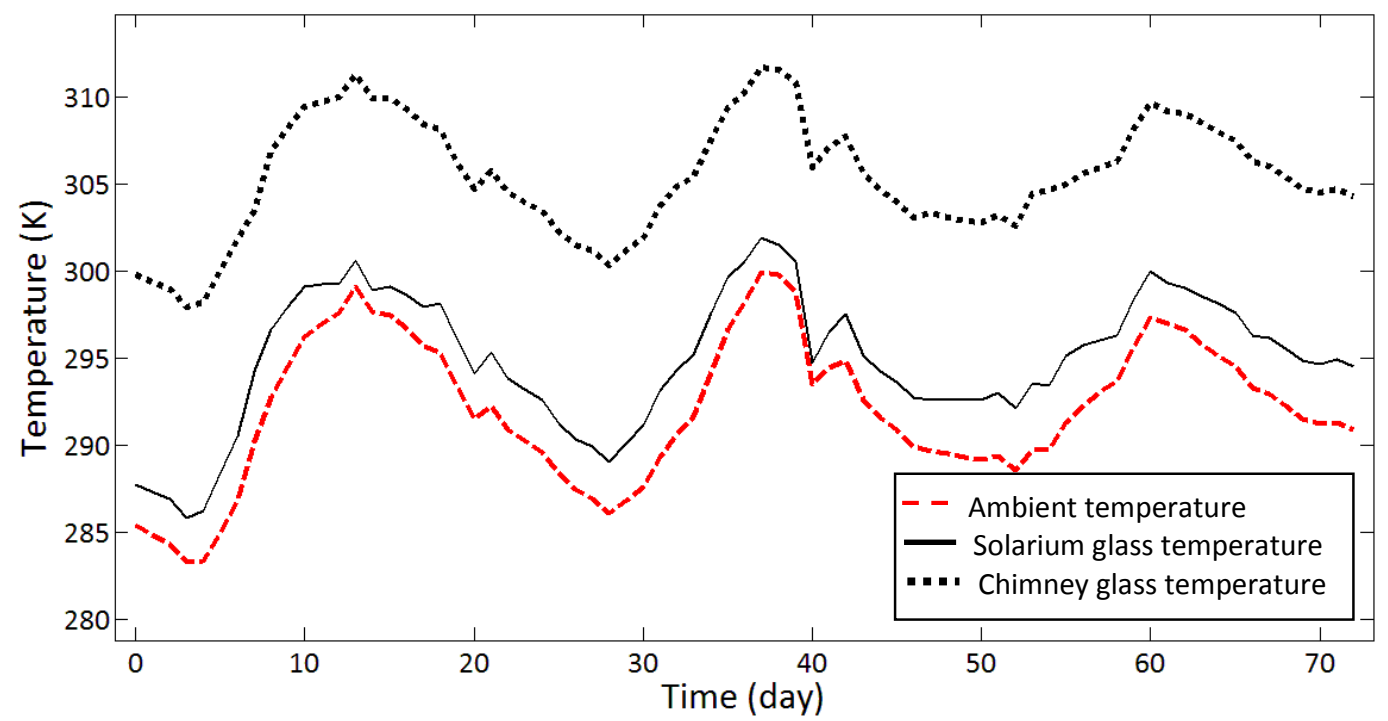

Fig. 15. The SCAS glass temperatures applying parameters of parametric study corresponding the time frame of July $15-18$ (trial 2)

As it is shown in Fig. 14-15, glass temperature in the solarium follows the ambient temperature pattern closely. The glass temperature in both the solarium and the solar chimney reach the lowest values at sunrise. This is due to the radiation heat loss to the sky during the night time. This natural phenomenon is the reason of lower wall temperature in the back wall of the solar 
chimney as well (see Fig. 22-23) compared to solarium concrete wall and floor. Part of the chimney wall that is in direct contact with the outside condition loses the heat during the night to the sky. The glass in the chimney follows the same pattern of temperature fluctuation as the glass in the solarium but with notably higher temperatures. The average temperature difference between the glasses is around 15 degrees throughout the month of July.

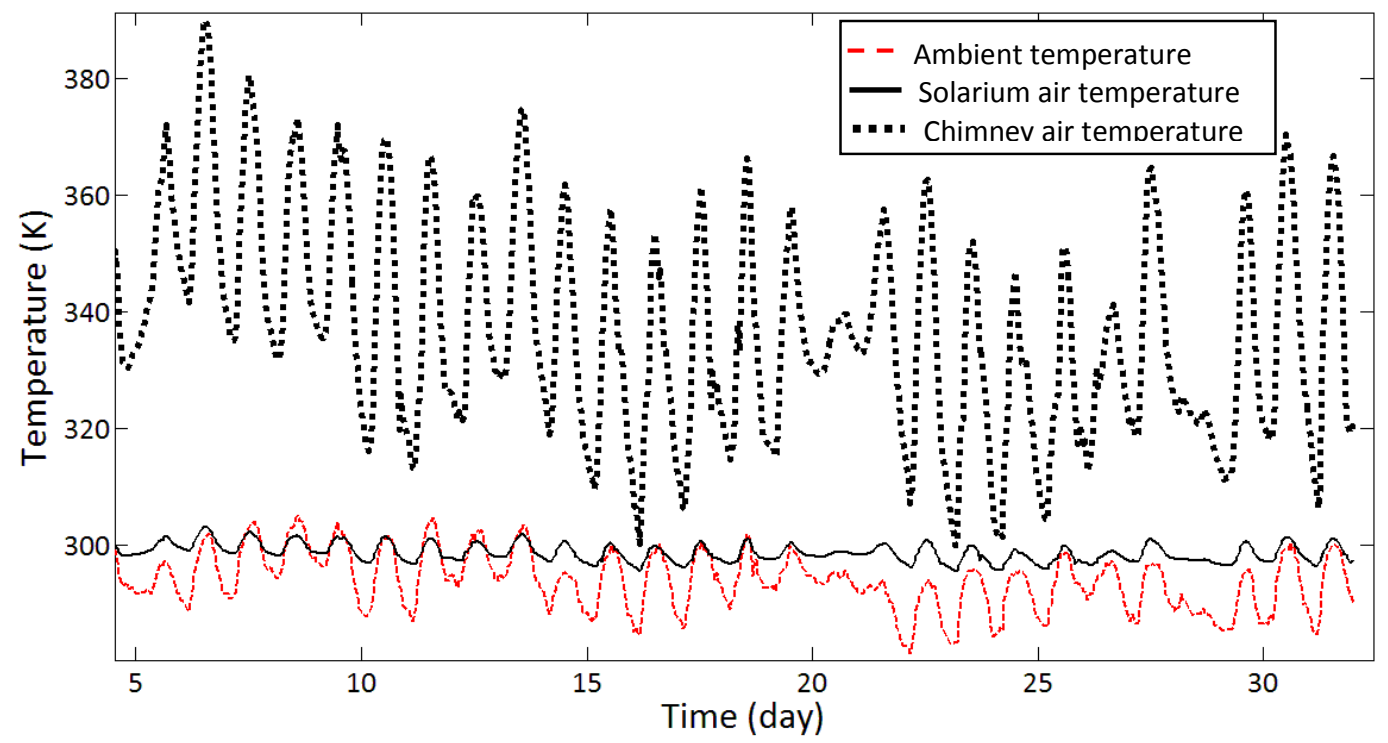

Fig. 16. The SCAS inside air temperature applying parameters of parametric study corresponding the time frame of the month of July (trial 1)

The fluid (inside air) temperature of the chimney is notably higher than that of the solarium. Not only the temperature of the fluid inside the chimney is higher but it also fluctuates more than the solarium air temperature during the trials time periods. This temperature soars up to $390 \mathrm{~K}$ and drops down to 300K on July 6 and 16, respectively (Fig. 16-17). The solarium fluid temperature stays around maximum ambient temperature at all time. 


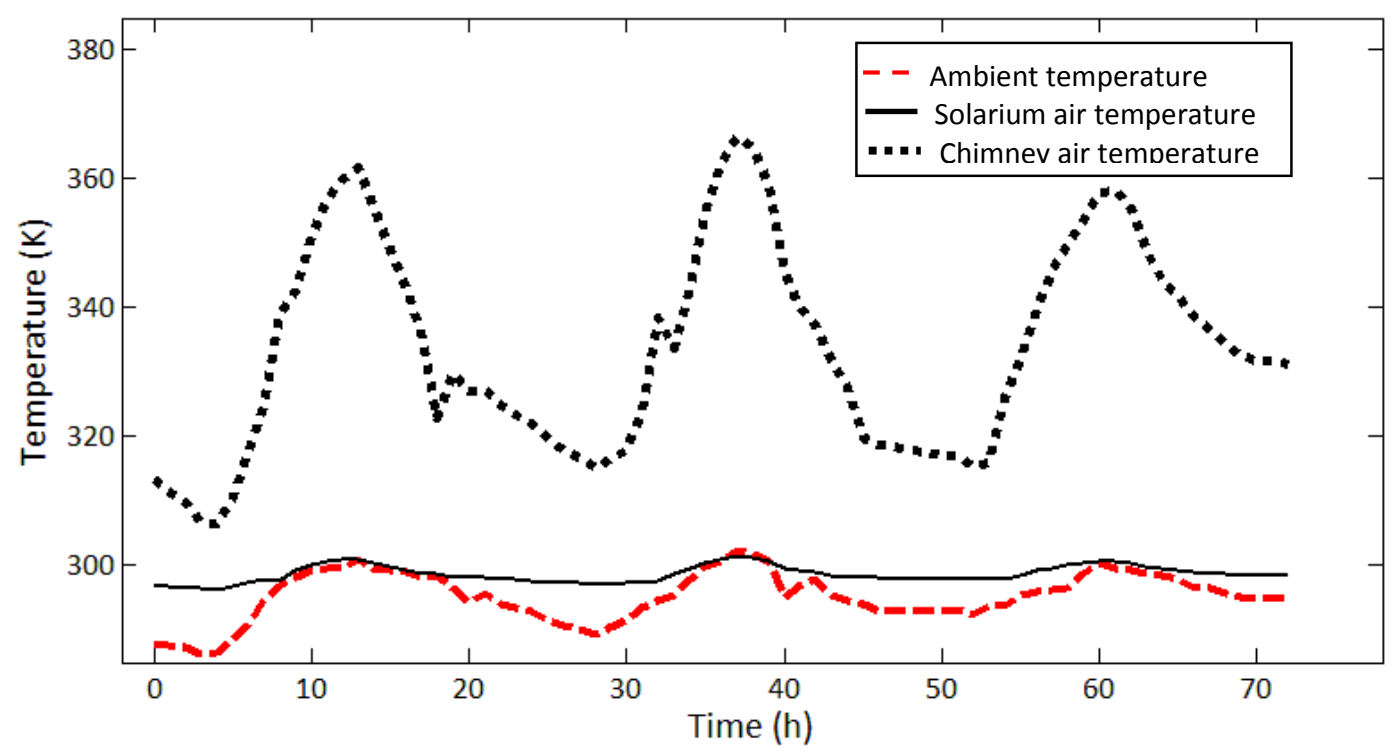

Fig. 17. The SCAS inside air temperature applying parameters of parametric study corresponding the time frame of July $15-18$ (trial 2)

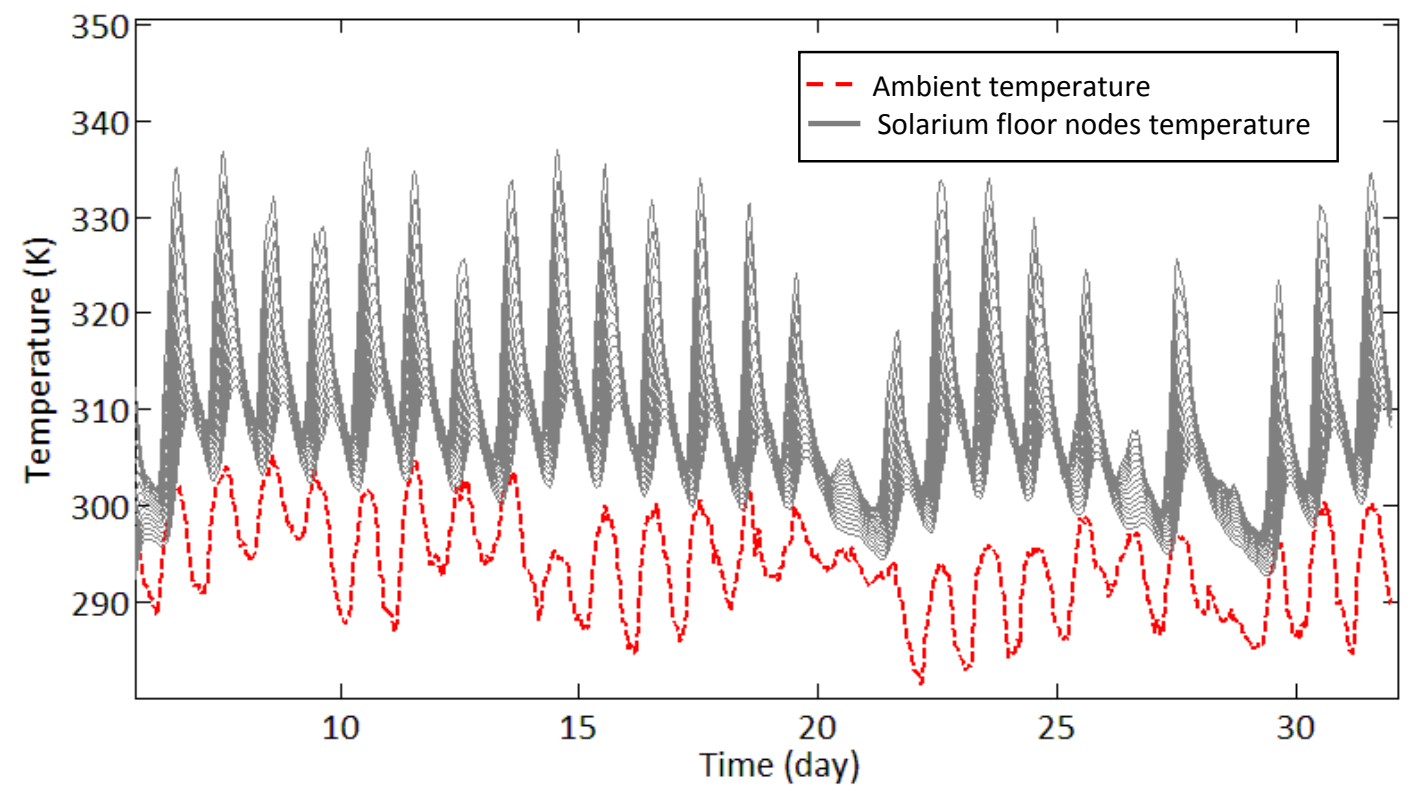

Fig. 18. The Solarium concrete floor nodes temperature applying parameters of parametric study corresponding the time frame of the month of July (trial 1) 


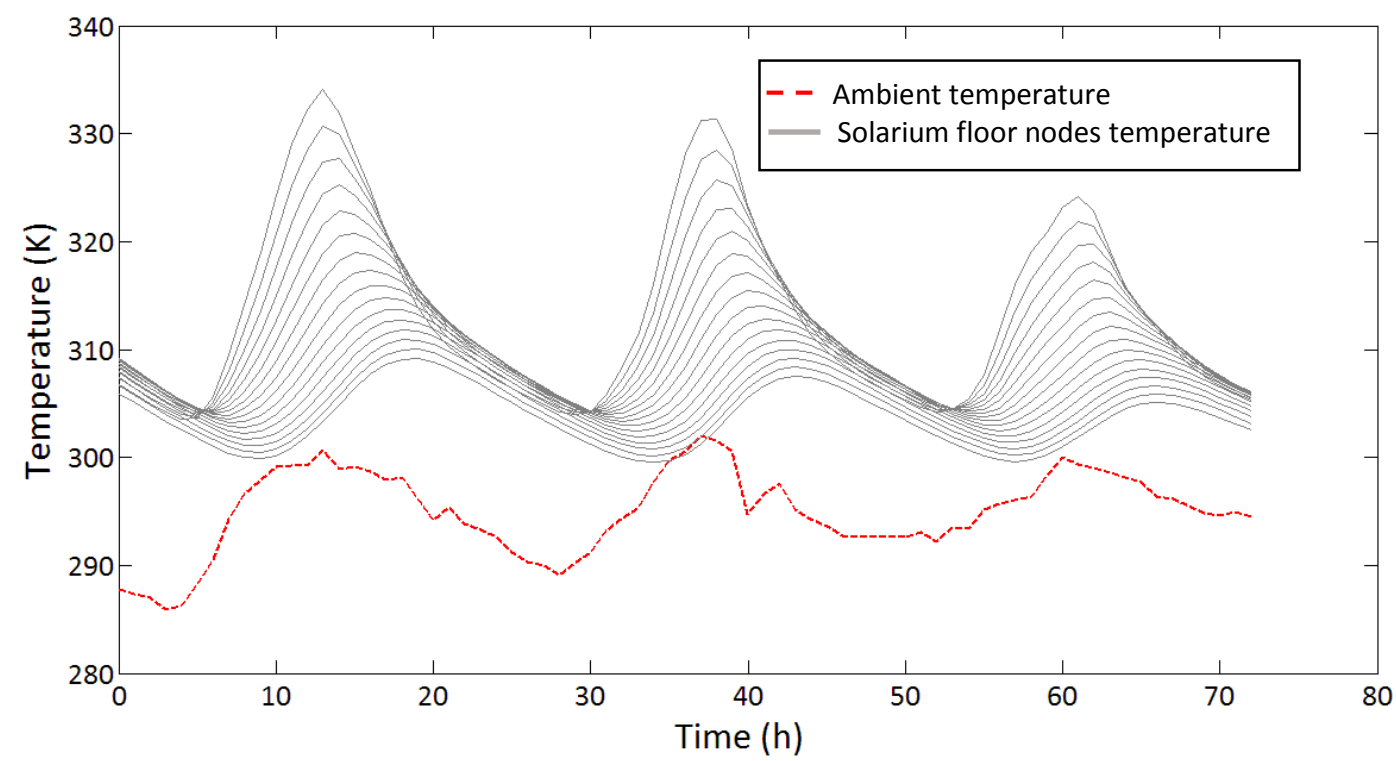

(b)

Fig. 19. The Solarium concrete floor nodes temperature applying parameters of parametric study corresponding the time frame of July 15 - 18 (trial 2)

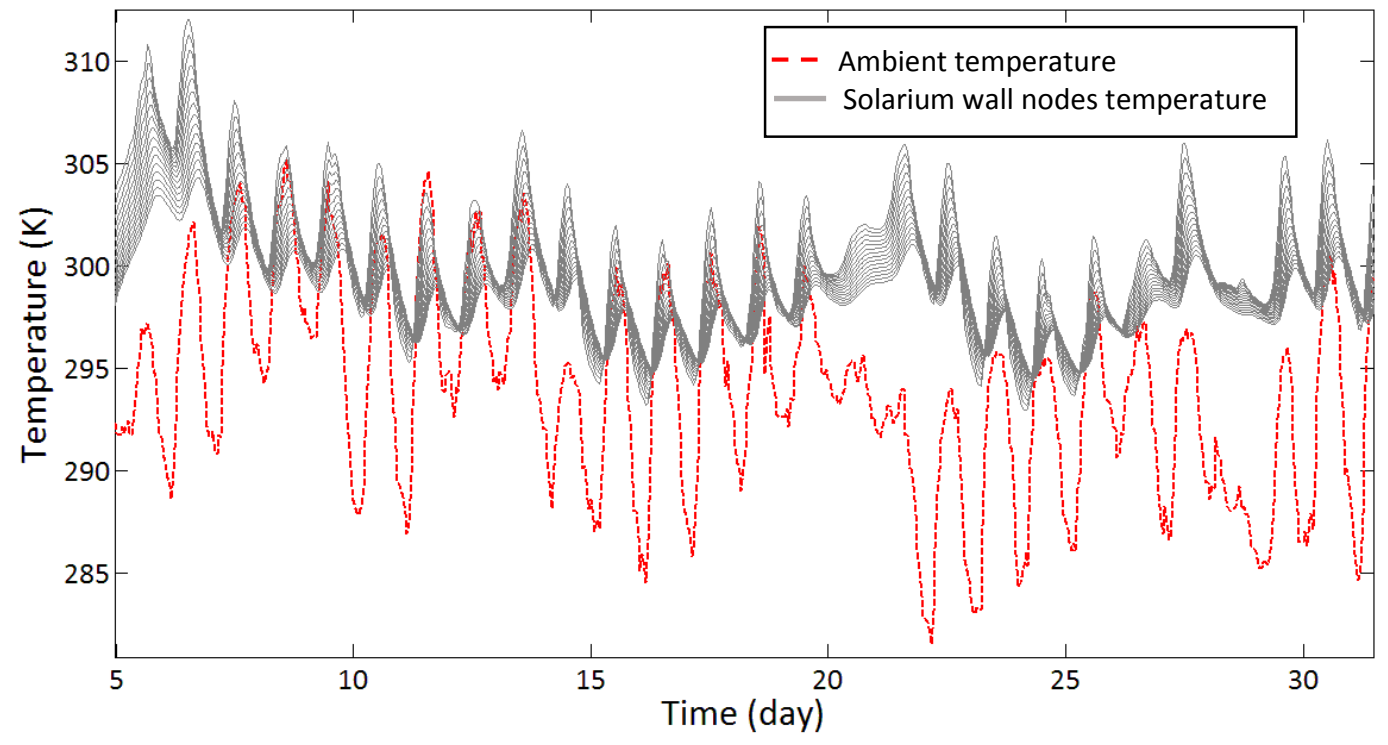

Fig. 20. The Solarium concrete wall nodes temperature applying parameters of parametric study corresponding the time frame of the month of July (trial 1 ) 


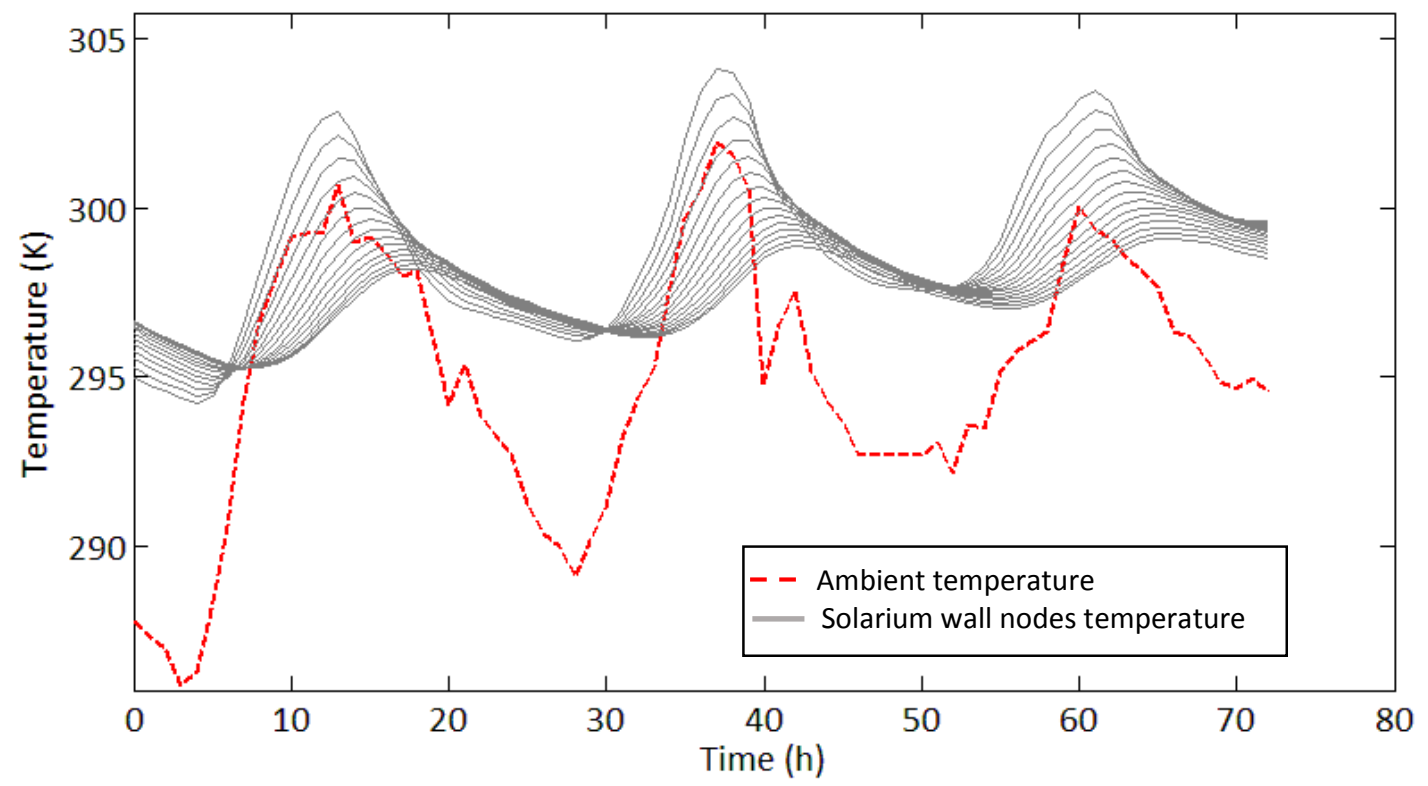

Fig. 21. The Solarium concrete wall nodes temperature applying parameters of parametric study corresponding the time frame of July 15 - 18 (trial 2)

Despite the fact that all concrete components of the SCAS share the same physical aspects, they show various thermal behaviours (Fig. 18-23). This is firstly due to differences in solar radiation on horizontal and vertical surfaces. The radiation is higher on the horizontal surface in the month of July for Toronto by the factor of 2.48. Secondly, as mentioned earlier, the wall in the solar chimney is partly exposed to the outside condition and has some radiative and convective heat losses to the ambient temperature, and therefore at sunrise, the temperature in this wall is lower than the ambient temperature due to its thermal inertia (Fig. 22-23).

The inertial temperature shift is around 2-5 hours for the internal and external surfaces respectively. This number rises up to 8 hours delay for the exterior wall surface to reach its maximum temperature compared to the highest ambient temperature. The temperature difference between interior surface and outdoor temperature is significantly higher in the solarium floor than its wall and these two numbers are higher than that of the solar chimney wall. The interior wall surface temperature in both concrete walls are lower or equal to the outdoor temperature for several hours after sunrise until almost noon. 


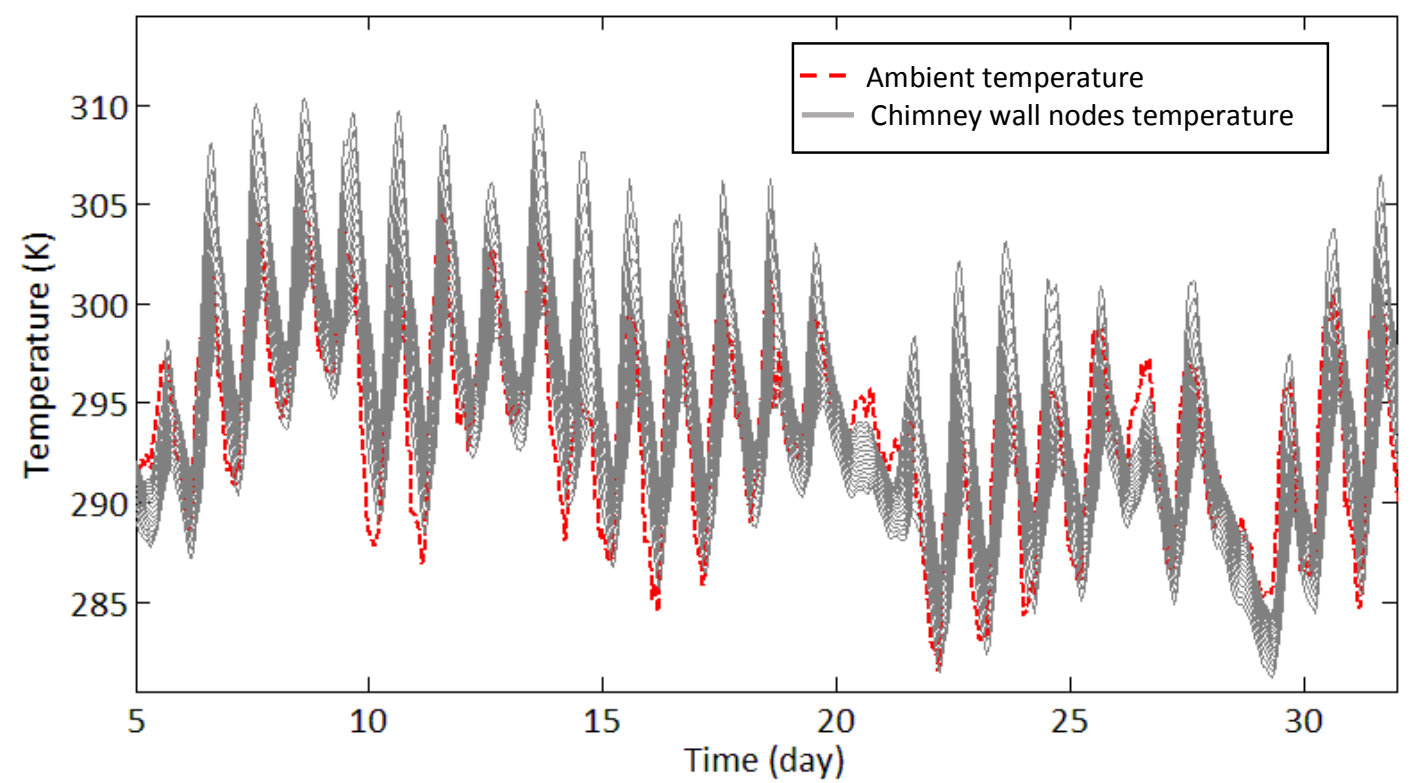

Fig. 22. The Solar chimney concrete wall nodes temperature applying parameters of parametric study corresponding the time frame of the month of July (trial 1 )

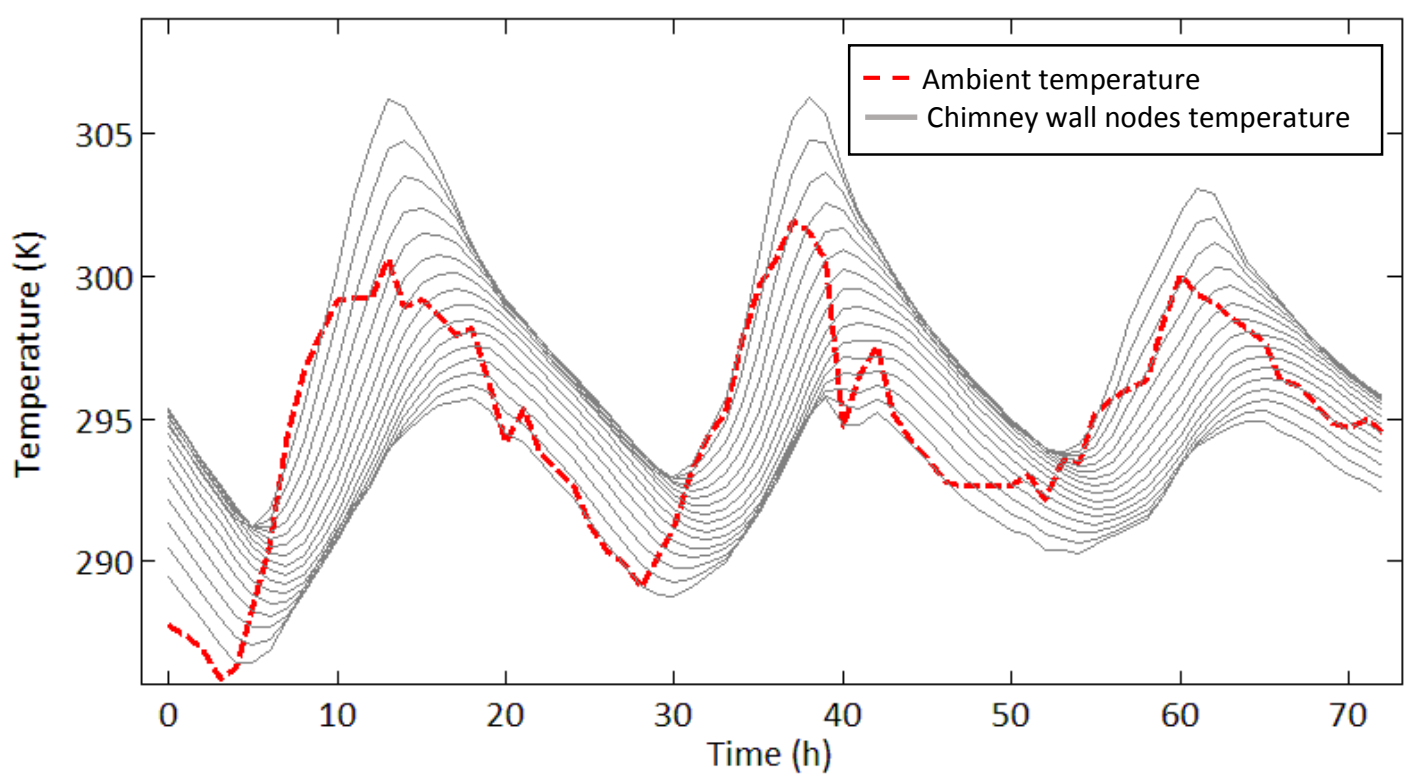

Fig. 23. The Solar chimney concrete wall nodes temperature applying parameters of parametric study corresponding the time frame of July 15 - 18 (trial 2)

During the time of trial 1, the temperature difference between the chimney interior surface and ambient temperature reaches up to $12 \mathrm{~K}$ related to July $14^{\text {th }}$, which has the highest solar radiation. The difference between solarium wall interior surface temperatures is higher around sunrise 
when the temperature is in the lowest level. This difference reaches up to $18 \mathrm{~K}$ in July 22 . The solarium floor has the highest interior temperature difference with the ambient temperature. This difference reaches up to $40 \mathrm{~K}$ on July 14 . This temperature variation follows almost the same pattern as the chimney air temperature. The greater the temperature difference, the higher the chimney air temperature throughout the month of July.

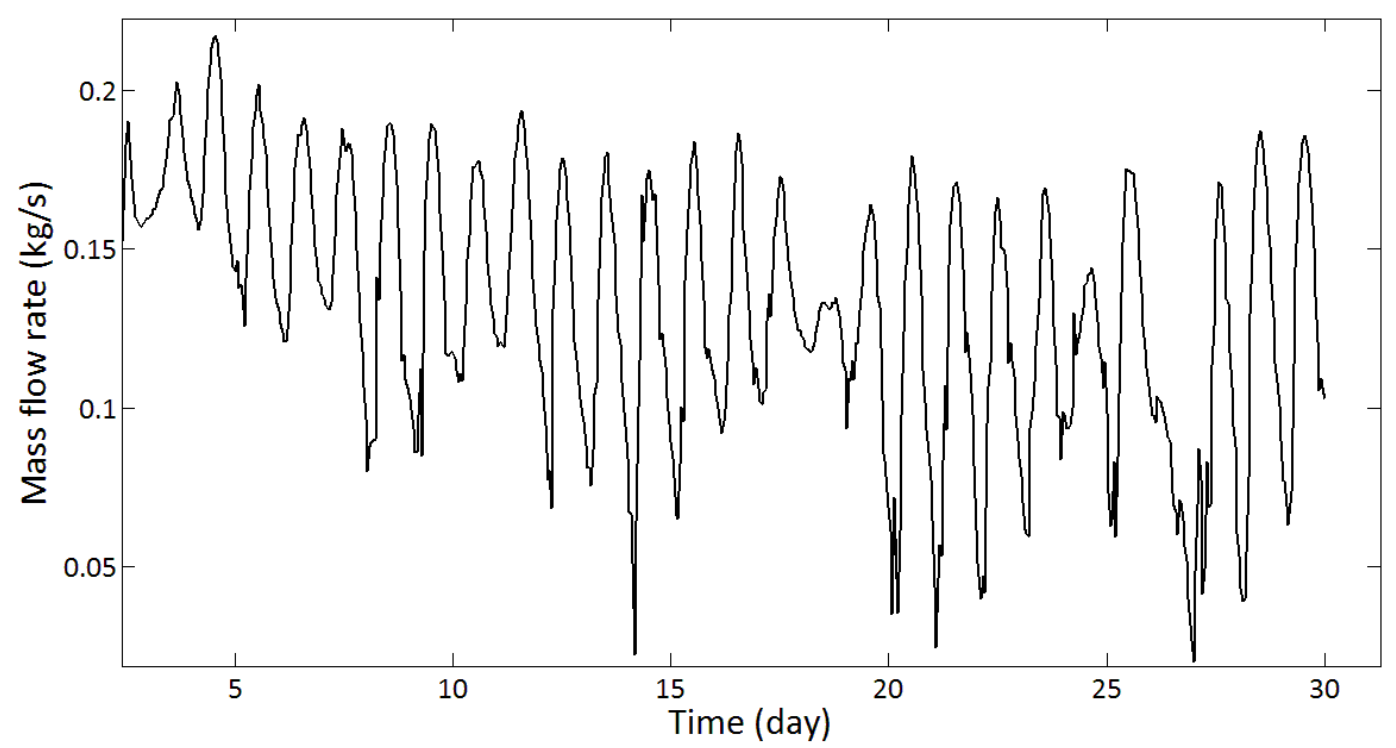

Fig. 24. The mass flow rate that crosses the SCAS applying parameters of parametric study corresponding the time frame of the month of July (trial 1)

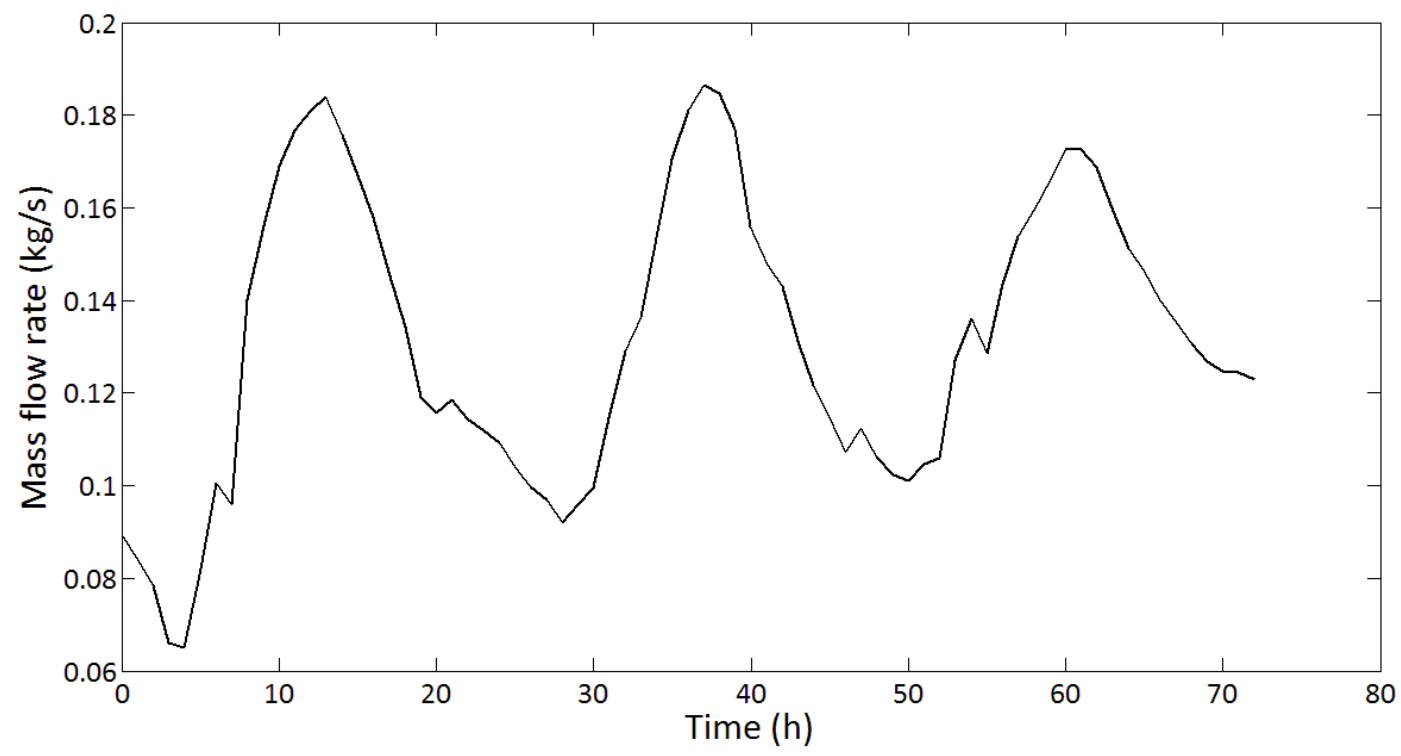

Fig. 25. The mass flow rate that crosses the SCAS applying parameters of parametric study corresponding the time frame of July 15 - 18 (trial 2) 
The most important figures of all, Fig. 24 -25 depict how the mass flow rate inside the SCAS swings during the trial time periods. The flow rate was higher than $0.01 \mathrm{~kg} / \mathrm{s}$ during the whole simulation time. Flow rate was the lowest value around sunrise. This minimum flow rate is as high as 0.85 $0.9 \mathrm{~kg} / \mathrm{s}$ on, for example, July 5-9 and $20-21$ and is related to the sunrise hours (5 am). The air flow rate reaches its maximum around $1 \mathrm{pm}$. The temperature difference between the inner surfaces of chimney concrete wall and the solarium concrete wall and floor compared to ambient temperature during the second trial reaches around 5, 5 and $15 \mathrm{k}$ at the midnight producing a mass flow rate of around $0.07 \mathrm{~kg} / \mathrm{s}$.

Since according to Brager and de Dear (2002) many building reports indicate that in most air conditioned buildings, air stillness is associated with poor air quality. Therefore, higher air speed in occupied zone can lead to achieving thermal comfort in higher temperature and enhance air quality by offsetting the enthalpy effect. The study indicated that applying the ACS to a mixed mode building allows the occupants to choose their preferred air speed.

With the cross sectional air movement that a SCAS creates inside the adjacent building, the higher temperature leads to considerable cooling and energy savings where the outdoor air can be used in $85 \%$ of the warmest month of the year for cooling with natural ventilation.

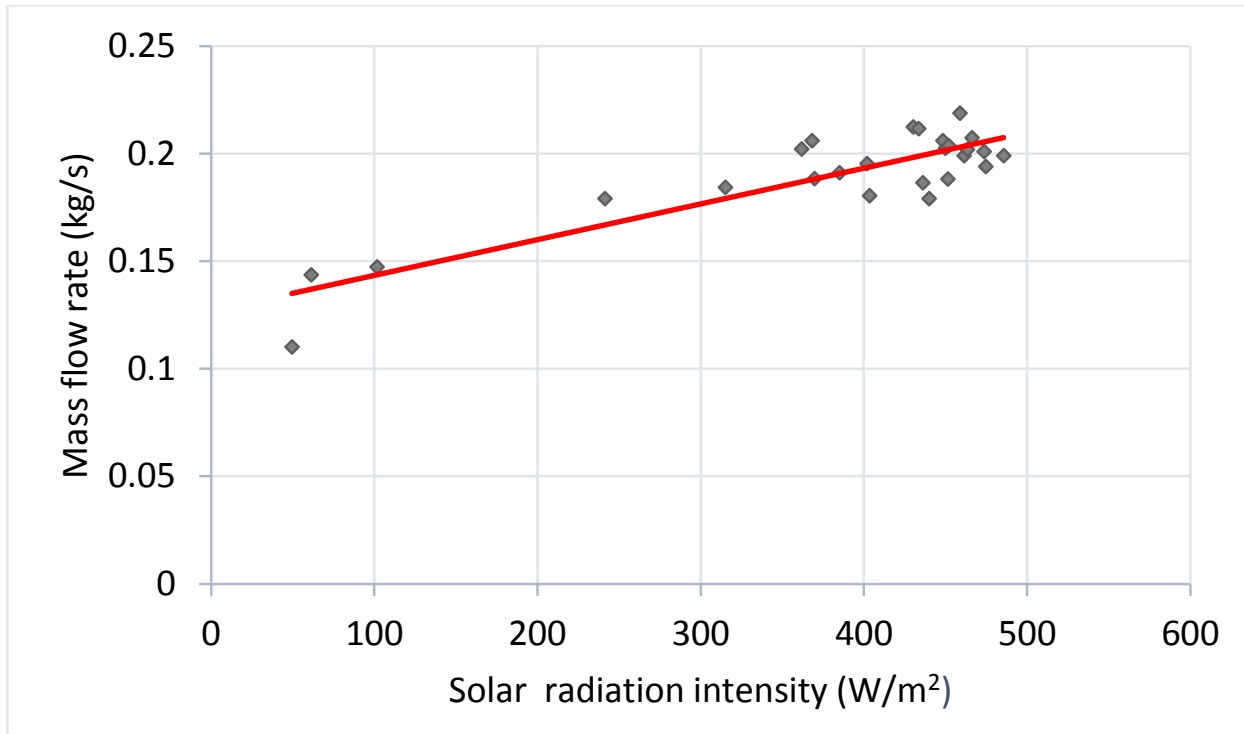

Fig. 26. Effects of solar radiation intensity on the mass flow rate inside the SCAS 
Fig. 26 shows how solar radiation intensity affects the mass flow rate inside the SCAS. The intensity of the solar heat flux is the driving force for the operation of the SCAS configuration and is thus one of the most determinant factors for the SCAS performance. The air flow rate was found to rise with the increase in solar heat flux. From Fig. 26, it can be seen that the mass flow rate calculated for the solar radiation of $486 \mathrm{~W} / \mathrm{m}^{2}$ is decreased by approximately $45 \%$ when solar radiation intensity drops to $50 \mathrm{~W} / \mathrm{m}^{2}$.

The proposed model to examine the ventilation performance of the SCAS has been evaluated with the actual weather data of the city of Toronto and demonstrated consistent results in various component temperatures and recommended physical problems. 


\section{Chapter 5: Conclusion}

This research establishes a reliable and effective methodology for evaluating the performance of a solar assisted ventilation system in a solarium attached to a residential building in Toronto at the initial design stage. Unlike the existing simulation process in the previous studies, the actual weather data of Toronto has been fed into the simulation model to support the theoretical results. Simulations were performed in the SIMULINK software in a way that the weather data in the computer codes can easily be alternated with other cities in Canada. Hence, the presented SIMULINK model is an effective tool for the study of the SCAS in its design stage. Various SCAS configurations and parametric studies were carried out to examine the effect of each design parameter on the thermal conditions in the building.

The proposed model describing the energetic performance of a SCAS shows satisfactory results that do not contradict with the previous published studies. The parametric study identified the solarium height, the solarium floor area and the solar chimney cross section area as the determinant parameters in the SCAS performance. The following main conclusions were drawn from this study:

- A tall solarium with a rather short solar chimney, that is $40 \%$ of the solarium height, produces the best ventilation rate and therefore has the best performance.

- It was found that a wider solar chimney, within the limits, integrated with a solarium with greater floor area resulted in greater natural ventilation enhancement.

- For the smaller outlet width, $10 \mathrm{~cm}$, inlet/outlet area ratio has no significant influence on the buoyancy-driven natural ventilation.

- It was noted that inlet/outlet area ratio of 4:1 found to be optimal in the SCAS application.

- The intensity of the solar heat flux is the most determinant factor for inducing the buoyancy-driven ventilation airflows in the SCAS. The air flow rate was found to rise with 
the increase in solar heat flux producing higher air temperature inside the solarium and the chimney around noon, maintaining a substantial temperature difference between the chimney air and the ambient temperature.

- The $24 \mathrm{~cm}$ concrete walls and floor provide up to 5-hour delay to reach up its peak temperature resulting in a temperature variation up to $18 \mathrm{~K}$ and producing natural ventilation when solar radiation no longer exists.

- The cross sectional air movement produced by a SCAS in an adjacent building interior condition is able to be maintained within the ACS limits in about $85 \%$ of the month of July resulting in a potential cooling energy saving of $85 \%$ that would otherwise be used by an air-conditioner.

The dynamic model proposed for the description of a SCAS, shows the interest in continuing investigation on the topics of cooling techniques, and shows the viability of future experimental investigations. 


\section{Chapter 6: Future work}

Even though this dissertation is the first research evaluating the feasibility of the SCAS in a dwelling especially in the weather condition such as Toronto area, it has some limitations all of which are introduced and explained in this section as follows:

- The view factor and the solar collection property for a highly glazed space have not been addressed in this work.

While developing a generic computational system for simulation study of the solar-assisted, ventilation in an attached solarium in a residential building in the weather condition of Toronto region is a great start to assess the feasibility of such an application, significant progress can certainly be made by pursuing the fundamental problems in a more solar radiation focused manner. As mentioned in bibliography, Wall (1997) stressed on the significance of a detailed calculation of the solar radiation distribution in a highly glazed space such as a solarium. Certainly there are many possible approaches to examine the solar radiation in a SCAS with different configuration such as ray tracing and radiosity methods to measure the amount of the radiation either absorbed or transmitted inside the SCAS. Some parameters such as view factor and solar collection property must be studied for this specific space.

- The details of different parameters and physical aspects of the SCAS have not been studied specifically for the SCAS application.

Different physical properties such as utilizing different types of glazing (single, double pane or triple pane, application of different glass kind such as low emissivity) must be examined in the structure of the SCAS. The other parameters that could be considered are as follows:

- Different thermal mass materials and thicknesses

- Different inlet/outlet configurations

- Different chimney shapes such as cylindrical, pyramidal or conical

- Different insulation materials and applications 
- Study of the air change rate created by the SCAS and possible energy saving in the summer is not covered in the content of this research.

Possible energy saving through solar-assisted ventilation throughout the summer in a space attached in a SCAS and possible ways of interior design of the building to improve the air circulation in the house must be explored precisely. The possible energy saving in the winter time utilizing the excess heat inside the solarium also must be studied.

- The performance of the SCAS in the winter and possible configurations to work properly throughout the year have not been investigated in this study.

As provided in the literature review section a solarium can provide an extra heat to the adjacent space during the winter leading to some extra energy saving in this season. Certainly there are many various approaches such as designing multifunctional outlet to alternate the SCAS performance depending on the ambient weather condition which can be easily explored through a possible future study.

- The comfort index of a typical residential building attached in the corresponding SCAS are not studied.

The summer ventilation and winter heating ability of the SCAS and their thermal effects on the inside temperature and air condition should be studied carefully. The internal air condition should be compared to the established thermal comfort criteria such as ASHRAE 55 (ASHRAE, 2010) and ISO EN7726 (ISO, 2002) to find a way to tune the function of different components. To do so, different passive and active control systems such as operating fan and inlet/outlet controlling devices and thermostats should be studied to find the best system with the least energy consumption.

- The SCAS is not investigated aesthetically in this research.

Attaching an extension such as a SCAS to a building specially a residential building needs an extra attention to the appearance and aesthetic aspect of the SCAS and its combination to either an existing building (retrofit) or a new building. This attachment can potentially 
backfire and decrease the price of the building in spite of all costs loads. This attachment can also affect the urban perspective and must be studied carefully in this regard as well.

- Finally, to possibly commercialize the SCAS, a real size of the SCAS must be built to evaluate and confirm the efficiency of such an application in relation to all above issues in the climates close to Toronto.

Given the successful method and results including in this study, next step would be building an experimental model of the SCAS integrated with an assumed typical residential building to evaluate the extracted data and prove the feasibility of energy saving potential of such an extension to a typical residential building.

It is my sincere hope that this work would provide some useful insights for introducing the SCAS as a mean of energy saving in a building. 


\section{References}

Afonso, A., Oliveira, A., 2000. Solar chimneys: simulation and experiment, Energy and Buildings 32: 71-79.

Afriyie, J.K., Rajakaruna, H., Nazha, M.A.A., Forson, F.K., 2009. Experimental investigations of a chimneydependent solar crop dryer, Renewable Energy 34(1): 217-222

Afriyie, J.K., Rajakaruna, H., Nazha, M.A.A., Forson, F.K., 2011. Simulation and optimisation of the ventilation in a chimney-dependent solar crop dryer, Solar Energy 85: 1560-1573.

Andersen, K.T., 1995. Theory for natural ventilation by thermal buoyancy in one zone with uniform temperature, Building and Environment 38: 1281-1289.

Arce, J., Jimenez, M.J., Guzman, J.D., Heras, M.R., Alvarez, G., Xaman, J. 2009. Experimental study for natural ventilation on a solar chimney. Renewable Energy 34:2928-2934.

ASHRAE, Handbook: Fundamentals, 2008, American Society of Heating, Refrigeration and Air Conditioning Engineers Inc., Atlanta

ASHRAE, 2010. ASHRAE Standard 55: Thermal Enviormental Condi tions for Human Occupancy, American Society of Heating, Refrigeration and Air Conditioning Engineers Inc., Atlanta.

Awbi, H.B., Gan, G., 1992. Simulation of solar-induced ventilation, Renewable Energy Technology and the Environment 4:2016-30.

Bansal, N.K., Mathur, R., Bhandari, M.S., 1993. Solar chimney for enhanced stack ventilation, Building and environment 28: 373-377.

Bargach, M.N., Tadili, R., Dahman, A.S., Boukallouch, M., 2000. Survey of thermal performances of a solar system used for the heating of agricultural greenhouses in Morocco, Renewable energy 20, 415-433.

Bassiouny, R. and Koura, N.S.A. 2008. An analytical and numerical study of solar chimney use for room natural ventilation, Energy and Buildings 40:865-873. 
Bastien, D., Athienitis, A.K., 2010. Analysis of the Solar Radiation Distribution and Passive Thermal Response of an Attached Solarium/Greenhouse, International High Performance Buildings Conference.

Barozzi, G.S., Imbab, M.S.E., Nobile, E., Sousa, A.C.M., 1992. Physical and Numerical Modelling of a Solar Chimney-based Ventilation System for Buildings, Building and Environment 27:43-145.

Borgers, T.R., Akbari, H., 1979. Laminar flow within the Trombe wall channel, Solar Energy 22:165-174.

Bouchair, A., Fitzgerald, D., 1988. The optimum azimuth for a solar chimney in hot climates, Energy and Buildings, 12: $135-140$.

Bouchair, A., 1994. Solar chimney for promoting cooling ventilation in southern Algeria, Building Services Engineering Research and Technology 15(2):81-93.

Brager, G. S., de Dear, R. J., 2002. Thermal comfort in naturally ventilated buildings: revisions to ASHRAE Standard 55, Energy and Buildings, 34 (6): 549-561

Bryn, I., Schiefloe, P. A., 1996. Atrium models for the analysis of thermal comfort and energy use: a report of task 12, SINTEF Energy, Indoor Environment Technology, Trondheim.

Chantawong, P., Hirunlabha, J., Zeghmati, B., Khedari, J., Teekasap, S., Win, M. M., 2005. Investigation on thermal performance of glazed solar chimney walls, Solar Energy 80: 288-297.

Charvat, P., Jicah, M., Stetina, J., 2004. Solar chimneys for ventilation and passive cooling, World Renewable Energy Congress, Denver, USA.

Chen, Z.D., Li, Y., 2001. A numerical study of a solar chimney with uniform wall heat flux, In: Proceedings of the Fourth International Conference on Indoor Air Quality, Ventilation and Energy Conservation in Buildings, Human, China, p.1447-54. 
Chen, Z.D., Bandopadhayay, P., Halldorsson, J., Byrjalsen, C., Heiselberg, P., Li, Y., 2003. An experimental investigation of a solar chimney model with uniform wall heat flux, Building and Environment 38:893-906.

Chungloo, S., Limmeechokchai, B., 2008. Utilization of cool ceiling with roof solar chimney in Thailand: The experimental and numerical analysis, Renewable Energy 34: 623-633.

Connellan, G., 1986. Solar greenhouse using liquid collectors. In: Proceedings of Solar Energy Society. Atlanta, GA.

Ding, W., Hasemi, Y., Yamada, T., 2005. Natural ventilation performance of a double-skin façade with a solar chimney, Energy and Buildings 37: 411-418.

Duffie, J.A., Beckman, W.A., 1980. Solar engineering of thermal processes, Wiley, New York.

Ekechukwu, O. V., Norton, B., 1997. Design and measured performance of a solar chimney for natural circulation solar energy dryers, Renewable Energy, 10 (4): 81-90

Flourentzou, F., Van der Maas, J., Roulet, C., A., 1997. Natural ventilation for passive cooling: measurement of discharge coefficients, Energy and Building 27: 283-292.

Fuchs, R., McClelland, J.F., 1979. Passive solar heating of buildings using a transwall structure, Solar Energy 23(2), 123-128.

Gan, G., Riffat, S.B., 1998. A numerical study of solar chimney for natural ventilation of buildings with heat recovery, Applied Thermal Engineering 18: 1171 -1187.

Gan, G., 1998. A parametric study of Trombe walls for passive cooling of buildings, Energy and Buildings 18: 1171-87.

Gan, G. 2006. Simulation of buoyancy-induced flow in open cavities for natural ventilation, Energy and Buildings 38: 410-420. 
Gan, G. 2010. Impact of computational domain on the prediction of buoyancy-driven ventilation cooling. Building and Environment 45: 1173-1183.

Gontikaki, M., Trcka, M., Hensen, J.L.M., Hoes, P., 2010. Optimization of a solar chimney design to enhance natural ventilation in a multi-storey office building, Proceedings of 10th International Conference for Enhanced Building Operations, Kuwait: ICEBO.

Harris, D.J., Helwig, N. 2007. Solar chimney and building ventilation, Applied Energy 84: 135-146.

Hirunlabh, J., Kongduang, W., Namprakai, P., Khedari, J., 1999. Study of natural ventilation of houses by a metallic solar wall under tropical climate, Renewable Energy 18: 109-119.

Ho Lee, K. and Strand, R.K. 2009. Enhancement of natural ventilation in buildings using a thermal chimney. Energy and Buildings 41: 615-621.

Holforda, J.M., Hunt, G.R., 2001. Fundamental atrium design for natural ventilation, Building and Environment 38: $409-426$.

Hussaini, H.A., Suen, K.O., 1998. Using shallow solar ponds as a heating source for greenhouses in cold climates, Energy Conversion and Management 39 (13): 1369-1376.

Horan, J. M., Finn, D. P., 2008. Sensitivity of air change rates in a naturally ventilated atrium space subject to variations in external wind speed and direction, Energy and Buildings 40: 1577-1585.

Incropera, F.P., De Witt, D.P., Bergman, T.L., Lavine, A.S., 2007. Introduction to Heat Transfer, fifth ed. John Wiley \& Sons Inc., Hoboken, New Jersey.

Incropera, F.P., DeWitt, D.P., 1996. Fundamentals of Heat and Mass Transfer, fourth ed. John Wiley, New York.

Ismail, K., Goncalves, M.M., 1999. Thermal performance of a PCM storage unit. Energy Conversion and Management 40: 115-138. 
Jain, D., Tiwari, G.N., 2003. Modeling and optimal design of ground air collector for heating in controlled environment greenhouse. Energy Conversion and Management 44 (8), 1357-1372.

Ji, Y., Cook, M.J. 2007. Numerical studies of displacement natural ventilation in multi-storey buildings connected to an atrium, Building Services Engineering Research \& Technology 28 (3): 207-222.

Khalaji Assadi, M., Dalir, F., Hamidi, A.A., 2011. Analytical model of atrium for heating and ventilating an institutional building naturally, Energy and Buildings 43: 2595-2601.

Khedari, J., 1999. Study of natural ventilation of houses by a metallic solar wall under tropical climate, Renewable Energy 18: 109-119.

Khedari, J., Boonsri, B., Hirunlabh, J., 2000. Ventilation impact of a solar chimney on indoor temperature fluctuation and air change in a school building, Energy and Buildings 32: 89-93.

Koua, K.B., Gbaha, P., Koffi, E.P.M., Fassinou, W.F., Toure, S., 2011. Modelling of thermal behaviour of a direct solar drier possessing a chimney: Application to the drying of cassava, Indian Journal of Science and Technology 4: 1609-1618.

Kumar, S., Tiwari, G.N., Sinha, S., 1994. Optimization and comparative thermal evaluation of four different solarium-cum- solar houses, Energy Conversion and Management, 35(10): 835-842.

Kurpaska, S., Slipek, Z., 2000. Optimization of greenhouse Substrate Heating. Journal of Agricultural Engineering Research 76: 129-139.

Letan, R., Dubovsky, V., Ziskind, G., 2003. Passive ventilation and heating by natural convection in a multistorey building, Building and Environment, 38(2): 197-208.

Maloney, T. J., Habib, V., 1979. Fabrication and testing of marketable waterwall components, DOE repot, dsD-517-2. 
Marti-Herrero, J., Heras-Celemin, M.R., 2006. Dynamic physical model for a solar chimney, Solar Energy 81: 614-622.

Mathur, J., Bansal, N.K., Mathur, N.K., Jain, M., Anupma. 2006. Experimental investigations on solar chimney for room ventilation, Solar Energy 80: 927-935.

McAdams, W.H., 1954. Heat Transmission, third ed., McGraw-Hill, New York.

Murphy, A. B., Brusca, S., 1986. Bernoulli Effect, Physics Education, 21(5): 262 - 263

Nouanégué, H.F. and Bilgen, E. 2009. Heat transfer by convection, conduction and radiation in solar chimney systems for ventilation of dwellings. International Journal of Heat and Fluid Flow 30: 150-157.

Oliphant, M.V., 1980. Measurement of wind speed distributions across a solar collector, Solar Energy 24: 403-405.

Ong, K.S., Chow, C.C., 2003. Performance of a solar chimney, Solar Energy 74: 1-17.

Palyvos, J.A., 2008. A survey of wind convection coefficient correlations for building envelope energy systems' modeling, Applied Thermal Engineering 28: 801-808.

Punyasompun, S., Hirunlabh, J., Khedari, J. Zeghmati, B., 2009. Investigation on the application of solar chimney for multi-storey buildings. Renewable Energy 34: 2545-2561.

Raja, I. A., Fergus Nicol, J., McCartney, K. J., Humphreys, M. A., 2001. Thermal comfort: use of controls in naturally ventilated buildings. Energy and Buildings, 33 (3): 235-244

Rodrigues, A. M., Canha da Piedade, A., Lahellec, A., Grandpeix, J.Y., 2000. Modeling natural convection in a heated vertical channel for room ventilation, Building and Environment 35: 455-469.

Reuss, M., Benkert, S.T., Aeberhard, A., Martina, P., Raush, G., Rentzell, B.V., 1997. Modelling and experimental investigation of a pilot plant for solar wood drying, Solar Energy, 59 (4-6): 259-270 
Santamouris, M., Balaras, C.A., Dascalaki, E., Vallindras, M., 1994a. Passive solar agricultural greenhouse: a worldwide classification evaluation of technologies and systems used for heating purpose. Solar Energy 53 (5): 426-441.

Santamouris, M., Argiriou, A., Vallindras, M., 1994b. Design and operation of a low energy consumption passive solar agricultural greenhouse. Solar Energy 52 (5): 371-378.

Santamouris, M., Mihalakakou, G., Balaras, C.A., Lewis, J.O., Vallindras, M., Argiriou, A., 1996. Energy conservation in greenhouse with buried pipes. Energy 52 (5): 353-360.

Sodha, M. S., Bansal, N. K., Kumar, A., Malik, M. A. S., 1986. Solar passive building: science and design, International series on building engineering, Vol. 2.

Spencer, S., Chen, Z.D., Li, Y., Haghighat, F., 2000. Experimental investigation of a solar chimney natural ventilation system, In: Proceedings of Room Vent, Seventh International Conference on Air Distribution in Rooms, Reading, UK, 813-818.

Swinbank, W.C., 1963. Long wave radiation from clear skies, Q.J.R. Meterol, Soc. 89: 339.

Tiwari, G.N., Dhiman, N.K., 1986. Design and optimization of a winter greenhouse for the Leh-type climate. Energy Conversion and Management 26 (1): 71-78.

Tiwari, G. N., Din, Yadav, Y. P., Lawrence, S. A., 1988. Performance of a solarium: an analytical study. Building and Envinroment, 26: 203-215.

Tiwari, G. N., Din, M., Shrivastava, N. S. L., Jain, D., Sodha, M. S., 2002. Evaluation of solar fraction (Fn) for north wall of a controlled environment greenhouse: an experimental validation. International Journal of Energy Research, 26: 203-215.

Wall, M., 1995. A design tool for glazed spaces. Pat I: Description. In ASHRAE Transactions 101, 12611271. 
Wall, M., 1997. Distribution of solar radiation in glazed spaces and adjacent buildings. A comparison of simulation programs. Energy and Buildings, 26(2): 129-135.

Wei, D., Qirong, Y., Jincui, Z., 2010. A study of the ventilation performance of a series of connected solar chimneys integrated with building, Renewable Energy 36: 265-271. 


\section{Appendix 1}

\section{Nomenclature}

\begin{tabular}{|c|c|c|c|}
\hline $\boldsymbol{A}$ & area $\left(m^{2}\right)$ & $\rho$ & air density $\left(\mathrm{kg} / \mathrm{m}^{3}\right)$ \\
\hline$C_{d}$ & coefficient of discharge of air channel & $\boldsymbol{\mu}$ & dynamic viscosity $(\mathrm{kg} / \mathrm{m} \mathrm{s})$ \\
\hline$C_{f}$ & specific heat of air (J/kg K) & $\sigma$ & Stefan-Boltzmann constant $\left(\mathrm{W} / \mathrm{m}^{2} \mathrm{~K}^{4}\right)$ \\
\hline$g$ & gravitational constant $(\mathrm{m} / \mathrm{s})$ & $\boldsymbol{\tau}$ & transmittance of glazing \\
\hline Gr & Grashof number & $\Delta w$ & wall thickness $(m)$ \\
\hline $\boldsymbol{h}$ & convection heat transfer coefficient $\left(\mathrm{W} / \mathrm{m}^{2} \mathrm{~K}\right)$ & $\Delta x$ & distance between nodes $(\mathrm{m})$ \\
\hline $\boldsymbol{h}_{\boldsymbol{r}}$ & Radiation heat transfer coefficient $\left(\mathrm{W} / \mathrm{m}^{2} \mathrm{~K}\right)$ & Subs & scripts \\
\hline $\boldsymbol{h}_{\text {wind }}$ & convective wind heat loss coefficient $\left(W / \mathrm{m}^{2} K^{1}\right)$ & $a$ & atmospheric air \\
\hline I & solar radiation on vertical surface $\left(\mathrm{W} / \mathrm{m}^{2}\right)$ & $\boldsymbol{b}$ & solarium base \\
\hline$k$ & thermal conductivity ( $\mathrm{W} / \mathrm{m} \mathrm{k}$ ) & bg & base-glass \\
\hline$L$ & height $(m)$ & $E$ & ground \\
\hline$\dot{m}$ & air mass flow rate ( $\mathrm{kg} / \mathrm{s})$ & $f$ & Fluid (air) \\
\hline $\mathrm{Nu}$ & Nusselt number & $f_{s c}$ & Air in solar chimney \\
\hline $\operatorname{Pr}$ & Prandtl number & $g$ & glass \\
\hline$\dot{q}^{\prime \prime}$ & heat transfer to air stream $\left(\mathrm{W} / \mathrm{m}^{2}\right)$ & $g a$ & glass-air \\
\hline$R a$ & Rayleigh number & gs & glass-sky \\
\hline$S$ & solar radiation gain $\left(\mathrm{W} / \mathrm{m}^{2}\right)$ & $i$ & inlet \\
\hline$T$ & temperature $(K)$ & ins & insulation \\
\hline$u$ & conductive heat transfer coefficient $\left(\mathrm{W} / \mathrm{m}^{2} \mathrm{~K}\right)$ & int & interior \\
\hline
\end{tabular}




$\begin{array}{llll}\boldsymbol{V} & \text { wind speed }(\mathrm{m} / \mathrm{s}) & \boldsymbol{0} & \text { outlet } \\ \boldsymbol{v} & \text { air velocity }(\mathrm{m} / \mathrm{s}) & \boldsymbol{r} & \text { room } \\ \boldsymbol{W} & \text { uniform width }(\mathrm{m}) & \boldsymbol{s} & \text { solarium } \\ \boldsymbol{\alpha} & \text { thermal diffusivity } & \boldsymbol{s c} & \text { solar chimney } \\ \boldsymbol{\beta} & \text { coefficient of expansion of air }(1 / \mathrm{K}) & \boldsymbol{w} & \text { wall } \\ \boldsymbol{\gamma} & \text { mean temperature approximation constant } & \mathbf{w a} & \text { wall-air } \\ \boldsymbol{\epsilon} & \text { emissivity of a surface } & \mathbf{w g} & \text { wall-glass } \\ \boldsymbol{\theta} & \text { roof tilt angle } & \mathbf{w s} \text { wall-sky }\end{array}$

